This item was submitted to Loughborough's Research Repository by the author.

Items in Figshare are protected by copyright, with all rights reserved, unless otherwise indicated.

\title{
Modeling occupant behavior in buildings
}

PLEASE CITE THE PUBLISHED VERSION

https://doi.org/10.1016/j.buildenv.2020.106768

PUBLISHER

Elsevier BV

VERSION

AM (Accepted Manuscript)

PUBLISHER STATEMENT

This paper was accepted for publication in the journal Building and Environment and the definitive published version is available at https://doi.org/10.1016/j.buildenv.2020.106768.

\section{LICENCE}

CC BY-NC-ND 4.0

\section{REPOSITORY RECORD}

Carlucci, Salvatore, Marilena De Simone, Steven Firth, Mikkel B Kjærgaard, Romana Markovic, Mohammad Saiedur Rahaman, Masab Khalid Annaqeeb, et al.. 2020. "Modeling Occupant Behavior in Buildings". figshare. https://hdl.handle.net/2134/11988171.v1. 


\title{
Modeling occupant behavior in buildings
}

Salvatore Carlucci ${ }^{1,2, *}$, Marilena De Simone ${ }^{3}$, Steven K. Firth ${ }^{4}$, Mikkel B. Kjærgaard ${ }^{5}$, Romana Markovic ${ }^{6}$, Mohammad Saiedur Rahaman ${ }^{7}$, Masab Khalid Annaqeeb ${ }^{8}$, Silvia Biandrate ${ }^{2,9}$, Anooshmita Das ${ }^{5}$, Jakub Wladyslaw Dziedzic ${ }^{8}$, Gianmarco Fajilla ${ }^{3}$, Matteo Favero ${ }^{2}$, Martina Ferrando ${ }^{9}$, Jakob Hahn ${ }^{10}$, Mengjie Han ${ }^{11}$, Yuzhen Peng ${ }^{12}$, Flora Salim ${ }^{7}$, Arno Schlüter ${ }^{12}$, Christoph van Treeck ${ }^{6}$

${ }^{I}$ Cyprus Institute, Energy, Environment and Water Research Center, Nicosia, Cyprus

${ }^{2}$ Department of Civil and Environmental Engineering, Norwegian University of Science and Technology, Trondheim, Norway

${ }^{3}$ Department of Environmental Engineering, University of Calabria, Rende, Italy

${ }^{4}$ School of Architecture, Building and Civil Engineering, Loughborough University, Loughborough, UK

${ }^{5}$ Center for Energy Informatics, University of Southern Denmark, Odense, Denmark

${ }^{6}$ E3D - Institute of Energy Efficiency and Sustainable Building, RWTH Aachen University, Aachen, Germany

${ }^{7}$ School of Science, Computer Science \& IT, RMIT University, Melbourne, Victoria, Australia

${ }^{8}$ Department of Energy and Process Engineering, Norwegian University of Science and Technology, Trondheim, Norway

${ }^{9}$ Department of Energy, Politecnico di Milano, Milan, Italy

${ }^{10}$ CENERGIE - Research Center Energy Efficient Buildings and Districts, Munich University of Applied Sciences, Germany

${ }^{11}$ School of Technology and Business Studies, Dalarna University, Falun, Sweden

${ }^{12}$ Architecture and Building Systems, Institute of Technology in Architecture, Department of Architecture, ETH Zürich, Switzerland

* Corresponding author address: 20 Konstantinou Kavafi Street, 2121 Nicosia, Cyprus; email: s.carlucci@ cyi.ac.cy; tel: +357 22 208664

\begin{abstract}
In the last four decades several methods have been used to model occupants' presence and actions (OPA) in buildings according to different purposes, available computational power, and technical solutions. This study reviews approaches, methods and key findings related to OPA modeling in buildings. An extensive database of related research documents is systematically constructed, and, using bibliometric analysis techniques, the scientific production and landscape are described. The initial literature screening identified more than 750 studies, out of which 278 publications were selected. They provide an overarching view of the development of OPA modeling methods. The research field has evolved from longitudinal collaborative efforts since the late 1970s and, so far, covers diverse building typologies mostly concentrated in a few climate zones. The modeling approaches in the selected literature are grouped into three categories (rule-based models, stochastic OPA modeling, and data-driven methods) for modeling occupancy-related target functions and a set of occupants' actions (window, solar shading, electric lighting, thermostat adjustment, clothing adjustment and appliance use). The explanatory modeling is conventionally based on the model-based paradigm where occupant behavior is assumed to be stochastic, while the
\end{abstract}


data-driven paradigm has found wide applications for the predictive modeling of OPA, applicable to control systems. The lack of established standard evaluation protocols was identified as a scientifically important yet rarely addressed research question. In addition, machine learning and deep learning are emerging in recent years as promising methods to address OPA modeling in real-world applications.

\section{Keywords}

Occupant behavior; Data-driven methods; Deep learning; Machine learning; Stochastic methods; PRISMA 


\section{Introduction}

In the last four decades several methods have been used to model occupants' presence and actions (OPA) in buildings to meet different research objectives given available computational power and technical solutions. Often the purpose has been to understand how people use a space and how their behavior impacts on a building's energy performance. Indeed, occupant behavior is also one of the main sources of uncertainty in building's energy modeling [1]. In particular, the oversimplification of the OPA description can introduce a large discrepancy between the simulated and actual energy consumption of a building $[2,3]$. These and other issues have driven the exploitation of various approaches to explain and predict OPA in order to accurately model OPA in building energy simulation tools and to improve building management systems to decrease building's energy consumption. In order to address these issues, the attention of the building research community on OPA modeling has increased in recent years [4]. One initiative approved by the International Energy Agency (IEA) in 2013 is the Energy in Buildings and Communities (EBC) Annex 66 [5] that aimed to study the importance of occupant behavior in buildings and its modeling techniques and to formalize simulation approaches regarding occupant behavior. Following this, in 2017 IEA approved the EBC Annex 79 "Occupant-centric building design and operation”, which aims to explore open issues on the implementation and application of occupant modeling into practice [6]. In the context of IEA-EBC Annex 79, this review aims at providing a thorough and carefully-designed overview of the methods and techniques used for modeling OPA in buildings in order to create the current state-of-the-art and identify the latest trends in this research sector. Given these ambitious objectives, a systematic approach is used to review the scientific literature to reduce the risk of missing important contributions in the field, and bibliometric analysis tools are adopted to extract patterns and information from the identified database of documents. In the scope of this work, the existing OPA studies are grouped into three paradigms: rule-based models, stochastic OPA models, and datadriven methods. The first paradigm includes, but is not restricted to, the time-dependent users' profiles as defined, for example, in the ASHRAE standard 90.1 [7]. The second paradigm considers the occupant behavior to be stochastic since behavior varies between occupants and may evolve over time [8] and is the result of complex relationships between contextual factors, adaptive triggers, and non-adaptive triggers [9]. The third paradigm refers to data-driven methods where a black-box model is derived from relating input and output data [10] so that, the modeling is conducted without an explicit aim to understand the OPA [11] and/or only with the limited inclusion of the domain engineering knowledge [12]. Resultantly, the data-driven OPA modeling, for the scope of this study, can be defined as "an approach to modeling that focuses on using the computational intelligence and particularly 
machine learning (ML) methods in building models that would complement or replace the "knowledge-driven" models describing physical behavior" [12]. The present study aims at describing the features of methods used for OPA modeling in buildings rather than reporting their mathematical formulation that can be found in statistical and machine learning handbooks. A summary of a few modelling techniques is available in [13].

\subsection{Related work}

Numerous reviews about OPA modeling have tried to categorize and formalize the different approaches to OPA modeling [9]. However, they are usually limited in the covered time span, in the building typology investigated or in the OPA under study. For example, Gunay et al. [14] have reviewed the modeling approaches developed for the simulation engine EnergyPlus regarding occupant presence, window and shading operations, lighting, and clothing adjustment developed since 2014. Yang et al. [15], focusing on institutional buildings, have studied the available estimation, detection and modeling methods to assess presence and movement of occupants. Gilani and O'Brien [16] have reviewed the estimation and detection methods to study OPA in office buildings. Chen et al. [17] have studied presence estimation and detection methods developed between 2005 and 2017. Zhang et al. [4] have reviewed the modeling methods for OPA regarding residential and commercial buildings. Balvedi et al. [18] focused on residential buildings in the temporal coverage from 2006 to 2017. Dong et al. [19] did an extensive literature review including all typologies of buildings, but without considering any modeling method regarding occupants' movement and activity or their clothing adjustment. Li et al. [20] covered a large period, till 2018, and all typologies of buildings, however, clothing adjustment was not considered. Finally, Salimi and Hammad [21] covered all OPA aspects, considering a time coverage from 2008 till 2018 and focusing on office buildings. Table 1 compares the main features of analyzed literature reviews and identifies the main gaps that the present study aims to fill.

Table 1: Comparison of literature reviews on Occupant Presence and Actions since 2015

\begin{tabular}{|c|c|c|c|c|c|c|c|c|c|c|}
\hline \multirow{2}{*}{ Authors } & \multirow{2}{*}{ Year } & \multirow{2}{*}{$\begin{array}{l}\text { Temporal } \\
\text { coverage }\end{array}$} & \multirow{2}{*}{$\begin{array}{c}\text { Typology of } \\
\text { buildings }\end{array}$} & \multicolumn{7}{|c|}{ Occupant presence and actions } \\
\hline & & & & Presence & $\begin{array}{c}\text { Movement } \\
\text { activity }\end{array}$ & $\begin{array}{c}\text { Window } \\
\text { operation }\end{array}$ & $\begin{array}{l}\text { Shading Lighting } \\
\text { operation operation }\end{array}$ & $\begin{array}{l}\text { Thermostat } \\
\text { adjustment }\end{array}$ & Appliance use & $\begin{array}{c}\text { Clothing } \\
\text { adjustment }\end{array}$ \\
\hline $\begin{array}{c}\text { Gunay, } \\
\text { O'Brien, } \\
\text { Beausoleil- } \\
\text { Morrison }\end{array}$ & 2015 & Up to 2014 & All & $\bullet$ & & $\bullet$ & $\bullet$ & & & $\bullet$ \\
\hline $\begin{array}{c}\text { Yang, } \\
\text { Santamouris, } \\
\text { Lee } \\
\end{array}$ & 2016 & Up to 2016 & Institutional & $\bullet$ & $\bullet$ & & & & & \\
\hline Gilani, O’Brien & 2016 & Up to 2015 & Office & $\bullet$ & & $\bullet$ & $\bullet$ & $\bullet$ & $\bullet$ & $\bullet$ \\
\hline $\begin{array}{c}\text { Chen, Jiang, } \\
\text { Xie }\end{array}$ & 2018 & 2005-2017 & All & $\bullet$ & & & & & & \\
\hline
\end{tabular}




\begin{tabular}{|c|c|c|c|c|c|c|c|c|c|c|c|}
\hline $\begin{array}{l}\text { Zhang, Bai, } \\
\text { Mills, Pezzey }\end{array}$ & 2018 & Up to 2016 & $\begin{array}{l}\text { Residential } \\
\text { and } \\
\text { Commercial }\end{array}$ & $\bullet$ & $\bullet$ & $\bullet$ & & $\bullet$ & $\bullet$ & $\bullet$ & $\bullet$ \\
\hline $\begin{array}{l}\text { Balvedi, Ghisi, } \\
\text { Lamberts }\end{array}$ & 2018 & 2006-2017 & Residential & $\bullet$ & $\bullet$ & $\bullet$ & $\bullet$ & • & $\bullet$ & • & \\
\hline $\begin{array}{c}\text { Dong, Yan, Li, } \\
\text { Jin, Feng, } \\
\text { Fontenot }\end{array}$ & 2018 & Up to 2017 & All & $\bullet$ & & $\bullet$ & $\bullet$ & $\bullet$ & $\bullet$ & & \\
\hline $\begin{array}{c}\text { Li, Yu, } \\
\text { Haghighat, } \\
\text { Zhang }\end{array}$ & 2019 & Up to 2018 & All & $\bullet$ & $\bullet$ & $\bullet$ & $\bullet$ & $\bullet$ & $\bullet$ & $\bullet$ & \\
\hline $\begin{array}{l}\text { Salimi, } \\
\text { Hammad }\end{array}$ & 2019 & $\begin{array}{c}2008-2018 \\
\text { +adding }\end{array}$ & Office & $\bullet$ & $\bullet$ & $\bullet$ & $\bullet$ & $\bullet$ & $\bullet$ & $\bullet$ & $\bullet$ \\
\hline
\end{tabular}

\subsection{Motivation and objectives}

The overview of the state-of-the-art presented in Table 1 reveals a lack of review studies that cover thoroughly the different aspects of OPA modeling and the different building typologies, as well as the latest developments in this field. Therefore, standing as an addition to the work done in the IEA-EBC Annex 66 and embracing the new propositions of the IEA-EBC Annex 79, the main purpose of this study is (1) building an updated biographical database of the studies that have developed models on OPA, (2) based on analysis of this database, providing an overview of the scientific production and the current scientific landscape on OPA modeling, (3) identifying the key methods adopted in OPA modeling by considering different OPAs and by comparing documents that propose rulebase methods, data-driven methods, and a stochastic description of OPA, and (4) drawing a future outlook in OPA modeling.

\section{Methodology}

The purpose of this work is enabling a comprehensive analysis of the existing literature in the field of occupant behavioral modeling in building performance analysis. The presented systematic literature review is conducted following the PRISMA methodology, and the research question and the related literature search are built according to the guidelines proposed by Denyer and Tranfield [22]. Although the PRISMA methodology is a useful guideline for a critical development of systematic reviews, it is not an instrument that can automatically guarantee their quality [23]; thus, a large pool of experts from the IEA-EBC Annex 79 community has been involved in the planning, development and execution of this study. As such, the authors are aware of the possibility of relevant articles that might be missing in the review but are confident that the identified bibliographic database represents the main tendencies and approaches adopted into the field so far. 
The PRISMA methodology considers four main phases: (1) identification, (2) screening, (3) eligibility, and (4) inclusion of studies. The summary of the PRISMA methodology is presented with a flow chart that shows the number of bibliographic records initially identified by the search query and subsequently included in this study (Figure 1).

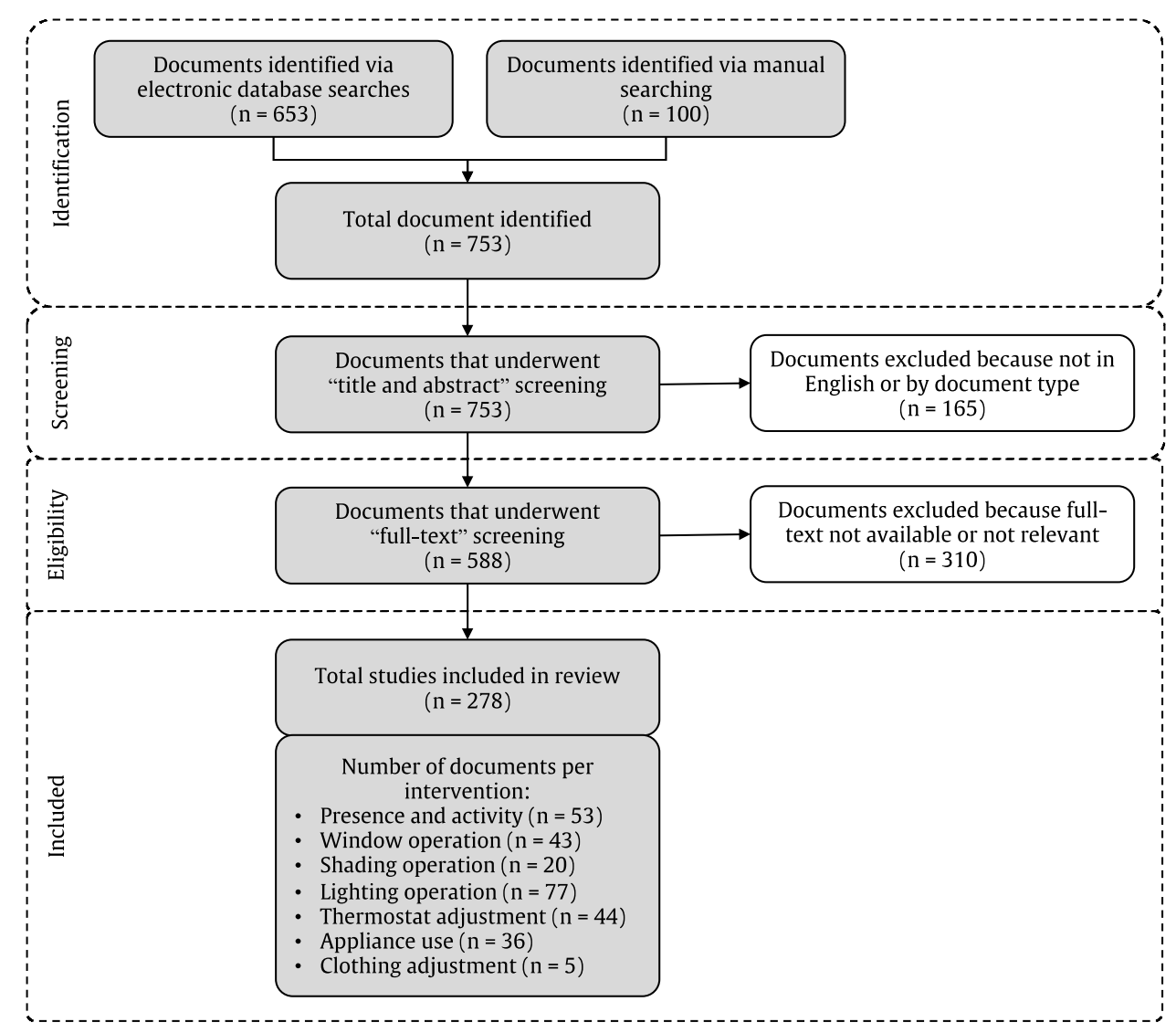

Figure 1: Literature screening process following the PRISMA framework (Moher et al., 2009).

\subsection{Identification of studies}

The first step consists in constructing the research question. In this work, the CIMO-logic [24] is adopted, where CIMO stands for Context, Intervention, Mechanism and Output, and the research question is: "How do we model (M) the occupant presence and actions (I) to simulate the performance (O) of buildings (C)?" (Table 2). 
Table 2: The CIMO-logic for studying modeling of Occupant Presence and Actions in buildings

\begin{tabular}{|c|c|c|c|}
\hline Context & Intervention & Mechanism & Outcome \\
\hline $\begin{array}{l}\text { Where? In which context } \\
\text { the intervention is } \\
\text { embedded? }\end{array}$ & $\begin{array}{l}\text { What? Which is the main } \\
\text { topic? }\end{array}$ & $\begin{array}{l}\text { How? Which is the } \\
\text { medium? }\end{array}$ & $\begin{array}{l}\text { To get what? What is the } \\
\text { wanted information? }\end{array}$ \\
\hline $\begin{array}{l}\text { Buildings } \\
\text { (all building types) }\end{array}$ & $\begin{array}{l}\text { Occupant presence and } \\
\text { actions: } \\
\text { - } \quad \text { Presence and activity } \\
\text { - Window operation } \\
\text { - } \quad \text { Shading operation } \\
\text { - Lighting operation } \\
\text { - } \quad \text { Thermostat } \\
\text { - } \text { adjustment } \\
\text { - } \quad \text { Clothing adjustment }\end{array}$ & $\begin{array}{ll}\text { Modeling techniques: } \\
\text { - } \\
\text { Rule-based } \\
\text { - } \\
\text { Stodels } \\
\text { modeling } \\
\text { - } \\
\begin{array}{l}\text { Data-driven } \\
\text { methods }\end{array}\end{array}$ & $\begin{array}{l}\text { Outputs: } \\
\bullet \quad \text { Energy performance } \\
\bullet \quad \text { Indoor comfort }\end{array}$ \\
\hline
\end{tabular}

Next, a comprehensive list of keywords is populated for each of the CIMO terms, and a research query is construct using the Boolean operators AND, OR and NOT and exploiting the list of keywords (1) to include all the keywords that have the same root but different declinations (e.g., for considering both British and American spelling), (2) to consider precise technical wording, (3) to exclude some divergent terms. Afterwards, exclusion criteria are applied to limit the search to usable documents in order to limit the search only to journal articles, conference papers, reviews, books, book chapters and articles in press written in English. Old articles and conferences proceeding not available anymore were also excluded. Finally, the search query is executed in the Scopus, Web of Science and EI Compendex databases. However, due to compatibility issues with the bibliometric tools, the file exported by EI Compendex could not be used. Furthermore, the files exported by Scopus and Web of Science could not be merged and, given the wider coverage, the Scopus file was eventually used for the literature search.

During the screening phase, the titles and abstracts of the identified documents were read, and several publications were excluded because not relevant. Afterwards, only studies with full-text were considered eligible for further analysis. Then, quality and consistency assessments were conducted by reading all the full-texts of the eligible documents. Those documents (i) not matching the research question, (ii) not relevant, (iii) without sufficient data, and (iv) presenting overlaps were also removed from the final database. Also, a few studies were removed due to overlap (e.g., the same set of data or models presented in both journal articles and conference papers). Finally, the bibliographic database was consolidated, and the bibliometric analysis were executed in Bibliometrix [25] to identify relationships between topics, patterns in the metadata of publications and thematic evolution. 


\subsection{Bibliometric analysis}

The bibliometric analysis provides information on the relevance of the identified bibliographic records and uses science mapping to extract knowledge at the nexus among conceptual, intellectual and social structures.

\subsubsection{Collaboration network}

A collaboration network involves the analysis of authors' productivity, affiliations, and countries (of their affiliated organizations) and is represented on a map. It specifically deals with the scientific production disaggregated by country and the collaboration between authors with affiliations in each country. When a document is written by two authors whose affiliations belong to different countries, it is considered a collaboration.

\subsubsection{Co-word analysis}

A co-word analysis is a quantitative method for mapping the structure of a science field [26]. This technique analyzes the pattern of co-occurrence of pairs of words, which is the simultaneous occurrence of two words in a piece of text. The co-word analysis is performed by adopting clustering algorithms that identify the main themes characterizing the work under study. Outcomes of the co-word analysis are typically displayed with a co-occurrence network. The dimension of the node representing a keyword is proportional to its frequency of appearance in the analyzed bibliographic database, while the thickness of the connecting lines is proportional to the equivalent index value. The equivalent index $e_{i j}$ is defined as $e_{i j}=c_{i j}{ }^{2} /\left(c_{i} c_{j}\right)$, where $c_{i j}$ represents the number of the documents in which both the keywords co-occur, $\mathrm{c}_{\mathrm{i}}$ and $\mathrm{c}_{\mathrm{j}}$ are the numbers of the documents in which each keyword appears.

\section{Analysis of bibliographic metadata}

In recent years, the interest on OPA modeling and the related scientific production have increased (Figure 2) [5,27]. It should be noted that the literature search in this article was conducted in August 2019, therefore, the count for 2019 does not account for the documents published in the second half of the year. 


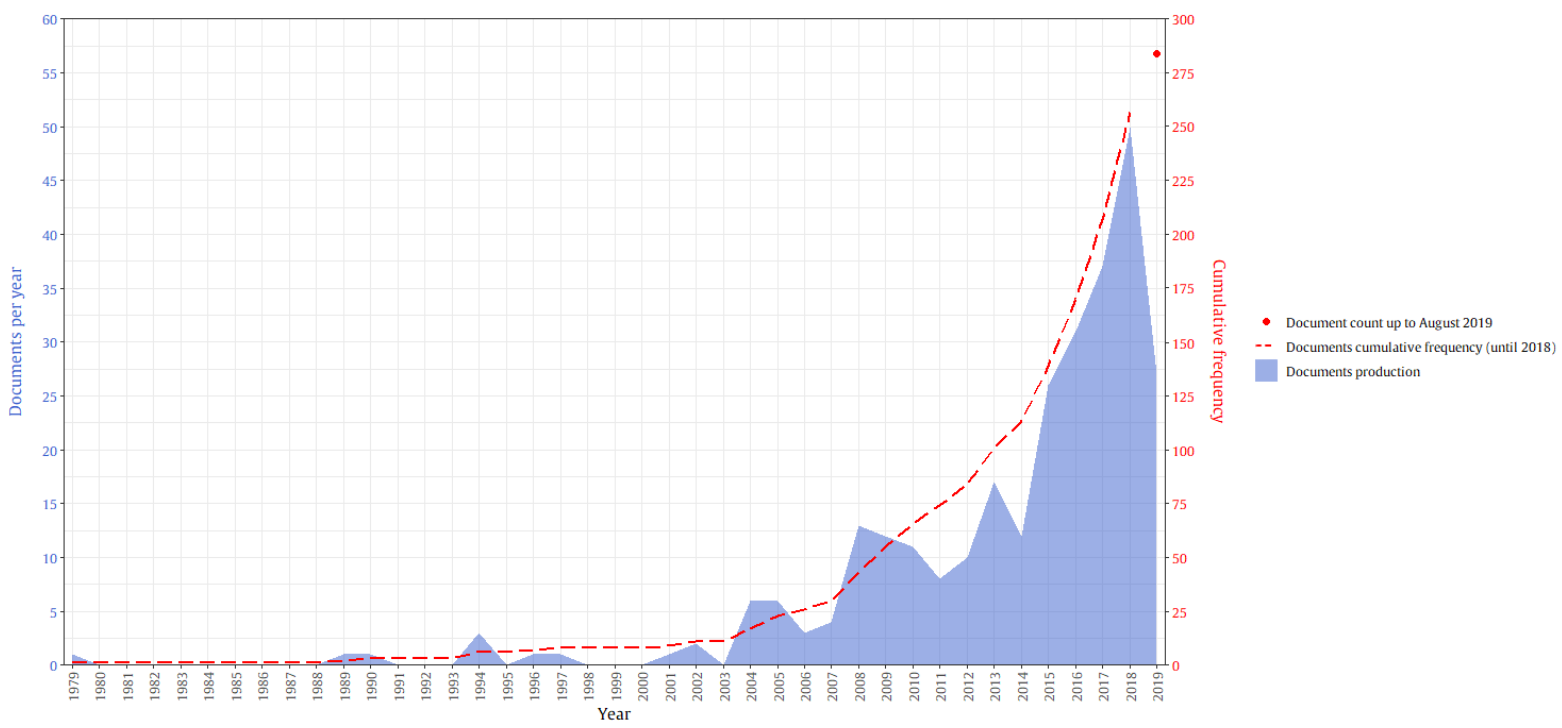

Figure 2: Annual scientific production of documents presenting Occupant Presence and Actions models. The count for 2019 considers only those documents indexed until August 2019

The median of the publication year is 2015 and the average is 2013, in other words, a large share of the collected documents has mainly been published in the last four to six years. Specifically, there is a strong rise in published documents on OPA since 2010. By consequence, this review may be considered as an assessment of the current practice in OPA modeling in buildings. Looking at the temporal evolution of the published documents by source, the journals that have published more documents regarding OPA modeling in the latest years are Building and Environment and Energy and Buildings, followed by the Journal of Building Performance Simulation (Figure 3).

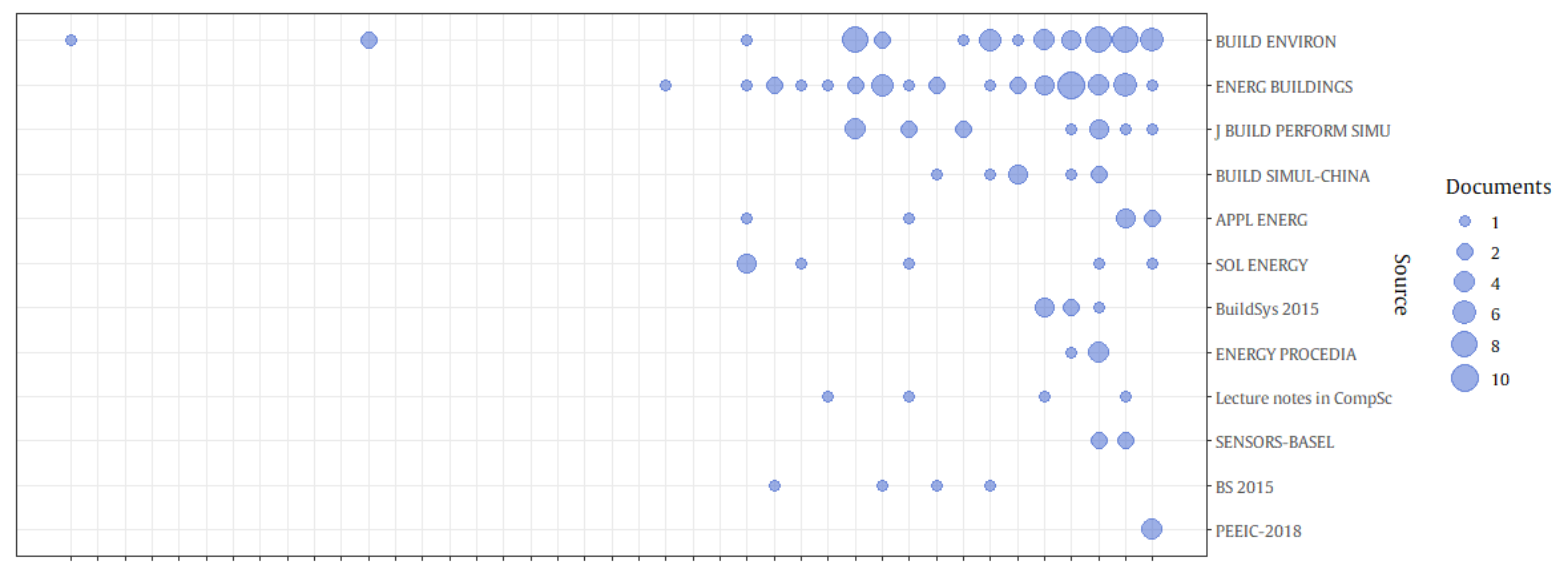

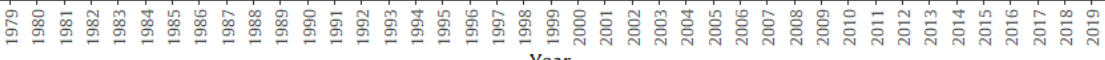

Figure 3: Chronological development of publication by sources. 
Regarding the document production by country, the United States of America is the most productive country with 74 published documents from 1979 onwards. In addition, its collaborations are the most numerous (with 20 coauthored documents) and the most spread around the world (11 collaborations involve multiple countries) (Figure 4). Europe, as a whole, is very productive with eight out of 16 countries having more than 10 publications (UK, Italy, Switzerland, Germany, Denmark, France, Belgium and Netherlands). European collaborations are mostly internal, but there are also connections with countries from all continents.

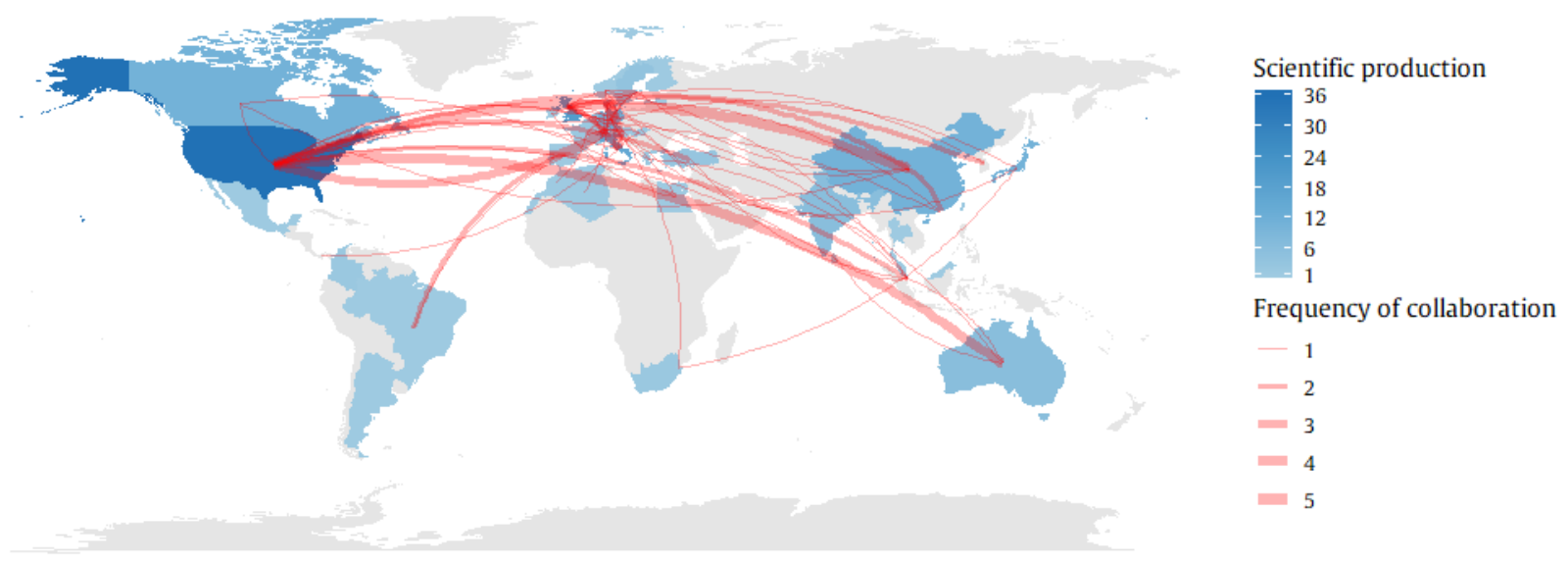

Figure 4: The collaboration network map shows country collaborations and production

\section{Analysis of the documents on OPA modeling}

The bibliographic collection is composed of 278 documents from 146 sources published from 1979 to nowadays. On average, each document is cited 46.1 times. The documents were written by 809 authors who appeared 1003 times as co-authors within this document collection with an average of 3.54 co-authors per document. These figures show a consolidated and spread international collaboration on this topic.

After the screening phase and having read all the full-texts, contextual data was extracted from the 278 documents and used to characterize the overall production of OPA models. Few documents propose more than one model and address more occupant actions; therefore, the number of models analyzed is up to 310 . Figure 5 displays aggregated figures on the number and percentage over the total number of collected models. 
a) Type for OPA model development

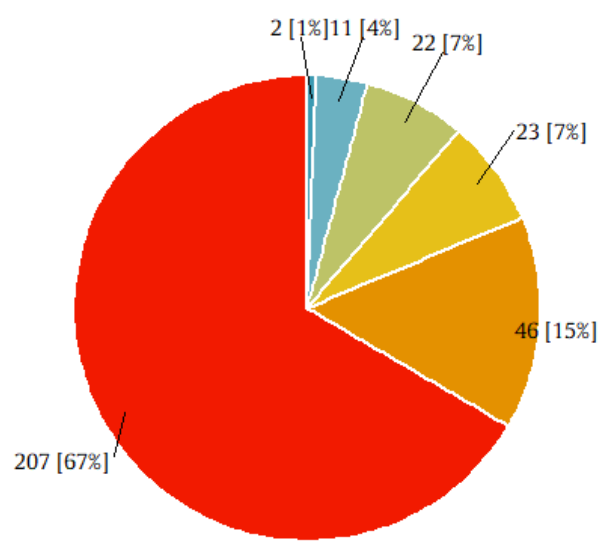

Measurements

Simulations

Datasets

Measurements and surveys

Surveys

Not available information

c) OPA models by operation mode

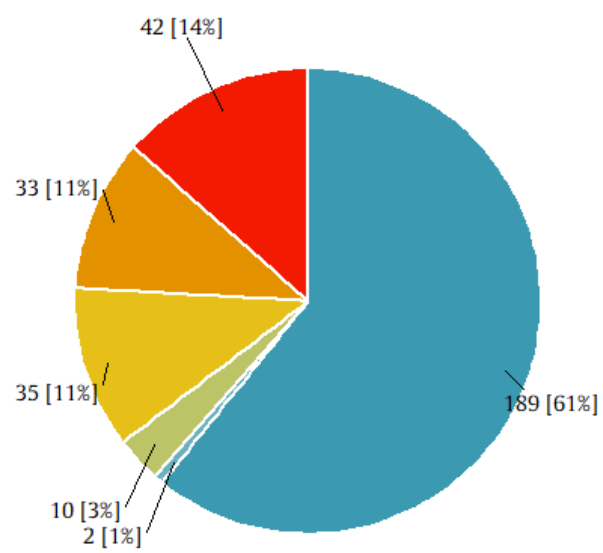

Naturally ventilated buildings

Mechanically heated \& naturally vent. buildings

Mechanically heated \& cooled buildings

Mechanically ventilated buildings

Mechanically cooled buildings

Not available information b) OPA models by building type
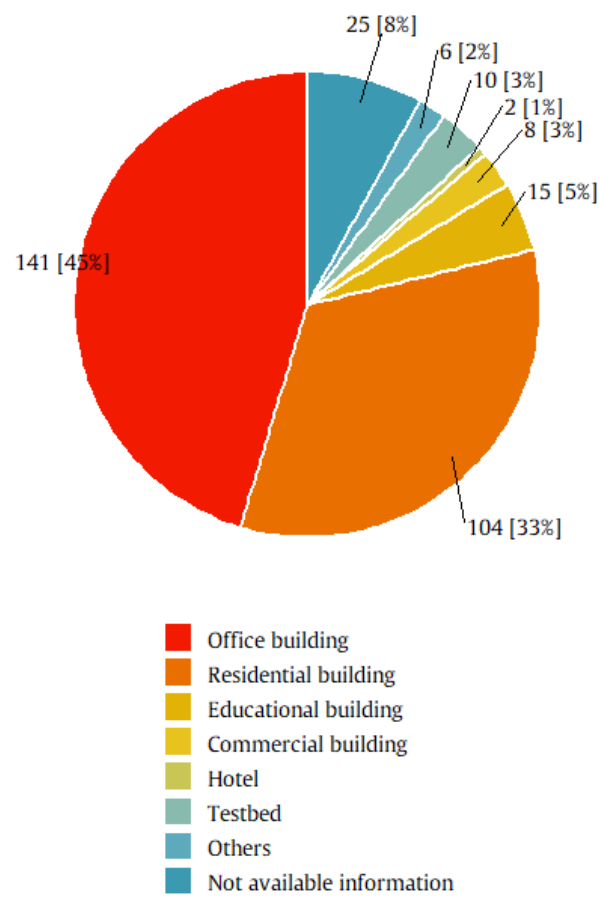

d) Type of methods used for OPA model development

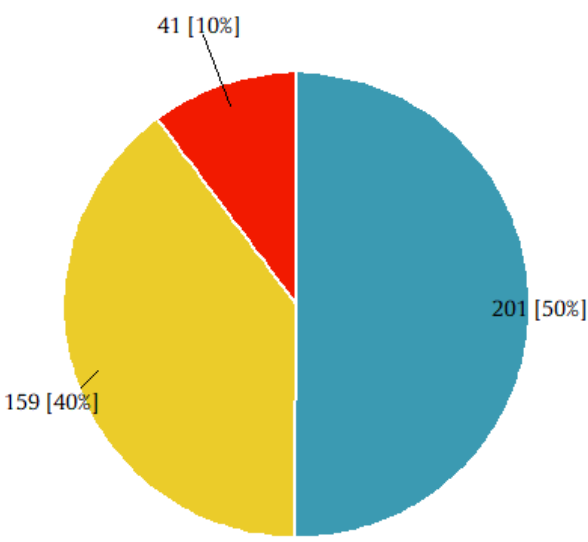

Deterministic or rule-based methods

Stochastic or probabilistic methods

Data-driven methods

Figure 5: Graphical description of the Occupant Presence and Actions models collected in the bibliographic database (number of OPA models; percentage) 
For the OPA model development, measurements are the most frequent data source. They represent a reliable manner to gather data and control uncertainty, but privacy issues may be encountered during the execution of measurement campaigns [28,29], typically when data collection happens in large buildings with general visitors for people-count purpose. From the analysis of the building use, offices are the most studied building type followed by residential units. In particular, the number of documents related to offices is around $60 \%$ higher than for residential buildings. This imbalance may be due to a more predictable occupant behavior in offices, an easier experimental setting, and a more direct transferability of models and results. In addition, the experiments on occupant behavior in offices can be less affected by privacy concerns when compared to the residential buildings. Naturally ventilated buildings are the most commonly researched building type and control strategy. This could be a result of the wider availability of collected data and the high variability of people interacting with a building and its devices, resulting more interesting from a model developmental perspective. However, several documents do not report explicit contextual information on the above three aspects and, hence, these descriptive statistics must be read as indicative figures.

All documents are also categorized on the base of the modeling approach used to develop the OPA models. It emerged that, in the last years, thanks to extended measurement campaigns and a higher wealth of available data, data-driven models are attracting increased interest for their capability to manage large data sources without missing the aleatory nature of OPA in buildings [30], followed by stochastic OPA modeling techniques, and rule-based methods. Next, the documents were grouped according to the Köppen-Geiger's climate classification system [31]. A high proportion of models are developed in temperate and continental climates identified respectively by the letters C and D with $50 \%$ and $21 \%$ out of the total number of models respectively. Follow tropical climates (A) with $5 \%$ and arid climates (B) with $2 \%$. In about $22 \%$ of the models, the climate condition was not mentioned.

The first five climatic zones by the number of developed OPA models represent almost the whole Europe, the USA and most populated portion of China (Figure 6), which are also the most productive countries per number of publications. 


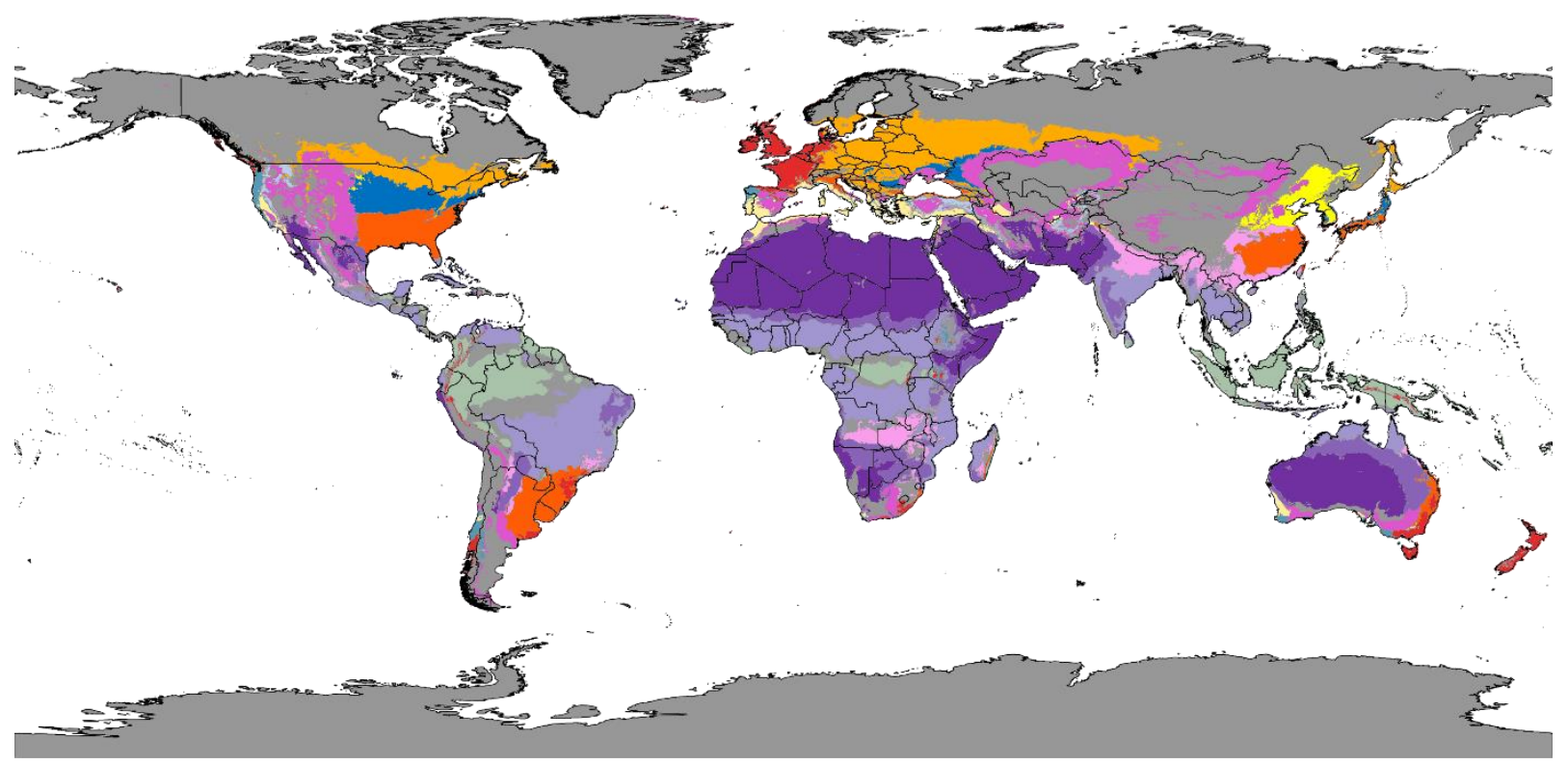

$\mathrm{Cfb}$, Oceanic

Cfa, Humid subtropical

Dfa, Humid subtropical

Dfb, Continental warm summer

Dwa, Continental hot summer dry winter

Csa, Mediterranean hot summer

Af, Tropical rainforest

Csb, Mediterranean warm/cool summer

Dfa, Hot summer continental

Dsb, Continental dry warm summer

Aw/As, Tropical wet/dry summer savanna

BSh, Arid and hot steppe

BWh, Arid and hot desert

Cwa, Dry winter humid sub-tropical

BSk, Arid and cold steppe

No models available

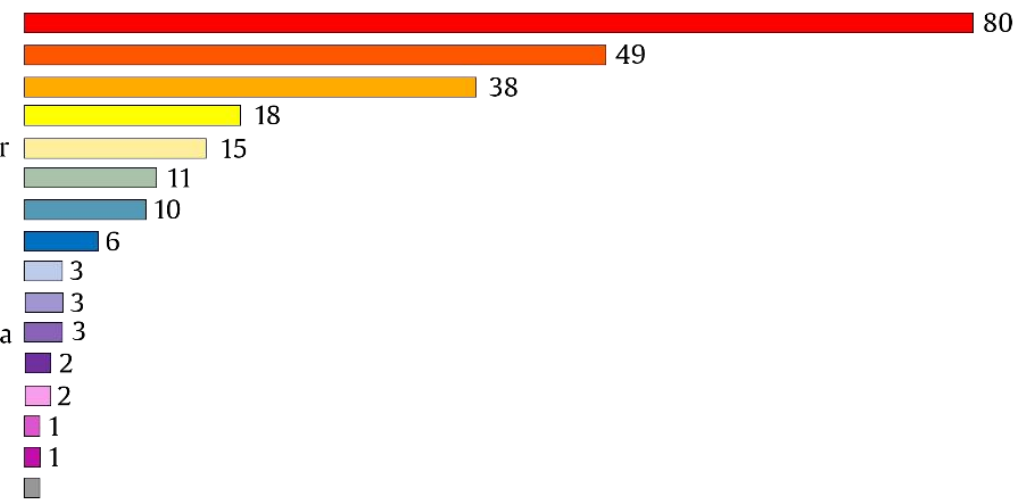

Figure 6: Number of available OPA models by Köppen-Geiger's climate zones in the bibliographic database.

\subsection{Scientific landscape}

Two main analyses are performed to describe the scientific landscape drawn by the bibliographic database: the three-field plot and the co-occurrence network map. These analyses help to understand the research trends and the connections among the themes rising from the state of the art.

The three-field plot displayed in Figure 7, shows the number of connections (size of the boxes) and strength of the connection (size of the connection lines) between most frequent words in abstracts (left field), Authors' Keywords (middle field) and scientific journals (right field). 


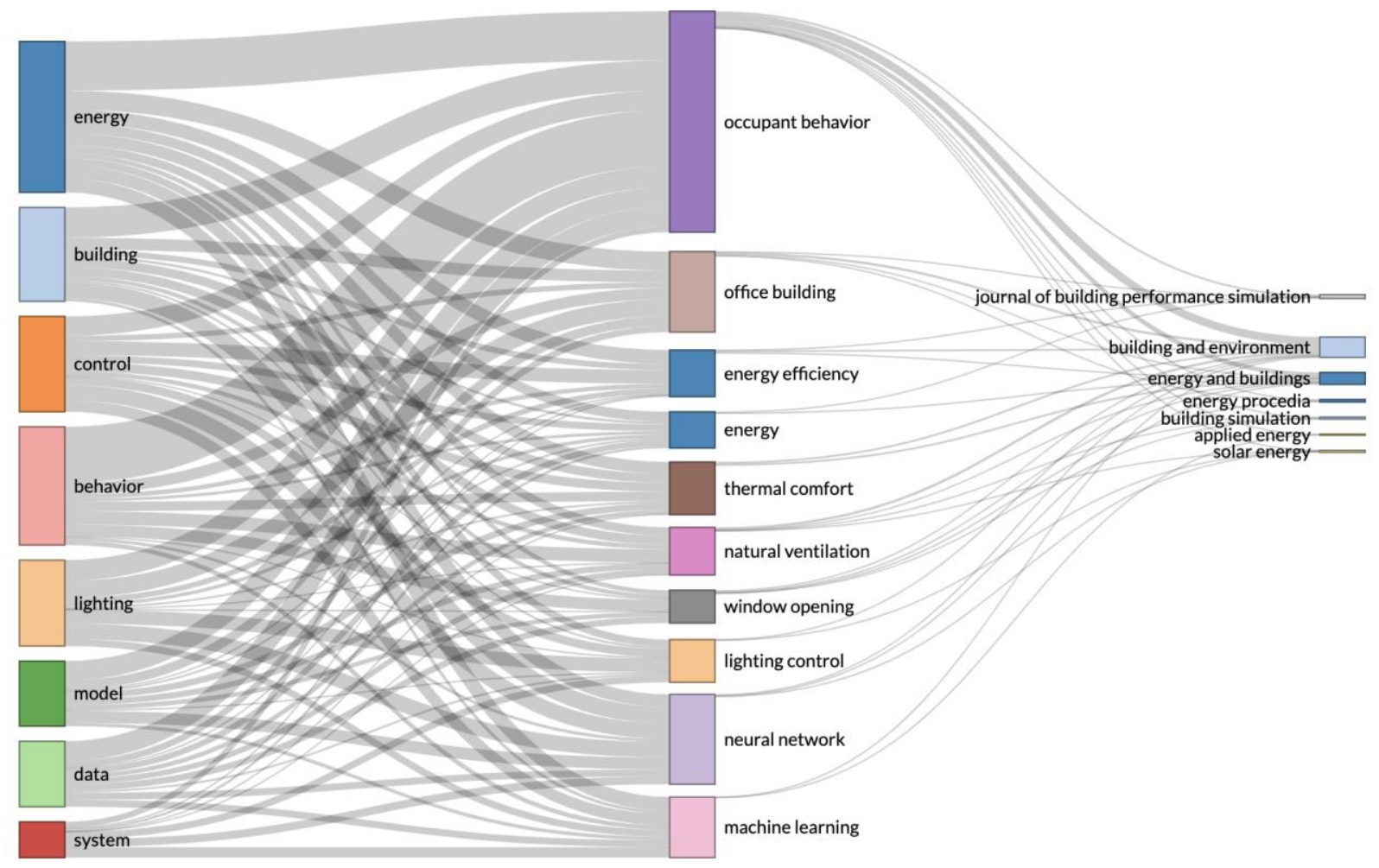

Figure 7: Evolution of the most frequent words in the abstracts (left field) to the keywords (middle field) and to the journal sources (right field) for the papers in the bibliometric database

The most frequent words in the abstracts point out the main and general terms of the research questions (like 'energy', 'building control'). In the middle field of the author's keywords, the main concepts on which the domain is built (like 'occupant behavior', 'thermal comfort', 'windows opening', 'lighting control', 'machine learning' and 'office building') is presented. Finally, the main keywords as available in the journals are shown. For example, 'occupant behavior' is a very general term that is present in all the most representative journals, but 'thermal comfort' is mostly present in Building and Environment and Energy and Buildings, 'lighting control' is mostly related to Solar Energy and Energy and Buildings, and 'machine learning' is more present in Applied Energy and Building and Environment. This analysis provides insights to researchers new to the field to aid identifying the most suitable journals for publishing their studies.

The co-occurrence network in Figure 8 shows the different clusters of Authors' Keywords, which are identified by the Walktrap clustering algorithm assuming 50 nodes and normalizing the relationships by the association strength [25]. 


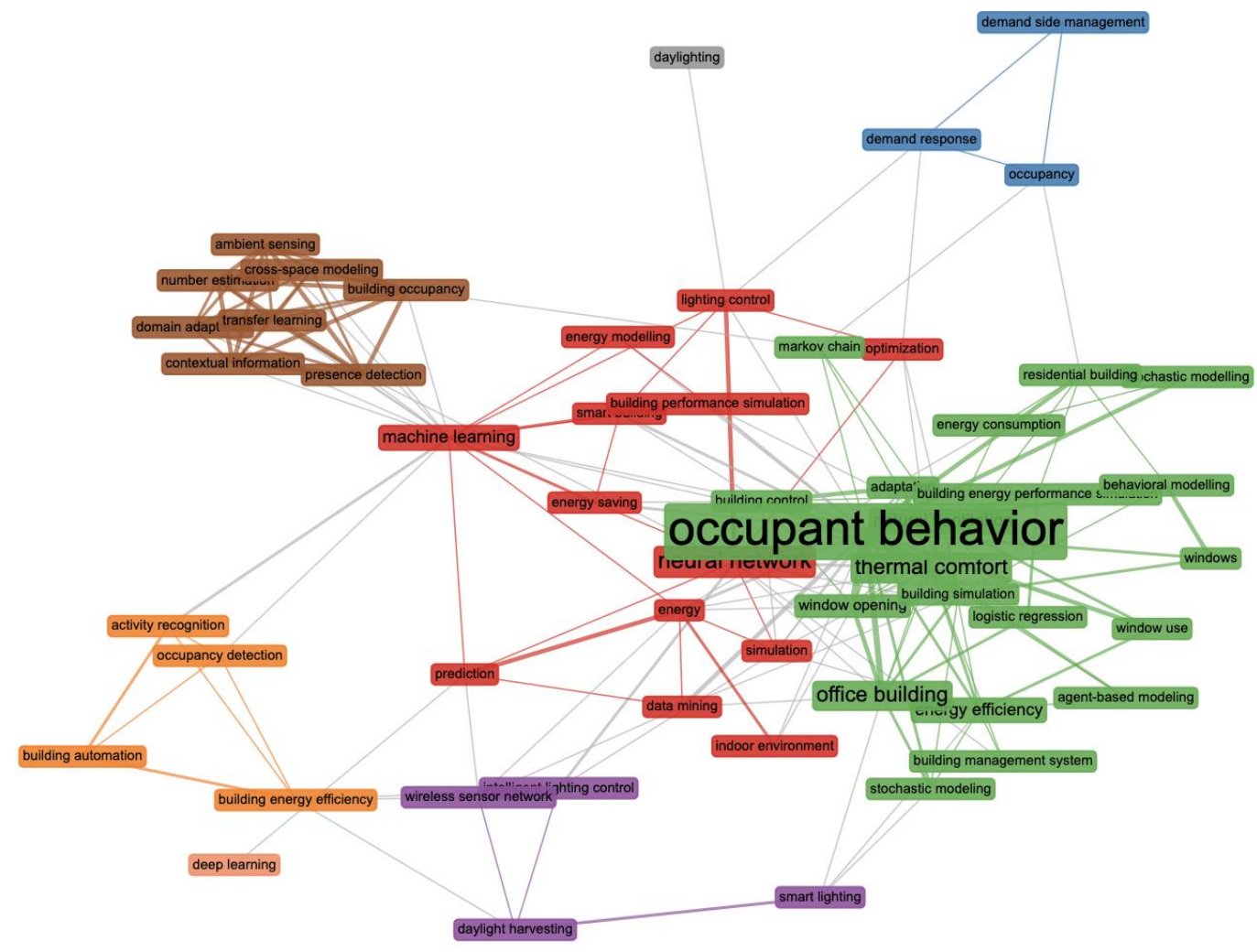

indoor positioning

Figure 8: Co-occurrence network of Author Keywords from papers in the bibliographic database

The largest cluster (in green) collects the most traditional keywords (e.g., 'occupant behavior', 'office building', 'energy efficiency', 'thermal comfort') and some satellite terms typical of stochastic modeling. The second cluster (in red) pivots on 'neural network' and includes several data-driven topics like 'machine learning', 'data mining', 'prediction' and other term referring to widely used application like 'building management systems' and 'smart buildings'. The third cluster (in brown) is somewhat distant from the other terms and is very concentrated. It deals primarily with 'occupant presence' and includes terms like 'presence detection', 'number estimation', 'building occupancy' and 'cross-space modeling'. The orange cluster pivots on 'building automation' for 'building energy efficiency' together with 'occupancy detection' and 'activity recognition'. The blue cluster vertex on 'demand side management' and includes the terms 'demand response' and 'occupancy'. The purple cluster focusses on 'intelligent 
lighting control', with terms like 'daylight harvesting' and 'smart lighting'. The keyword 'daylighting' is isolated but connected with 'lighting control' while 'visual comfort' and 'indoor positioning' are isolated and not connected.

\section{Explanatory and predictive power for Occupant Presence and Actions modeling}

In contrast to other scientific disciplines, the research on OPA requires models with both explanatory and predictive power, which represents a particular challenge. Motivated by the latter need for dual modeling objective, this section provides a comparison of the existing modeling formalisms for both causal explanation and predictive modeling. OPA models were developed (1) to optimize the building design, (2) to represent the occupants in building performance simulation (BPS), and (3) to predict the human behavior for the inclusion in building control systems. The first two goals may be achieved by explaining the relationship between OPA and a set of objective measurements. For instance, by knowing the fixed working hours it may be understood the reason why an occupant was present at the workspace. Alternatively, the causal explanation of the intervention on sunshades may be visual discomfort that can be correlated with the solar radiation on the window surface. Here an important property of the chosen methods is to possess high exploratory power.

Regarding the third goal, OPA models for the application in building control require predictive power, in order to forecast the events or states on the future time-steps with satisfactory accuracy. In this place, models that possess high explanatory power are often assumed to inherently possess predictive power [32]. However, the research on statistical modeling pointed out that the distinctive models are required for prediction and causal explanation $[32,33]$. The need for non-identical methods for representing the impact of occupants in BPS and for predictive modeling has already been pointed out by Mahdavi and Tahmasebi [34], hence, this distinction has sometimes been overlooked by the modeling studies.

The causal explanation can be addressed using statistical and linear models [32]. The research on explaining occupant behavior has a longer tradition when compared to the predictive OPA in buildings modeling. Therefore, the set of statistical and linear models in use widely overlaps with the established general modeling formalisms that were reviewed by D'Oca et al. [35]. In addition to the methods proposed by the latter study (namely Bernoulli models, generalized linear models, and survival models), the generalized class of probabilistic graphical models, which also includes discrete Markov models, showed to be powerful tools for the research on human-building interaction. For instance, logistic regression and linear models have been applied to investigate the relationship 
between the thermal conditions and the resulting occupants' actions [36,37]. Furthermore, the results of the past exploratory studies on the human-building interactions led to a better hypothesis formulation regarding the drivers of occupant behavior as well as defining the baseline predictive OPA models.

The prediction of OPA has been commonly addressed using machine learning-based methods. The literature screening has pointed out that the occupants' presence, activity recognition, and movement detection have been widely researched in the context of predictive modeling. For that purpose, the well-established modeling formalisms relied on probabilistic modeling, probabilistic graphical models, and conventional machine learning such as Support Vector Machine (SVM) and k-nearest neighbors (k-NN) algorithm. In the case of occupants' action prediction, different NN architectures have been investigated to model adaptive actions such as the use of lighting, solar shadings, windows, appliances, and clothing adjustment. The alternative widely explored methods include the conventional machine learning methods, such as k-NN, SVMs for classification and regression, as well as the variations of decision trees and ensembles of decision trees. The application of probabilistic methods and probabilistic graphical models led to promising modeling results for the application in the built environment. Hence, these classes of methods have not been comprehensively explored in the scope of existing OPA research. Moreover, stochastic models were also explored for their predictive capabilities for OPA. As a result, the logistic regression has been established as a baseline predictive model for window opening behavior, while in the scope of the recent study, the logistic regression showed promising results for learning the thermostat setpoints [38].

A first significant difference between the stochastic methods for the causality explanation and for the predictive modeling lies in the required data split. In the case of stochastic modeling, a set of data points is used to establish the hypothesis, while a set of distinct data points is eventually used to test the goodness of the hypothesis. Commonly, these two data sets were collected on the same occupant or on the same building, and the amount of available data is constrained by the design in terms of extent of the monitoring campaign [11]. Since these hypotheses widely address the relationship between the unique building design and the behavior, there are no strong requirements of the sample size.

An additional significant difference between the stochastic and machine learning modeling is the interpretability of models. Here, we refer to interpretability as the description of the internal rules of a system in a way that is understandable to humans [39]. Commonly, the machine learning models are developed to maximize the prediction accuracy and the results are often not interpretable using domain knowledge. This lack of interpretability has been seen as a major drawback for considering the machine learning approaches in the building design phase. However, as already pointed out by existing research, the most accurate explanations are not easily interpretable to people; 
and conversely, the most interpretable descriptions often do not provide predictive power [39]. Therefore, human interpretability is not a crucial property of the OPA models for inclusion in building control systems. Rather, the strict evaluation protocols in terms of models' effectiveness and the critical analysis of the predictive powers may be seen as the necessary components for the consideration of the machine learning methods in building control.

\section{Modeling occupant presence}

Human occupancy information is crucial for any modern building management system. The retrieved information can be utilized to understand both space utilization and building energy optimization, which enables informed decision making. Occupant presence is commonly declined in three sub-domains: occupancy detection, estimation and prediction; activity prediction and room occupation; and people movement between zones.

In this section, 53 documents published between 2004 and 2019 were analyzed. According to the developed bibliographic database, the annual scientific production in occupant presence modeling research reaches its peak (11 documents) during the period 2016-2018. The documents with most impact (in terms of a total number of citations) were published in Energy and Buildings. Next, there are documents published in journals with diverse scopes that do not belong to the core sources identified by Bradford's law, like Energy Conversion and Management and Geodesy and Cartography. These results point out that occupant presence modeling is a topic not exclusively related to energy and indoor environmental research in buildings.

The data-driven models represent $56 \%$ of the total, followed by stochastic OPA modeling techniques (30\%) and the rule-based models (14\%). In particular, $27 \%$ of the data-driven models use NN techniques, $13 \%$ SVMs, and $11 \%$ Hidden Markov model (HMM). Regarding the stochastic OPA modeling techniques, 42\% make use of Markov chain models, $17 \%$ of linear time series models, while $13 \%$ of the Monte Carlo method.

Figure 9 shows the percentage of documents using a typology of methods on the overall documents published in that year considered in this review. In the last years, data-driven models are emerging compared to the other two typologies. A cause for that could be the increase of data wealth due to the digitalization of the building lifecycle, large sensors installation campaigns, and availability of smart meters. 


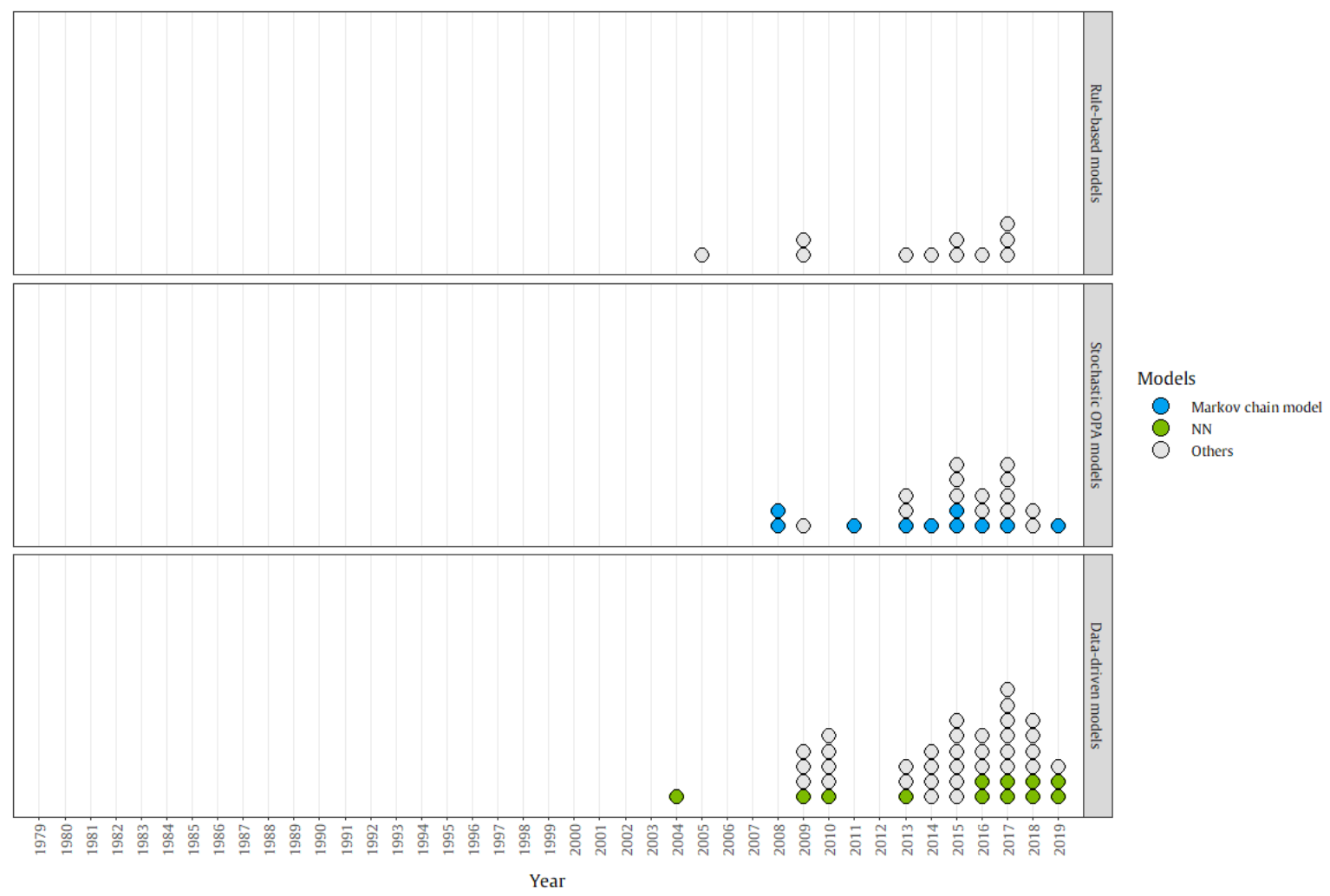

Figure 9: Yearly percentage of presence models with respect to the total number of published models belonging to the bibliographic database in each year

\subsection{Occupancy detection, estimation, and prediction}

Occupancy detection usually refers to the binary inference of occupant presence and absence in different zones of an indoor or outdoor space while occupancy estimation usually refers to the occupancy count. Occupancy prediction is to forecast the in a future time window. Occupancy detection, estimation, and prediction are challenging tasks due to many reasons. For instance, there is a wide variety of sites of interest (such as individual and open plan workplaces, shopping malls, cinemas, etc.), which differ in size and operation mode. Hence, the appropriate contextual information must be considered for effective deployment of any system for occupancy detection, estimation, and prediction. Recent technological developments and the proliferation of pervasive technologies have opened up many opportunities to detect, estimate, and predict indoor occupancy leveraging various sensors and smart devices [40].

Many sensor-based technologies are available to detect and estimate occupancy in different types of sites [41]. A comprehensive review that compares the capabilities of different sensor types and their fusion for occupancy detection and estimation is presented in [17]. However, these technologies require extensive installation of hardware and continuous maintenance. Moreover, their accuracy can be influenced by specific physical orientation (i.e. 
seating, standing, walking styles) of occupants since the sensors are usually placed under the desk or overhead. To reduce the cost of extensive sensor installation, a probabilistic method for room-level occupancy counting is presented in [42]. This model utilizes common sensors available at different rooms for disaggregating accurate building-level occupancy counts to room-level occupancy counts. Another probabilistic fusion technique to estimate indoor occupancy from 3D camera counts is presented in [43]. Data from smart electricity meters is also used to detect the occupant presence $[44,45]$. The basic idea is to conduct cluster analysis on continuous variables, like power load, carbon dioxide $\left(\mathrm{CO}_{2}\right)$ concentration, and estimate occupant presence. Another research highlights the use of different sensing systems including radio frequency, infrared, ultrasound, video cameras, and wireless local area network in recent literature [15]. However, these technologies are susceptible to surrounding electromagnetic conditions, inconsistent connections and may raise privacy concerns [15].

From the analysis of the developed bibliographic database, many state-of-the-art machine learning tools have been deployed to develop smart building applications which include occupancy detection, estimation, and prediction. Several classification models including Linear Discriminant Analysis, Classification and Regression Trees, and Random Forest models are evaluated for occupancy detection utilizing data from light, temperature, humidity and $\mathrm{CO}_{2}$ measurements. The data coming from various smart sensors are utilized to provide real-time as well as future predictions of occupancy status. However, it shall be mentioned that, since sensor data varies in dimensions and frequencies from one domain to another, a model trained for one domain cannot be applied effectively in another domain. To address this challenge, a semi-supervised domain adaptation method for $\mathrm{CO}_{2}$-based human occupancy counter is presented in [46].

Finally, several evaluation metrics are used to validate the occupancy detection and estimation models including prediction accuracy, precision, recall, f-1 score, mean average error (MAE), mean average percentage error (MAPE), and root mean squared error (RMSE). However, it would not be fair to quantify the widespread use of a model and evaluation metric as the performance of a model generally depends on the specific application, size and quality of the data. For example, the deep learning-based models require a large dataset for better performance while compromising the interpretability. If the purpose is casualty analysis, it is possible that the statistical and machine learning models are a better choice over deep learning.

The models discussed above are mainly developed and deployed using data from a specific site. Given the variety application scenarios, one of the key challenges is to transfer such models build for one site to another site as it may require extensive parameter tuning. In the future, efficient transfer learning methods could be adapted to mitigate this gap and more research effort needs to be given towards the adaptation of explainable machine learning and deep 
learning techniques. This will allow the research community and beyond to better understand the outcomes of the deployed models.

\subsection{Occupant activity recognition}

To adjust and operate control systems based on indoor occupant behavior, it becomes crucial for a building management system to recognize the indoor occupants' presence and its associated activities. The ability to identify or forecast a particular activity can minimize the exhaustion of unnecessary energy resources. Indeed, the difference in occupant activity might have a significant effect on the building's energy performance. Conservative behavior by occupants has been shown to save up to $30 \%$ of the building's energy consumption, while careless or reckless behavior can increase that amount by one-third [47]. Proper modeling of occupant activities is necessary to estimate building energy consumption and adjust the building's energy demands to optimize it [48]. Other notable uses of activity recognition and prediction include their use in health monitoring, to provide automated assistance and detect uncommon situations [49].

Activity recognition constitutes the monitoring of OPA along with the change of state in their environment. It is based on two main types of approaches, vision-based activity recognition and physical measurement-based or maybe environmental sensor-based. The former uses surveillance-based systems such as cameras [50], 3D-stereo vision systems [42], infra-red or depth registration [51], while the latter uses wearable or deployed sensors or RFID tags [52]. The typical solution for the detection of the occupant's activity involves a fusion of different environment monitoring techniques [53-56]. Most of the developed models are built on a foundation on quantity data but there are few examples that used quality-based data as the main development source [57]. Earlier works regarding the prediction of the occupant activities made use of probabilistic models and Bayesian belief networks [58]. Recent research efforts have also focused on Markov-chain models and HMM to estimate and forecast occupant activity levels $[59,60]$. Usually, most of the developed models are validated by ground truth data, obtained from visual observation via video recordings or notebook reporting [61]. Another development in the field of activity recognition and prediction is the use of deep learning methods for human activity recognition, where models are making use of Convolutional Neural Networks (CNN) [62-64] SVM [65,66], and Recurrent Neural Networks $[67,68]$.

The main gaps for activity recognition are having a wider range of activities, since most of the research efforts to date have targeted a selected number of pre-defined activities [58,62-67]. In addition, the interdependence between 
activities has to be recognized as well [69]. Future efforts can be outlined to incorporate the personalization perspective for accurate activity recognition, along with adaptation with evolving activities, and context aware recognition [70]

\subsection{People movement between zones}

People's movement between zones is intended as the transition of occupants from one room to another inside a building. Occupants with their movement change also the sensible and latent loads between zones and so influence the temperature and humidity in rooms. This topic is fundamental for detailed building models, in which the spaces are described at room-level and, on average, occupancy probability assigned to all the rooms are too simplistic.

The bibliometric analysis suggests that the topic of detection and modeling of indoor movement of occupants is gaining momentum as it is strictly related to the topic of smart buildings. The indoor tracking of occupants is not a new field of research [71]. However, only in the last years, some descriptive and predictive models are emerging aiming specifically the better description of occupants for buildings energy modeling [72]. The description of the localization of occupants in real-time is fundamental for a large variety of smart buildings services; specifically, energy management and indoor environmental control [73]. For example, the proper load calculation due to occupants and their spatial distribution could avoid over-heating/cooling or under-heating/cooling of areas which is of a major importance especially for large public spaces [72,74]. Furthermore, these models could help to track and learn inhabitant's daily routine unobtrusively with the aim to optimize energy usage without affecting occupants' comfort [75]. Moreover, although satellite-based radio navigation systems are the common method that provides accurate track and modeling of movements outside buildings [76] and their use for positioning inside buildings is theoretically possible [77], it is difficult with traditional Global Positioning System (GPS) receivers to locate occupants in buildings [71]. Firstly, because the signal must be unobstructed, indeed conservative models suggest that the attenuation in buildings can reach levels of $2.9 \mathrm{~dB}$ per meter of structure [76]. Secondly, because this typology of systems requires the user to carry a tag.

Generalizing, the overall research process can be summarized into two consecutive tasks: people movement detection, identification, and localization, and people movement modeling for forecasting and simulation.

The literature relates mainly to the first task, in which arrays of binary sensors [78], environmental sensors [79], cameras [80], pressure sensors [81], inertial and vibration sensors [82,83], radio-frequency identification sensors [84], Bluetooth $[75,85]$ and Wireless Local Area Network (WLAN) [86-88] are used to detect occupants and track 
their movements [89]. Generally, environmental sensors are the cheapest solution, but they provide less information about human movement, unless densely spread in the indoor space. Cameras or infrared sensors provide good accuracy, but they are usually expensive sensors with high maintenance costs and privacy issues. Pressure sensors, inertial and vibration sensors are usually employed under the floor, making the maintenance and the installation to be planned. Finally, the sensors like relying on Bluetooth or WLAN provide very detailed results, however, often they need that the occupant carries constantly a device.

The second task is usually performed with machine-learning algorithms that are able to learn representation from the data and use them to forecast, simulate and model the occupants' presence in rooms and their movements $[74,75,90,91]$. Some studies solve the simulation and forecasting via stochastic models, due to the lack of surveys and statistical information with proper detail [72,92].

To summarize, the topic of modeling people's presence, movement between zones and activity is relatively new, and machine learning methods are emerging as a promising approach to forecast, simulate, and model the occupants' presence in rooms and their movements inside buildings.

\section{Modeling occupant actions}

People interact with a building and its devices in various manners to meet individual needs. Occupant actions have a role in modulating energy fluxes exchanged by a space and the outdoors and, hence, have an important impact on the actual energy use in buildings and perceived occupants' comfort. In this study, considered occupant actions are windows operation, solar shading operation, electric lighting operation, thermostat adjustment, appliance use, and clothing adjustment.

\subsection{Window operation}

Window operation is an important control mechanism that, enabling physical connection with the outdoors, provides occupants with the ability to control the local indoor environment (i.e. regulate the indoor air quality and room air temperature). Moreover, since the '70s, building regulations are progressively increasing the energy conservation requirements of the building envelope with a reduction of infiltrations and conductive heat losses. Thus, the share of the ventilation losses on a building's overall energy balance is enlarging. In this context, window operations 
become even more important, and there is a high demand for window operation models that create realistic patterns for use in building energy simulations and for the predictive modeling for building control systems.

In this section, 43 documents published since 1990 were analyzed. According to the analysis of the developed bibliographic database, the control mechanisms, even though clearly influenced by physical conditions, tend to be governed by a stochastic rather than a deterministic relationship [93]. Stochastic models estimate an outcome by assuming a probabilistic relationship with one or more predictor variables. For modeling window opening behavior, the most common approach used so far are logit models and logistic regressions. These models can be used to predict the probability of a window's state (i.e. open or closed) $[36,94,103,104,95-102]$ or the probability that a certain action will occur (i.e. window opening or closing action) [105-108]. The former has been typically implemented with a Bernoulli process while the latter with a Markov process. A Bernoulli process [37] is a sequence of independent binary random variables where the current state has no impact on the future state; by definition, it ignores the actual dynamic processes leading occupants to perform actions. This limitation can be overcome using a Markov process [37,94,103,109-111], since it is a random process where future states are dependent only on a current state together with the probabilities of the state changing. However, to integrate these simulation approaches in a conventional BPS tool, since the time advances in fixed time steps, they have to be discrete (discrete-time random process). Therefore, the temporal resolution of predictions is limited (e.g., short duration openings could be ignored if they last less than the given time step). Furthermore, the time in which the active state (e.g., window closed) will be reversed is not predicted. To pose a solution, Haldi and Robinson [112] developed a hybrid approach: state transitions were predicted as Markov processes, while a continuous-time approach was employed through a survival analysis to estimate the time to reversal of the state.

Several studies implement NN and also deep learning has been used so far [113]. NNs are capable of learning the relationship between input signals and capturing key information through the training process based on historical records. Furthermore, they also possess a number of other strengths such as fault tolerance, robustness, and noise immunity $[114,115]$. However, the architecture choice and hyperparameters optimization in the current NNs are still developed on an ad hoc basis. This implies that NNs applications are usually case dependent [116]. They have to be designed and validated each time for every diff erent applications.

From the analysis of the bibliographic database, it was observed that other ML techniques adopted to analyze window-opening behavior are based on a Gaussian distribution model (e.g., [95]), a Bayesian network (e.g., [117]), a cluster analysis and mining association rules (e.g., [118]). 
Researchers have adopted diff erent indices to evaluate the performance of their models, such as the true positive rate (TPR), true negative rate (TNR), the accuracy of the model (ACC), the mean absolute error (MAE), the mean signed deviation (MSD), and area under the curve (AUC). Consequently, there is a lack of horizontal comparison among these models. The motivation behind this difference is due to the fact that a convergence towards a systematic set of statistics for the prediction of the performance of behavioral models is missing. In this regard, Mahdavi and Tahmasebi [34] suggest two categories of indicators: indicators addressing aggregate aspects of models' predictions, and indicators addressing the interval-by-interval congruence between predictions and measurements.

Following the Köppen climate classification scheme, the majority of the analyzed window opening models were developed in temperate climate zones $\mathrm{Cfb}(43 \%), \mathrm{Cfa}(23 \%)$, Csa (2\%), while the remaining in continental climate Dwa (16\%) and Dfb (16\%). Furthermore, most published studies referring to occupant window behavior have been carried out in European countries [37,94,113,117,119-126,102,127-133,105-107,109-112]. Since window operation enables physical connection with the outdoor environment, it can be directly influenced by different conditions such as the atmospheric environment but also contextual factors such as routine/habits [134] and individual preferences [135]. It is therefore evident that in-depth research of window behavior in other climates and contexts is necessary.

While statistical models are a quite consolidate approach to model window operation (Figure 10), data-driven models still requires further exploration, although deep learning has been recently used to investigate window operation [113]. 


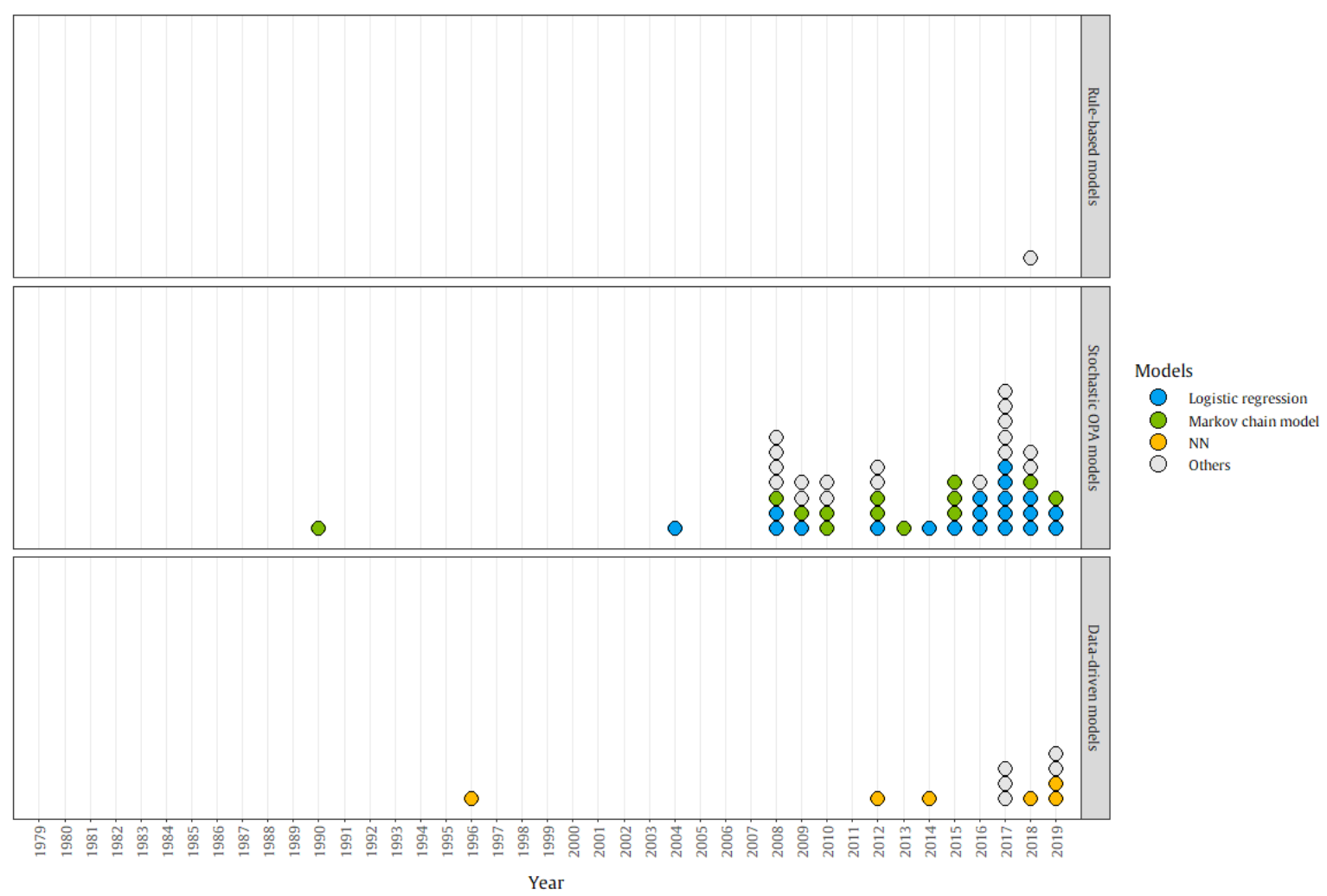

Figure 10: Timeline of window operation models

\subsection{Solar shading operation}

Solar shading devices coupled with electric lighting are fundamental instruments to provide indoor thermal and visual comfort. The use of solar shading controls the internal daylight and influences the resulting solar heat gains. On one hand, solar shading can allow solar radiation to enter and passively heat the indoor environment, and on the other hand, it influences the operation of electric lighting that contributes to indoor sensible heat gains. Furthermore, solar shading is also used to provide privacy by blocking the view into a room from the outside.

In this section, 20 documents published since 1979 were analyzed. Solar shading operation is mainly modeled by predicting a shading state (or its change) as a binary variable (i.e. open or closed) $[122,123,132,136-142]$ or by estimating a shading device multi state [143-147]. Moreover, there are some specific models that predict the Venetian blind slat angle $[148,149]$ and some others that couple the slat angle with the blind multi state $[150,151]$. The occupant-controlled shading devices has become of great interest in building performance simulation for different reasons. 
A fundamental role in OPA models is played by the choice of the predictor variables. From the bibliometric analysis, it emerges that the most used predictors in shading control models are indoor and/or outdoor air temperatures $[122,123,132,140,151]$, work plane daylight level $[137,139,142,143]$, indoor illuminance $[138,146,150]$, external radiation [146,150], and rainfall [122]. Since most of the models use external conditions as predictors, the climate in which the data for model construction are gathered is of great interest. In the analyzed bibliographic database, almost all models for shading operation come from temperate [123,137,139,140,146] and Continental [122,132,150,151,136,138,141-143,147-149] climates, except for Kurian et al. [145] that worked in the tropics. Next, except from Andersen et al. [140] that predict shading movements in residential building, all other models are built for offices [122,123,147,149-151,132,136-139,141-143].

From the performed analysis came that the first shading control model was developed by Hunt in 1979 who used a stochastic method (Figure 11). Since 2000, even data-driven methods have been used as accurate tools to predict the occupant-driven use of solar shading, with fuzzy logic and regularized logistic regression as the most used methods. NNs have been used for controlling the slat angle of Venetian blinds to optimize the energy consumption for lighting, and space heating and cooling [143,148,149], and also reinforced learning has been adopted to develop a controller to adjust both electric lighting and blind position [150].

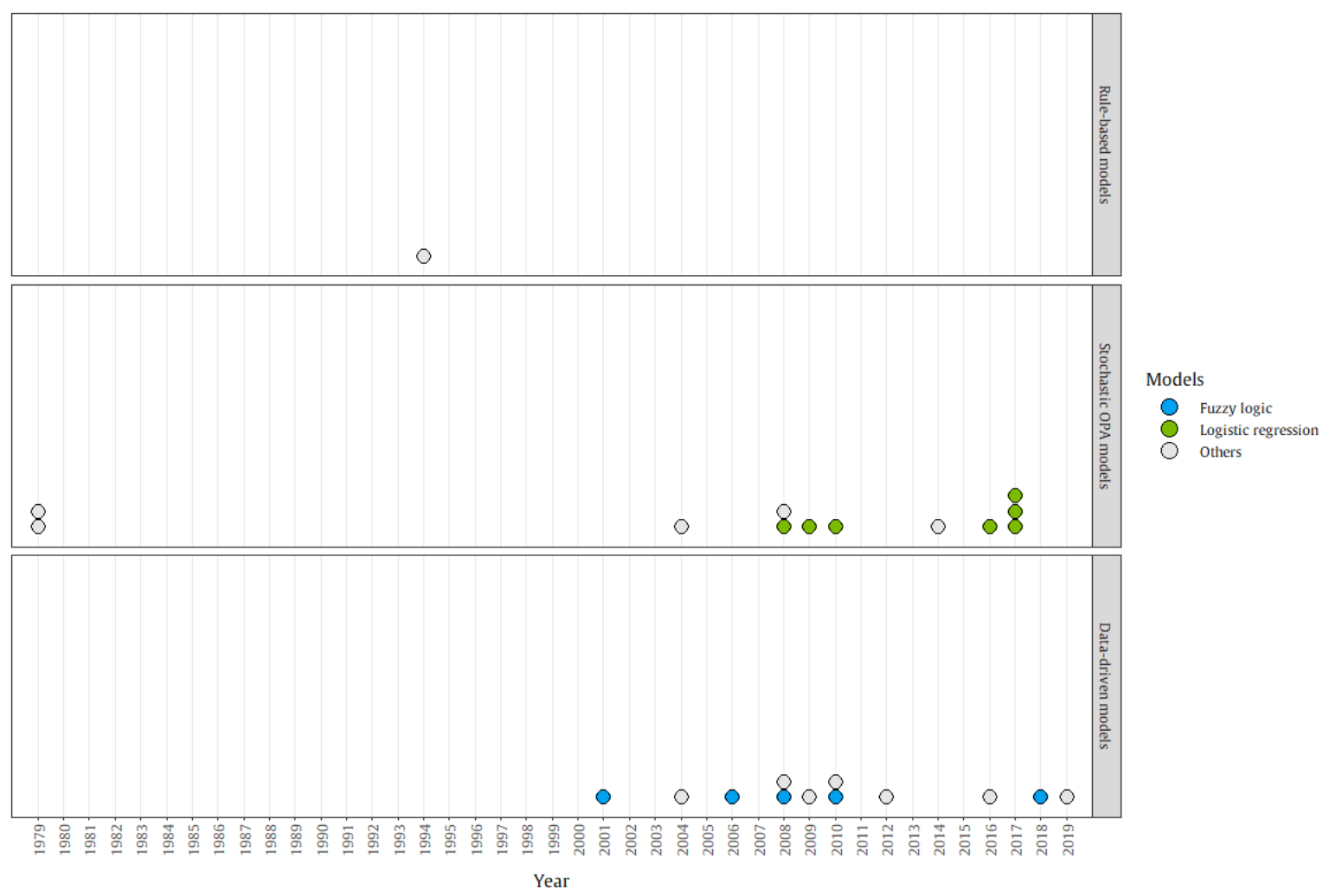


Figure 11: Timeline of solar shading operation models

In summary, models reflecting the operation of solar shading on tropical and arid climates are missing. Furthermore, more investigations should address residential and other types of buildings, providing a wider support for building energy modeling.

\subsection{Lighting operation}

In this section, 77 documents published between 1994 and 2019 and focused on electric lighting operation were analyzed. The analysis of the collected bibliographic records shows that, in the last 20 years, smart lighting control systems have been proposed to simultaneously satisfy personalized lighting levels and harvest natural daylight reducing energy consumption [152-154]. The first lighting controls were created such as on/off switch control or dimming by using sensors' outputs. Also, user-centric models based on occupants' location and their activities were used to define optimal lighting intensity level as a balance between user satisfaction and energy cost [155-157]. Lighting models that use sensor input (mostly occupancy and illuminance level) were primarily applied in office buildings. These models aimed to optimize the lighting conditions with respect to the work satisfaction and productivity $[158,159]$. NN technique was adopted in dwellings to implement programming schedules of lighting control in [160].

With regard to the climatic conditions, the majority of the analyzed investigations were developed in temperate climate zones Cfa (18\%), Cfb (16\%), Csa (12\%), and some studies fall into the continental climate Dfb (12\%). The main percentage of investigations $(55 \%)$ was conducted in office buildings, followed by houses (17\%) and laboratories (9\%). The less analyzed building types are dormitories, hotels, and commercial buildings. Analyzing the type of data adopted for the models' development, it appears that the most common sources come from measurements (42\%) and simulations (26\%). Some documents adopt both measurements and simulations (18\%). Surveys are rarely adopted alone, but they are typically coupled with measurements (9\%) or with both measurements and simulations (4\%). Regarding the models' categories, the highest percentage of identified documents belongs to the category of discriminative machine learning models $(66 \%)$ followed by stochastic OPA modeling techniques and deterministic models that present similar applications. Some studies implement more than one model that falls into the same or into different typologies. 
The most frequent category is the data-driven models $[121,144,161-170,148,171-180,149,181-190,152,191-$ 194,155-158,160], followed by the stochastic OPA modeling methods [153,159,195-204,161,205-212,184-190] and, then, the rule-based methods [139,157,219-223,160,206,213-218].

NNs allow forecasting multiple continuous variables based on design parameters because they are able to predict unique light use schedules for each design variant [172]. Furthermore, nonlinear transformation from input variables to output variables enables the designer to make predictions or classifications with regard to lighting controls $[161,193]$. However, their main drawbacks are that it takes too much time for the training phase [161] and needs to be trained again if the layout of any lamp is changed $[163,165,166]$. Regression models can help in predicting the lighting consumption of buildings [210] by providing an accurate estimation of the energy consumption compared to the results obtainable with extrapolation methods that use data from office lighting systems [191]. Furthermore, regression models were used to predict a state (i.e. on/off) (e.g., [212]), to estimate the probability of light switch actions (e.g., [207]), and the interactions with window shades (e.g., [206]). Rule-based models are a simpler manner to set a lighting control strategy and, in the case of large datasets, they provide acceptable results when compared with stochastic OPA models [206].

The historical overview shows an increasing development of models since 2004 (Figure 12). Rule-based models like schedules and profiles were implemented for this intervention [215,216]. Logit model [224] was the first technique used to describe stochastically OPA behavior in European countries and Pakistan [195], but its application was time limited. Successively, there was the implementation of Markov chain model [159,205]. Since 2005, NNs [225] have become the most used data-driven method due to their abilities to learn from input data and the breakthroughs made in computing power at the beginning of the $20^{\text {th }}$ century. Other methods for lighting modeling, for example, SVMs and decision tree, have emerged since 2010, but are relatively less used than NNs. As a prediction method, linear regression is easy to use, and the historical use rate is similar to SVMs and decision trees. 


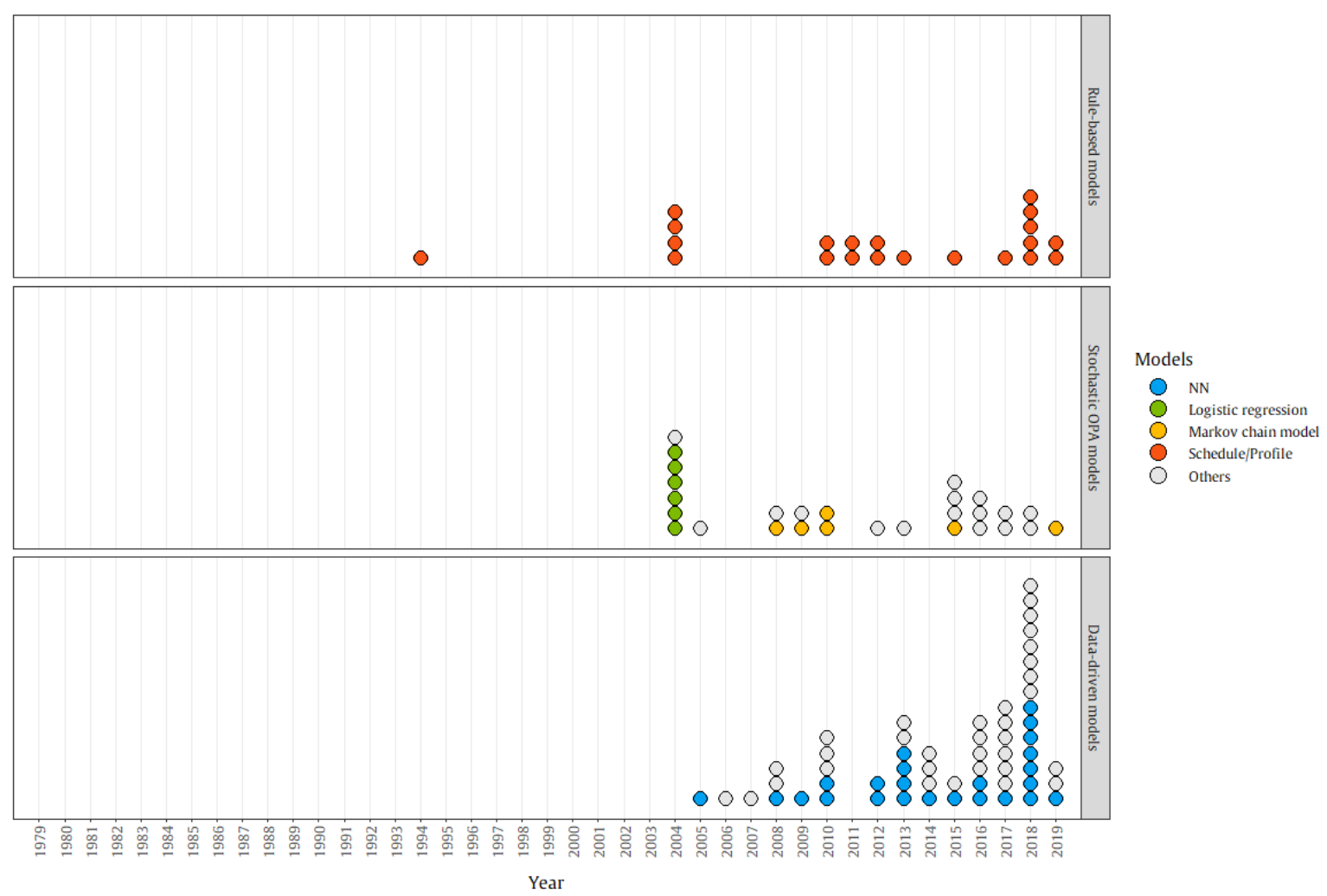

Figure 12: Timeline of models for operate electric lighting

Researchers validated their models by means of different evaluation metrics: error or accuracy $[149,155,202-$ $204,164,166,170,177,179,180,186,201]$; comparison between the performances of the proposed system and the existing system in terms of energy saving or illumination level [139,153,221,173,174,181,191,192,194,199,206]; MSE [155-157,161,163,168,193,208]; RMSE [121,152,166,183,184,208,210,211]; statistical parameters such as standard deviation, kurtosis, and skewness [165,167,197,209].

The analysis of the existing literature showed that the research about electric lighting modeling was mainly conducted in locations characterized by temperate climatic conditions. Nevertheless, the user's interaction with electric lighting is influenced by the daylight availability that depends on local sky conditions and latitude. This limitation can negatively affect model's generalization and suggests future studies in diverse geographical contexts. Also, offices were the most investigated indoor environments due to the easiness to apply sensors and collect measured data. Thus, research should be dedicated to residential, educational, and commercial buildings.

Discriminative machine learning models were widely developed and tested, stochastic and deterministic models require more investigation in order to verify their efficacy. Generally, accurate analyses about user's habits, 
preferences, and perceptions of indoor conditions are missing and so investigations could be improved by administrating targeted surveys during the monitoring phase.

\subsection{Thermostat adjustment}

Thermostat adjustment behavior is a key component of building performance modeling as it directly influences the amount of energy used for space Heating, Ventilation, and Air-Conditioning (HVAC) systems. Thermostats are used as control devices to determine when space heating, cooling, or ventilation should be applied to a building thermal zone. Thermostats typically include sensors that measure the air temperature or humidity of the building thermal zone and will request space heating, cooling, or ventilation if the indoor climate is above or below a setpoint value. The occupants within buildings interact with a thermostat by adjusting the set-points for temperatures and humidity and by setting schedules for when the HVAC systems should be active and inactive. Thus, the occupant behavior (setting the set-points and the schedules) is one factor determining when an HVAC system switches on and off; other factors include the many thermal processes which influence the indoor climate such as the thermal properties of the building envelope, the internal heat gains and the capacity of the HVAC.

The choice of thermostat set-points and operation schedules by the building simulation modeler will have a significant impact on the predictions of energy use and occupants' thermal comfort. This is a key factor of the performance gap as international and national building performance standards and calculations often assume constant, simplistic occupant behavior for the thermostat control. In reality, many occupants will continually adjust the thermostat set-points and schedules depending on when they are at home or at work, the external weather conditions and for occasions such as holidays. The difference between these assumptions and the actual occupant behavior may lead to significant uncertainty in the predictions of building energy use [226].

In this section, 44 documents published after 1989 are analyzed. The occupant behavior modeling methods have been identified in the developed bibliographic database (Figure 13). The most used methods include General/generalized linear model (33\%) [227,228], Markov chain models (23\%) [229,230] and logit analysis (20\%) [121,132]. The studies are based on a wide range of buildings such as residential buildings (54\%), offices (26\%), commercial buildings, educational buildings (7\%), and commercial buildings $(6 \%)$. Measurement campaigns are used to collect training and calibration data for model development, including internal temperatures (set-point and indoor air temperature), occupancy/presence, heating/cooling/ventilation energy demand, and outdoor weather. For residential applications, it can be difficult to directly measure thermostat set-points and schedules (as this requires 
a direct interface with the control equipment) and often indirect measurements are used as a proxy such as estimating thermostat settings using the zone air temperature [132,231,232]. This further adds to the uncertainty of the model predictions. In the numerous studies in this field, there is no agreement on the choice or amount of measurement variables that are required to construct the occupant behavior models or the choice of evaluation metrics which should be employed to validate the models.

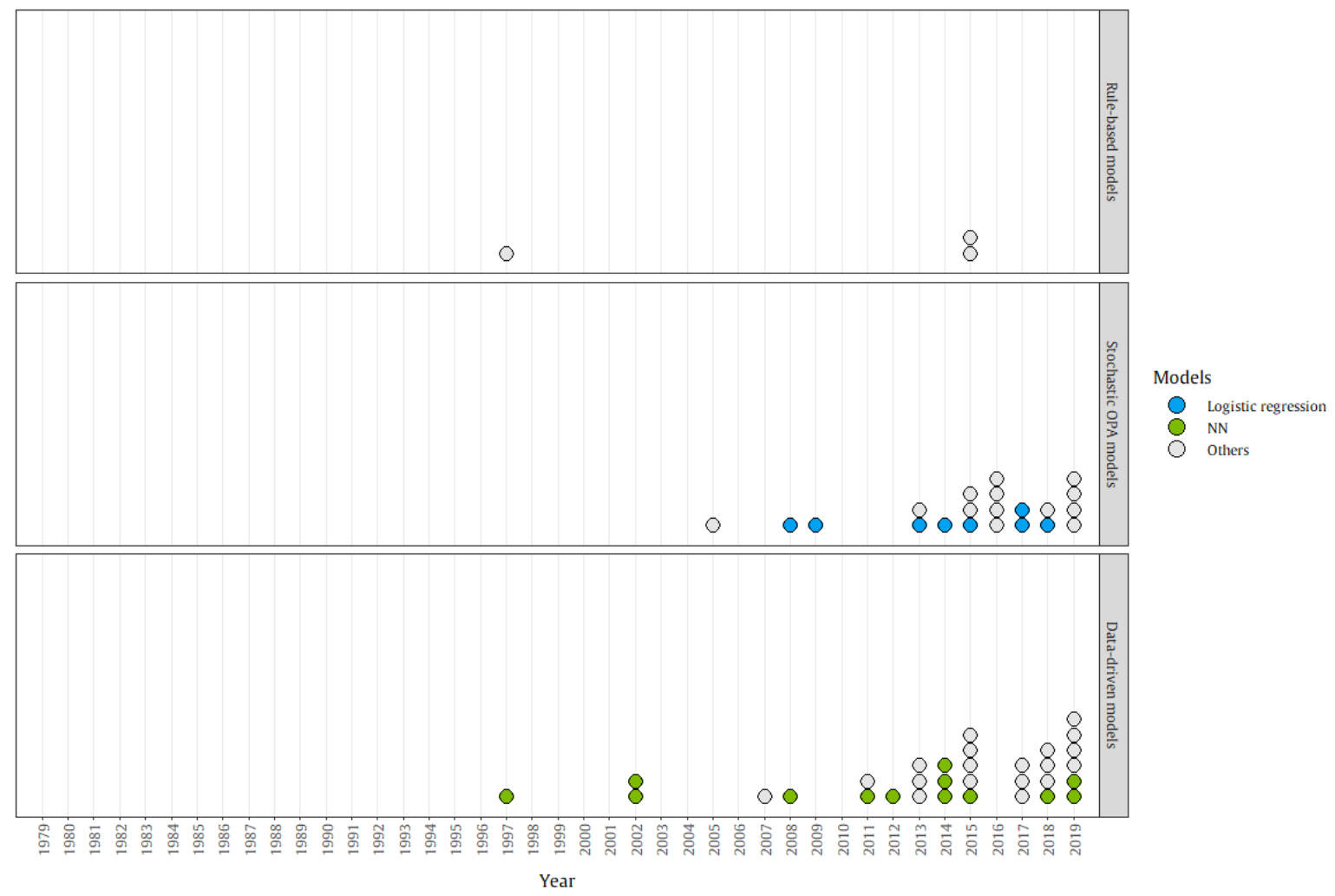

Figure 13:Timeline of models for thermostat adjustment

In connection to the previously described thermostat set point adjustments, the occupants' interactions with the HVAC systems have also been explored in residential [227,233-235] as well as in office and commercial contexts [236,237]. As a result, the use of the HVAC in residential buildings has been conducted using approaches such as Markov transfer probabilities [227] and descriptive statistics [233-235]. In the case of commercial buildings, the application of logistic regression and rule-based agent models have been identified as a suitable modeling approach [236]. This study pointed out that both logistic regression-based models and the agent-based framework could identify approximately $50 \%$ of the fan use or heater use events correctly, while the proportion of the false positive rate remained around $20 \%$. In another study of office and commercial buildings, NN was evaluated for performance among four different machine-learning algorithms [237], which actively learned occupants' interactions with thermostats under dynamic, time and space varied contexts. For a period of five months, the interaction model was 
conducted to an HVAC system in the case study building. The results reported $4 \%$ to $25 \%$ energy consumption reduction as compared to static temperature set points at the low values of the preferred temperature range.

Significant further work is required in this area. The field of OPA thermostat set-point modeling is underdeveloped in relation to other OPA areas because of the challenges in collecting thermostat data (in residential settings) and in modeling the complex interrelated effects of occupant thermal comfort, building thermal response and dynamic external conditions. A clear data collection methodology and standardized model testing framework needs to be developed, with clear reporting criteria and evaluation metrics. To maximize the potential of existing and future datasets, a common data collection vocabulary or ontology should be created which would enable data reuse and ultimately meta-analysis of multiple datasets across different building types, sample sizes and country of origin.

\subsection{Appliance use}

Appliance are electrical devices that support people's daily life, ranging from small machines (like laptop computers, air purifiers, coffeemakers and microwaves) to large ones (like fridges, clothes washers and dryers). Especially in the residential sector, appliances become one type of key electricity consumers. The energy demand for household appliances is growing as rising living standards worldwide [238]. Human behavior has an impact on appliance operation and spurs the associated energy consumption within buildings. Better understanding such activities offers potentials to operate appliances and their energy supplies (including the power grid and renewable energy) in an efficient way. Measuring and modeling appliance usages triggered by occupants, if properly visualized and communicated to together with suggestions, can promote energy-saving awareness [239]. Yu et al. [240] proposed a data mining-based method for estimating the saving potentials related to standby energy use considering the occupant behavior. Meanwhile, energy/load management based on appliance operation minimizes the variation of power supply [241], shifts appliance operation from the peak electricity demand [242] and makes appliance adapt to changes in electricity price [243].

In this section, 36 documents published since 1994 were analyzed. They describe models for identifying and modeling appliance states that were based on measurements, simulation, and surveys. Overall, the majority of the data used is measured data from field studies and home applications (69\%). The studies were undertaken mostly in temperate climates (Cfa 39\%, Cfb 33\%, Csb 6\%) with some models in continental (Dfb 11\%) and arid climates (Bsh 6\%, Bwh 6\%). Sensing infrastructure for the data collection differed for the individual studies. It included four distinct groups of sensing devices: energy-related measurement (power, voltage, and current meters); 
communications technology (barcode and Bluetooth); environmental sensing (temperature, carbon monoxide, and acoustic sensors); and activity-related sensing (triaxial accelerometer and gyroscope, motion, door, and ultrasonic positioning sensors). Among them, power meters installed at the main power inlet of households were widely used by the studies as predictors.

Appliances are operated in on/off or multi states. Identifying their states was mainly described stochastically or predicted with data-driven methods. The former approaches use Bayesian networks [244,245] and hierarchical clustering models [246]. The latter use two different machine-learning-based algorithms: HMMs [239,247-249] and NNs [250-252]. To model occupants' indoor behavior and activities in interaction with appliances, diverse algorithms were employed in the studies, such as pedestrian dead reckoning [253], Bayesian network mode and linear regression [254], k-means and Gaussian mixture [69], random forest [255], and SVMs [256]. According to power usage of appliances, Gaussian mixture [257], k-means [258], optimization based on defined objective function [243] were used to infer load distribution and scheduling for systems. Similarly, power data showed potentials to extract building occupancy using data-driven approaches, such as decision trees [259] and NNs [260]. Two studies used both power data and occupant surveys [261,262]. Based on such data, the former study aimed to identify occupant behavioral predictors using a linear method, and the latter employed a Gaussian mixture method to model load patterns of the appliance in offices. For appliance controls in households, NNs [263] and stochastic sliding mode control [241] were utilized. As shown in Figure 14, most of the studies were based on recognition of appliance states and associated occupant activities using data-driven models. 


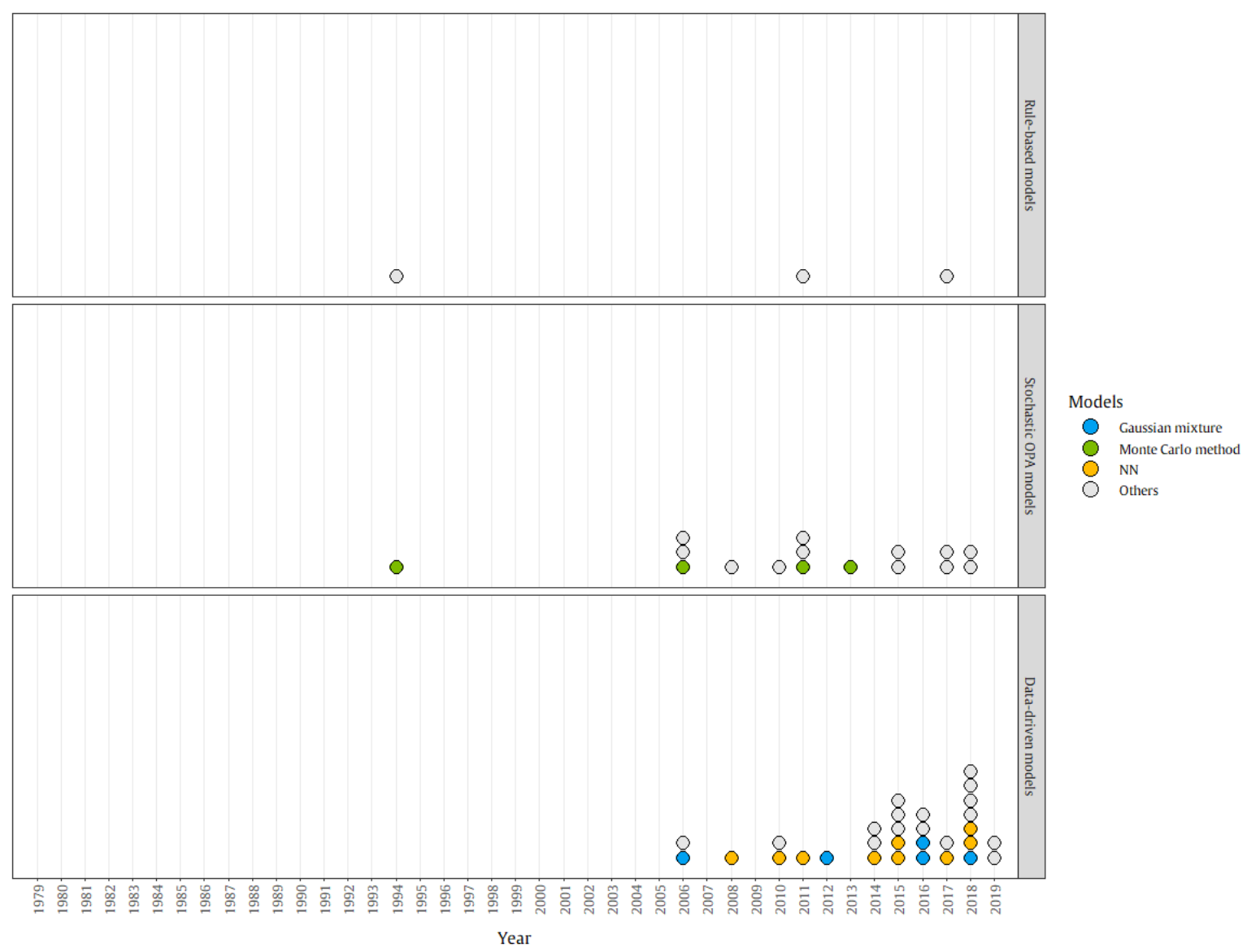

Figure 14: Timeline of models for appliance operation

Evaluation metrics applied to verify the above behavior modeling for appliance uses included precision, recall, Fscore, RMS, RMSE, NRMSE, MAE, distance and positioning accuracy, and variances of positioning errors. Most of the studies focused on one type of data (i.e. total electricity consumption of individual buildings or households) or one case study with several specified appliances. In actual buildings, diverse appliances are used by occupants which are affected by the purposes of the buildings (for example, residential and commercial buildings), and occupants' requirements. Meanwhile, occupant behavior interacting with appliances differs from device to device and person to person. In future research, one of the key research questions could be how to generalize methodologies for different appliance applications.

\subsection{Clothing adjustment}

Clothing has been considered as a critical interface between humans and their surrounding environmental settings [264-267] and is an influential input parameter in a few thermal comfort models. According to current knowledge, 
age, gender, and relative humidity have no significant effect on the clothing insulation levels chosen by people [267]. However, Humphreys [267] stated that the outdoor daily mean temperature to be the most crucial parameter affecting clothing insulation levels. Studies before this one had studied clothing insulation using conventional linear regression approaches. Deng and Chen [264] argued that the association between clothing and potential factors that affects clothing behavior might not be linear, hence, they developed clothing prediction models using ordinal logistic regression and NN using data collected in offices. The training accuracies of the NN model for three kinds of actions (lowering the set point or reducing the clothing level, no response, and raising the set point or adding clothing) were $89.4 \%, 87.3 \%$, and $91.2 \%$, respectively, and its overall training accuracy in predicting all three kinds of behaviors was $87.5 \%$, resulting in an accurate tool for predicting occupants' behavior in the offices.

The main predictors used for the clothing adaptation in the existing literature include indoor air and operative temperature, relative humidity, $\mathrm{CO}_{2}$, air velocity, outdoor air temperature, skin temperature, human activities and time of the day [268].

The common evaluation metrics used in the existing literature are $\mathrm{R}^{2}$, RMSE, MAE, MAPE for the regression models, and accuracy, F1-score, precision, and recall for the classification models.

Most of the existing methods in clothing insulation estimation assume the values to be fixed by using in-situ clothing estimation methods, thermal models, or depending on the outdoor air and indoor operative temperatures [265267,269,270]. Also, some data-driven methods (e.g., NNs, SVMs, and regression models) have been used to establish thermal comfort inside a built environment [264-267,269-271]. These data-driven models reflect the occupants' responses and interactions with the building utilities and management facilities. Recently, the focus has shifted toward applying machine learning and deep learning models for predicting indoor clothing levels [264,267]. From the literature, it is affirmative that the clothing adaptation to any given situation is associated to three influencing factors: occupant behavioral adjustment, physiological factors, and psychological factors [265-267]. Therefore, for future research directions, the interrelationships and correlations between different influencing factors can be studied meticulously in those building types not already analyzed and under different individual conditions, like different metabolic activity levels.

\subsection{Combined occupant actions}

Researchers have also developed models that combine more than one user's actions with the aim of analyzing the multiple aspects of comfort and energy consumption in buildings. Lighting operation is one of the most co-modeled 
aspects due to its impact on both visual comfort, thermal comfort, and electricity demand. For example, schedules/profiles, stochastic OPA modeling techniques, and data-driven models were implemented by combining lighting operation with shading control [139,141,144,148-151,154,192,272]. Regression models were also exploited for modeling different combined actions: light switching with window operation [121], window and solar shading operation [123], and light switching with both window and solar shading operations [122]. With the aim of analyzing visual discomfort, data-driven techniques were used in $[176,177]$ to model lighting switch in combination with blinds operation and change of the space heating set-point temperature. Furthermore, light switching and window operation combined with space heating and cooling operation were also modeled by means of schedule/profile and stochastic OPA models [185,215]. Moreover, data-driven models [210] and stochastic OPA models [196] were implemented to predict the energy consumption of buildings by considering both lighting and appliances use. More recently, Haldi et al. [122] investigated the combined operation of windows, solar shading, and light switching and developed logit models for residential buildings and offices. These models included random effects for all predictors that account the inter-individual variability in behavior among different occupants. This attempt allows overcoming the issue of modeling an occupants' average behavior and explicitly considering diversity and variability in occupant behavior.

Modeling combined actions seems a more effective approach providing a wider view of human actions and their impact in terms of energy consumption and occupants' comfort. The available literature still demonstrates gaps in this development and intersectional studies should be encouraged.

\section{Future outlook in OPA modeling}

Among the studies grouped under the data-driven models, there is a subset of studies recently published [54,62,274,275,63,64,67,113,252,264,267,273], which use deep learning (DL) techniques. DL is adopted for obtaining rich information about occupant behavior and is proven to be competent in extrapolating discriminatory features from raw sensor data accumulated from building management systems [273-276]. Traditional machine learning approaches perform tasks without exploiting the correlations between diverse input sensor data. For example, $\mathrm{CNN}$ tries to overcome this issue by implementing convolution across $\mathrm{n}$-dimensional temporal sequence to apprehend the dependencies in the input sensor data. However, the size of the kernel is an important parameter that can restrict the range of captured dependencies in the input sensor data for the CNN model [276]. Other advances in embracing deep learning methods are: 
1) ML classifiers rely heavily upon heuristic handcrafted features (i.e. the manual selection of features) and require expertise in domain knowledge. The manual selection of features could lead to inductive bias, because the algorithm uses inputs that it has not yet encountered to predict the target outputs. Typically, such bias is supplied by hand through the dexterity and insights of domain experts. Advancements in DL make it possible for automated feature extraction and selection, thus overcoming the inductive bias [273276].

2) Shallow features can be recognized well with ML but a difficulty in identifying context-aware activities of occupant behavior (e.g., cooking a meal) or extracting other dimensions of occupant behavior [20,277279].

3) In traditional approaches, extensive training data and labeled annotations are mandatory for supervised learning, but in real-world applications, most of the data remain unlabeled (unsupervised). Due to this, typical models are unadaptable to a diverse range of context-aware occupant actions and model configurations [20,45,275-279].

4) Another significant difference between DL and ML methods is the problem-solving capability and critical analysis approach. DL tends to solve the issue end-to-end, whereas ML needs the problem statement to be broken into stages/parts and explained separately and combined at the final phase.

In summary, unlike ML approaches, DL classifiers are trained through feature learning rather than distinct taskspecific algorithms [276]. However, DL is applicable when the task indented has a large dataset to work with; for smaller datasets, ML algorithms performs well with high accuracy. In general, when there is a lack and inadequacy of domain knowledge for feature introspection, DL outperforms most of the existing ML techniques [20,275-278].

\section{Conclusions}

In this study, the PRISMA methodology is exploited to conduct a systematic literature review on the topic of Occupant Presence and Actions (OPA) modeling in buildings. The identified documents were collected in a bibliographic database and analyzed. The analysis was supported by a data-driven bibliometric tool to provide an extended investigation of the methods and findings on the topic and to draw insights into the current state and future prospects of OPA modeling. This work, in the context of IEA EBC Annex 79, aimed to systematically cover all aspects of OPA modeling in different typologies of buildings. 
The bibliometric analysis showed that the most productive geographic regions are North America, Europe, and China and that the intensity of the collaborations is large and well established between research groups in such regions. The documents analyzed in the database mainly involved measurement data in office buildings located in temperate and continental climates. Therefore, there is a need to develop new research studies outside these consolidated domains to provide a wider coverage of the knowledge domain, specially, in those climate contexts where models are missing, and it is expected a substantial increase of population and the construction rate (e.g., Africa, Indo-China region, Latin America). Regarding the methods, data-driven models are emerging as the most used modeling methods in recent years, which may be due to the large wealth of data coming from sensors installation. In particular, there is a recent interest in adopting deep learning techniques to model some OPA aspects for both explaining and predicting purposes. Most of the studies on occupant presence and activity detection aim at understanding occupant behavior, while the majority of studies on occupant actions are aiming at predicting occupants' interaction with given building devices for adaptive controls' development. It is highly appreciated the development of combined occupant behavioral models that provide a wider and closer-to-reality description of occupant use of the building and its systems. This is a domain where newer research is needed to increase accuracy of behavioral modeling.

In general, to maximize the potential of existing and future datasets, a common data collection vocabulary or ontology should be created which would enable data reuse and ultimately meta-analysis of multiple datasets across different building types, sample sizes and country of origin.

This review has to be intended as a work to be regularly updated and expanded with the rise in number and detail of the OPA modeling methods to provide information on developments and new tendencies in the field. To facilitate this task, this article provides a dynamic open-access review table as a supplementary material (https://osf.io/gnvp2/?view_only=00b08233881f471795d1d8dee79e9828), which can be expanded by other researchers to include future studies in order to represent an updated overview on the scientific production on occupant presence and action modeling.

Limitations of the current work are the possible and involuntary omission of OPA modeling documents not spotted by the literature search and not at the knowledge of the authors. However, the PRISMA methodology is designed to keep such oversights to a minimum. 


\section{Acknowledgments}

This work has been performed within the framework of the International Energy Agency - Energy in Buildings and Communities Program (IEA-EBC) Annex 79 “Occupant-centric building design and operation”. The authors would like to thank Prof. William Tolone for the useful inputs to the analysis.

Salvatore Carlucci and Matteo Favero would like to thank the Research Centre on Zero Emission Neighborhoods in Smart Cities (FME ZEN, Grant n. 257660) and the Research Council of Norway (Norges Forskingsrådet) for the support. Romana Markovic's and Christoph van Treeck's participation was funded by the German Research Foundation (Deutsche Forschungsgemeinschaft, Grant n. TR 892/4-1). Gianmarco Fajilla would like to thank the Calabria Region Government for his Ph.D. scholarship (POR Calabria FSE/FESR 2014-2020, Grant n. H21G18000170006). Mikkel Baun Kjærgaard and Anooshmita Das would like to acknowledge funding by the Energy Technology Development and Demonstration Program (Energistyrelsen, Grant n. 64018-0558). Jakob Hahn gratefully acknowledges the financial support provided by the Federal Ministry for Economic Affairs and Energy (Bundesministerium für Wirtschaft und Energie, Grant n. 03ET1299A-EnEff Stadt: +EQ-Net and Grant n. 03ET1648A-EnOB: NuData Campus). During the time of writing, Flora Salim is supported by Humboldt and Bayer Foundation. Any opinions, findings, conclusions, and recommendations expressed in this article are those of the authors and do not necessarily represent the views of the funding agencies.

\section{References}

[1] I. Gaetani, P.J. Hoes, J.L.M. Hensen, Estimating the influence of occupant behavior on building heating and cooling energy in one simulation run, Appl. Energy. 223 (2018) 159-171. https://doi.org/10.1016/j.apenergy.2018.03.108.

[2] W. O’Brien, I. Gaetani, S. Gilani, S. Carlucci, P.J. Hoes, J. Hensen, International survey on current occupant modelling approaches in building performance simulation†, J. Build. Perform. Simul. 10 (2017) 653-671. https://doi.org/10.1080/19401493.2016.1243731.

[3] K.U. Ahn, D.W. Kim, C.S. Park, P. de Wilde, Predictability of occupant presence and performance gap in building energy simulation, Appl. $\quad$ Energy. $208 \quad$ (2017) 1639-1652. https://doi.org/10.1016/j.apenergy.2017.04.083.

[4] Y. Zhang, X. Bai, F.P. Mills, J.C.V. Pezzey, Rethinking the role of occupant behavior in building energy performance: A review, Energy Build. 172 (2018) 279-294. https://doi.org/10.1016/j.enbuild.2018.05.017.

[5] D. Yan, T. Hong, B. Dong, A. Mahdavi, S. D’Oca, I. Gaetani, X. Feng, IEA EBC Annex 66: Definition and simulation of occupant behavior in buildings, Energy Build. 156 (2017) 258-270. https://doi.org/10.1016/j.enbuild.2017.09.084.

[6] International Energy Agency, IEA EBC - Annex 79 - Occupant-Centric Building Design and Operation, (2017).

[7] ANSI/ASHRAE/IES Standard 90.1-2016: Energy Standard for Buildings Except Low-rise Residential Buildings, (2016).

[8] D. Yan, W. O’Brien, T. Hong, X. Feng, H. Burak Gunay, F. Tahmasebi, A. Mahdavi, Occupant behavior modeling for building performance simulation: Current state and future challenges, Energy Build. 107 (2015) 264-278. https://doi.org/10.1016/j.enbuild.2015.08.032.

[9] M. Schweiker, S. Carlucci, R.K. Andersen, B. Dong, W. O’Brien, Occupancy and occupants' actions, in: 
Explor. Occupant Behav. Build. Methods Challenges, Springer International Publishing, 2018: pp. 7-38. https://doi.org/10.1007/978-3-319-61464-9_2.

[10] S. Formentin, K. Van Heusden, A. Karimi, A comparison of model-based and data-driven controller tuning, Int. J. Adapt. Control Signal Process. 28 (2014) 882-897. https://doi.org/10.1002/acs.2415.

[11] R. Markovic, D. Wölki, C. Van Treeck, J. Frisch, Transaction from stochastic modelling to supervised learning of occupant's behavior, 2017.

[12] D.P. Solomatine, A. Ostfeld, Data-driven modelling: Some past experiences and new approaches, in: J. Hydroinformatics, IWA Publishing, 2008: pp. 3-22. https://doi.org/10.2166/hydro.2008.015.

[13] D. Yan, T. Hong, Definition and Simulation of Occupant Behavior in Buildings - Annex 66 Final Report, 2018.

[14] H.B. Gunay, W. O’Brien, I. Beausoleil-Morrison, Implementation and comparison of existing occupant behaviour models in EnergyPlus, J. Build. Perform. Simul. 9 (2016) 567-588. https://doi.org/10.1080/19401493.2015.1102969.

[15] J. Yang, M. Santamouris, S.E. Lee, Review of occupancy sensing systems and occupancy modeling methodologies for the application in institutional buildings, Energy Build. 121 (2016) 344-349. https://doi.org/10.1016/j.enbuild.2015.12.019.

[16] S. Gilani, W. O'Brien, Review of current methods, opportunities, and challenges for in-situ monitoring to support occupant modelling in office spaces, J. Build. Perform. Simul. 10 (2017) 444-470. https://doi.org/10.1080/19401493.2016.1255258.

[17] Z. Chen, C. Jiang, L. Xie, Building occupancy estimation and detection: A review, Energy Build. 169 (2018) 260-270. https://doi.org/10.1016/j.enbuild.2018.03.084.

[18] B.F. Balvedi, E. Ghisi, R. Lamberts, A review of occupant behaviour in residential buildings, Energy Build. 174 (2018) 495-505. https://doi.org/10.1016/j.enbuild.2018.06.049.

[19] B. Dong, D. Yan, Z. Li, Y. Jin, X. Feng, H. Fontenot, Modeling occupancy and behavior for better building design and operation —A critical review, Build. Simul. 11 (2018) 899-921. https://doi.org/10.1007/s12273018-0452-x.

[20] J. Li, Z. (Jerry) Yu, F. Haghighat, G. Zhang, Development and improvement of occupant behavior models towards realistic building performance simulation: A review, Sustain. Cities Soc. 50 (2019). https://doi.org/10.1016/j.scs.2019.101685.

[21] S. Salimi, A. Hammad, Critical review and research roadmap of office building energy management based on occupancy monitoring, Energy Build. 182 (2019) 214-241. https://doi.org/10.1016/j.enbuild.2018.10.007.

[22] D. Denyer, D. Tranfield, Producing a systematic review, Sage Handb. Organ. Res. Methods. (2009) 671689.

[23] A. Liberati, D.G. Altman, J. Tetzlaff, C. Mulrow, P.C. Gøtzsche, J.P.A. Ioannidis, M. Clarke, P.J. Devereaux, J. Kleijnen, D. Moher, The PRISMA Statement for Reporting Systematic Reviews and MetaAnalyses of Studies That Evaluate Health Care Interventions: Explanation and Elaboration, PLoS Med. 6 (2009) e1000100. https://doi.org/10.1371/journal.pmed.1000100.

[24] D. Denyer, D. Tranfield, J.E. Van Aken, Developing design propositions through research synthesis, Organ. Stud. 29 (2008) 393-413. https://doi.org/10.1177/0170840607088020.

[25] M. Aria, C. Cuccurullo, bibliometrix: An R-tool for comprehensive science mapping analysis, J. Informetr. 11 (2017) 959-975. https://doi.org/10.1016/j.joi.2017.08.007.

[26] H. Qin, Knowledge Discovery Through Co-Word Analysis, Libr. Trends. 48 (1999) 133-159.

[27] H. Polinder, M. Schweiker, A. Van Der Aa, K. Schakib-Ekbatan, V. Fabi, R. Andersen, N. Morishita, C. Wang, S. Corgnati, P. Heiselberg, D. Yan, Total energy use in buildings (Final Report Annex53 - Occupant behavior and modeling), 2013.

[28] K. Amasyali, N.M. El-Gohary, A review of data-driven building energy consumption prediction studies, Renew. Sustain. Energy Rev. 81 (2018) 1192-1205. https://doi.org/10.1016/j.rser.2017.04.095.

[29] M.J.N. Oliveira Panão, M.C. Brito, Modelling aggregate hourly electricity consumption based on bottomup building stock, Energy Build. 170 (2018) 170-182. https://doi.org/10.1016/j.enbuild.2018.04.010.

[30] A. Capozzoli, M.S. Piscitelli, S. Brandi, Mining typical load profiles in buildings to support energy management in the smart city context, in: Energy Procedia, Elsevier Ltd, 2017: pp. 865-874. https://doi.org/10.1016/j.egypro.2017.09.545.

[31] W.P. Köppen, R. Geiger, Handbuch der Klimatologie, Berlin: Gebrüder Borntraeger, 1930.

[32] G. Shmueli, To explain or to predict?, Stat. Sci. 25 (2010) 289-310. https://doi.org/10.1214/10-STS330.

[33] L. Breiman, Statistical modeling: The two cultures, Stat. Sci. 16 (2001) 199-215. https://doi.org/10.1214/ss/1009213726.

[34] A. Mahdavi, F. Tahmasebi, On the quality evaluation of behavioural models for building performance $\begin{array}{lllllll}\text { applications, J. } & \text { Build. } & \text { Perform. } & \text { Simul. } & 10 & \text { (2017) 554-564. }\end{array}$ 
https://doi.org/10.1080/19401493.2016.1230148.

[35] S. D’Oca, H.B. Gunay, S. Gilani, W. O’Brien, Critical review and illustrative examples of office occupant modelling formalisms, Build. Serv. Eng. Res. Technol. $40 \quad$ (2019) $732-757$. https://doi.org/10.1177/0143624419827468.

[36] H.B. Rijal, P. Tuohy, M.A. Humphreys, J.F. Nicol, A. Samuel, J. Clarke, Using results from field surveys to predict the effect of open windows on thermal comfort and energy use in buildings, Energy Build. 39 (2007) 823-836. https://doi.org/10.1016/j.enbuild.2007.02.003.

[37] M. Schweiker, F. Haldi, M. Shukuya, D. Robinson, Verification of stochastic models of window opening behaviour for residential buildings, J. Build. Perform. Simul. 5 (2012) 55-74. https://doi.org/10.1080/19401493.2011.567422.

[38] H.B. Gunay, W. O’Brien, I. Beausoleil-Morrison, J. Bursill, Development and implementation of a thermostat learning algorithm, Sci. Technol. Built Environ. 24 (2018) 43-56. https://doi.org/10.1080/23744731.2017.1328956.

[39] L.H. Gilpin, D. Bau, B.Z. Yuan, A. Bajwa, M. Specter, L. Kagal, Explaining Explanations: An Approach to Evaluating Interpretability of Machine Learning, 2018.

[40] M.B. Kjærgaard, B. Dong, S. Carlucci, F.D. Salim, J. Yang, C.J. Andrews, O. Ardakanian, Poster Abstract: Data-driven Occupant Modeling Strategies and Digital Tools enabled by IEA EBC Annex 79, in: BuildSys 2018 - Proc. 5th Conf. Syst. Built Environ., Association for Computing Machinery, Inc, 2018: pp. 188-189. https://doi.org/10.1145/3276774.3281015.

[41] B. Dong, M.B. Kjærgaard, M. De Simone, H.B. Gunay, W. O’Brien, D. Mora, J. Dziedzic, J. Zhao, Sensing and data acquisition, in: Explor. Occupant Behav. Build. Methods Challenges, Springer International Publishing, 2017: pp. 77-105. https://doi.org/10.1007/978-3-319-61464-9_4.

[42] M.B. Kjærgaard, M. Werner, F.C. Sangogboye, K. Arendt, DCount - A probabilistic algorithm for accurately disaggregating building occupant counts into room counts, in: Proc. - IEEE Int. Conf. Mob. Data Manag., Institute of Electrical and Electronics Engineers Inc., 2018: pp. 46-55. https://doi.org/10.1109/MDM.2018.00021.

[43] F.C. Sangoboye, M.B. Kjærgaard, PLCount: A probabilistic fusion algorithm for accurately estimating occupancy from 3D camera counts, in: Proc. 3rd ACM Conf. Syst. Energy-Efficient Built Environ. BuildSys 2016, Association for Computing Machinery, Inc, 2016: pp. 147-156. https://doi.org/10.1145/2993422.2993575.

[44] D. Mora, G. Fajilla, M.C. Austin, M. De Simone, Occupancy patterns obtained by heuristic approaches: Cluster analysis and logical flowcharts. A case study in a university office, Energy Build. 186 (2019) 147168. https://doi.org/10.1016/j.enbuild.2019.01.023.

[45] F. Causone, S. Carlucci, M. Ferrando, A. Marchenko, S. Erba, A data-driven procedure to model occupancy and occupant-related electric load profiles in residential buildings for energy simulation, Energy Build. 202 (2019) 109342. https://doi.org/10.1016/j.enbuild.2019.109342.

[46] I.B. Arief-Ang, F.D. Salim, M. Hamilton, DA-HOC: Semi-supervised domain adaptation for room occupancy prediction using CO2 sensor data, in: BuildSys 2017 - Proc. 4th ACM Int. Conf. Syst. EnergyEfficient Built Environ., Association for Computing Machinery, Inc, 2017. https://doi.org/10.1145/3137133.3137146.

[47] T.A. Nguyen, M. Aiello, Energy intelligent buildings based on user activity: A survey, Energy Build. 56 (2013) 244-257. https://doi.org/10.1016/j.enbuild.2012.09.005.

[48] T. Hong, S.C. Taylor-Lange, S. D’Oca, D. Yan, S.P. Corgnati, Advances in research and applications of energy-related occupant behavior in buildings, Energy Build. 116 (2016) 694-702. https://doi.org/10.1016/j.enbuild.2015.11.052.

[49] A. Fleury, M. Vacher, N. Noury, SVM-based multimodal classification of activities of daily living in health smart homes: Sensors, algorithms, and first experimental results, IEEE Trans. Inf. Technol. Biomed. 14 (2010) 274-283. https://doi.org/10.1109/TITB.2009.2037317.

[50] J. Zou, Q. Zhao, W. Yang, F. Wang, Occupancy detection in the office by analyzing surveillance videos and its application to building energy conservation, Energy Build. 152 (2017) 385-398. https://doi.org/10.1016/j.enbuild.2017.07.064.

[51] J.W. Dziedzic, Y. Da, V. Novakovic, Indoor occupant behaviour monitoring with the use of a depth registration camera, Build. Environ. 148 (2019) 44-54. https://doi.org/10.1016/j.buildenv.2018.10.032.

[52] L. Chen, C.D. Nugent, J. Biswas, J. Hoey, Activity Recognition in Pervasive Intelligent Environments, 2011. https://doi.org/10.2991/978-94-91216-05-3.

[53] M. Aprea, E. Nothen, L. Uberman, Home Automation: Proposal for a low-cost and noninvasive approach, in: Congr. Argentino Ciencias La Inform. y Desarro. Investig. CACIDI 2018, Institute of Electrical and Electronics Engineers Inc., 2018. https://doi.org/10.1109/CACIDI.2018.8584341.

[54] Z. Wang, T. Hong, M.A. Piette, Data fusion in predicting internal heat gains for office buildings through a 
deep learning approach, Appl. Energy. (2019) 386-398. https://doi.org/10.1016/j.apenergy.2019.02.066.

[55] P. Viertel, M. Küper, J. Wiegmann, Konig, J. Wiegmann, M. König, Determining room usage through a multi-sensor system and machine learning, in: Proc. Des Work. "Lernen Und Arb. Im Wandel," 2018.

[56] S.S. Shetty, D.C. Hoang, M. Gupta, S.K. Panda, Learning desk fan usage preferences for personalised thermal comfort in shared offices using tree-based methods, Build. Environ. 149 (2019) 546-560. https://doi.org/10.1016/j.buildenv.2018.12.040.

[57] A. Ozawa, Y. Kudoh, Y. Yoshida, A new method for household energy use modeling: A questionnairebased approach, Energy Build. 162 (2018) 32-41. https://doi.org/10.1016/j.enbuild.2017.12.032.

[58] S. Mahmoud, A. Lotfi, C. Langensiepen, Behavioural pattern identification and prediction in intelligent environments, Appl. Soft Comput. J. 13 (2013) 1813-1822. https://doi.org/10.1016/j.asoc.2012.12.012.

[59] S. Wolf, J.K. Møller, M.A. Bitsch, J. Krogstie, H. Madsen, A Markov-Switching model for building

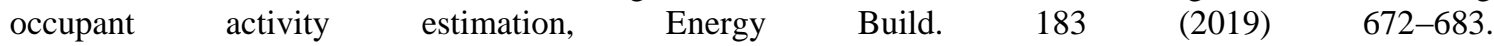
https://doi.org/10.1016/j.enbuild.2018.11.041.

[60] Z. Wang, Y. Ding, An occupant-based energy consumption prediction model for office equipment, Energy Build. 109 (2015) 12-22. https://doi.org/10.1016/j.enbuild.2015.10.002.

[61] D. Yan, C. Wang, X. Feng, B. Dong, Validation and ground truths, in: Explor. Occupant Behav. Build. Methods Challenges, Springer International Publishing, 2017: pp. 239-260. https://doi.org/10.1007/978-3319-61464-9_9.

[62] A. Ignatov, Real-time human activity recognition from accelerometer data using Convolutional Neural Networks, Appl. Soft Comput. J. 62 (2018) 915-922. https://doi.org/10.1016/j.asoc.2017.09.027.

[63] A. Elboushaki, R. Hannane, K. Afdel, L. Koutti, MultiD-CNN: A multi-dimensional feature learning approach based on deep convolutional networks for gesture recognition in RGB-D image sequences, Expert Syst. Appl. 139 (2020) 112829. https://doi.org/10.1016/j.eswa.2019.112829.

[64] H. Cho, S.M. Yoon, Divide and Conquer-Based 1D CNN Human Activity Recognition Using Test Data Sharpening, Sensors. 18 (2018) 1055. https://doi.org/10.3390/s18041055.

[65] M. Rawashdeh, M.G.H. Al Zamil, S. Samarah, M.S. Hossain, G. Muhammad, A knowledge-driven approach for activity recognition in smart homes based on activity profiling, Futur. Gener. Comput. Syst. (2017). https://doi.org/10.1016/j.future.2017.10.031.

[66] A. Das, F.C. Sangogboye, E.S.K. Raun, M.B. Kjærgaard, HeteroSense: An occupancy sensing framework for multi-class classification for activity recognition and trajectory detection, in: Soc. 2019 - Proc. 2019 4th Int. Work. Soc. Sens., Association for Computing Machinery, Inc, 2019: pp. 12-17. https://doi.org/10.1145/3313294.3313383.

[67] M.Z. Uddin, M.M. Hassan, A. Alsanad, C. Savaglio, A body sensor data fusion and deep recurrent neural network-based behavior recognition approach for robust healthcare, Inf. Fusion. 55 (2020) 105-115. https://doi.org/10.1016/j.inffus.2019.08.004.

[68] M.Z. Uddin, A wearable sensor-based activity prediction system to facilitate edge computing in smart healthcare system, J. Parallel Distrib. Comput. 123 (2019) 46-53. https://doi.org/10.1016/j.jpdc.2018.08.010.

[69] S. Ahmadi-Karvigh, A. Ghahramani, B. Becerik-Gerber, L. Soibelman, Real-time activity recognition for energy efficiency in buildings, Appl. Energy. 211 (2018) 146-160. https://doi.org/10.1016/j.apenergy.2017.11.055.

[70] Z.S. Abdallah, M.M. Gaber, B. Srinivasan, S. Krishnaswamy, Activity recognition with evolving data streams: A review, ACM Comput. Surv. 51 (2018). https://doi.org/10.1145/3158645.

[71] J. Collin, O. Mezentsev, G. Lachapelle, Indoor positioning system using accelerometry and high accuracy heading sensors, in: Proc. ION GPS/GNSS 2003 Conf., 2003: pp. 9-12.

[72] C. Wang, D. Yan, Y. Jiang, A novel approach for building occupancy simulation, Build. Simul. 4 (2011) 149-167. https://doi.org/10.1007/s12273-011-0044-5.

[73] P. Mohebbi, E. Stroulia, I. Nikolaidis, Indoor Localization: A Cost-Effectiveness vs. Accuracy Study, in: Proc. - IEEE Symp. Comput. Med. Syst., Institute of Electrical and Electronics Engineers Inc., 2017: pp. 552-557. https://doi.org/10.1109/CBMS.2017.126.

[74] W. Wang, J. Chen, T. Hong, Modeling occupancy distribution in large spaces with multi-feature $\begin{array}{llllll}\text { classification } & \text { algorithm, } & \text { Build. } & \text { Environ. } & 137 & \text { (2018) }\end{array}$ https://doi.org/10.1016/j.buildenv.2018.04.002.

[75] A. Alhamoud, A.A. Nair, C. Gottron, D. Böhnstedt, R. Steinmetz, Presence detection, identification and tracking in smart homes utilizing bluetooth enabled smartphones, in: Proc. - Conf. Local Comput. Networks, LCN, IEEE Computer Society, 2014: pp. 784-789. https://doi.org/10.1109/LCNW.2014.6927735.

[76] R. Mautz, Overview of current indoor positioning systems, Geod. Cartogr. 35 (2009) 18-22. https://doi.org/10.3846/1392-1541.2009.35.18-22.

[77] G. Dedes, G. Dedes, A.G. Dempster, Indoor GPS positioning - challenges and opportunities, IEEE FALL 
Veh. Technol. CONF. (2005) 412--415.

[78] P. Zappi, E. Farella, L. Benini, Enhancing the spatial resolution of presence detection in a pir based wireless surveillance network, in: 2007 IEEE Conf. Adv. Video Signal Based Surveillance, AVSS 2007 Proc., 2007 : pp. 295-300. https://doi.org/10.1109/AVSS.2007.4425326.

[79] L.M. Candanedo, V. Feldheim, Accurate occupancy detection of an office room from light, temperature, humidity and CO2 measurements using statistical learning models, Energy Build. 112 (2016) 28-39. https://doi.org/10.1016/j.enbuild.2015.11.071.

[80] Y. Benezeth, H. Laurent, B. Emile, C. Rosenberger, Towards a sensor for detecting human presence and characterizing activity, Energy Build. 43 (2011) 305-314. https://doi.org/10.1016/j.enbuild.2010.09.014.

[81] A. Bränzel, C. Holz, D. Hoffmann, D. Schmidt, M. Knaust, P. Lühne, R. Meusel, S. Richter, P. Baudisch, GravitySpace: Tracking users and their poses in a smart room using a pressure-sensing floor, in: Conf. Hum. Factors Comput. Syst. - Proc., 2013: pp. 725-734. https://doi.org/10.1145/2470654.2470757.

[82] S. Pan, T. Yu, M. Mirshekari, J. Fagert, A. Bonde, O.J. Mengshoel, H.Y. Noh, P. Zhang, FootprintID: Indoor Pedestrian Identification through Ambient Structural Vibration Sensing, Proc. ACM Interactive, Mobile, Wearable Ubiquitous Technol. 1 (2017) 1-31. https://doi.org/10.1145/3130954.

[83] X. Tang, M.C. Huang, S. Mandal, An "Internet of Ears" for crowd-aware smart buildings based on sparse sensor networks, in: Proc. IEEE Sensors, Institute of Electrical and Electronics Engineers Inc., 2017: pp. 13. https://doi.org/10.1109/ICSENS.2017.8234263.

[84] S. Depatla, A. Muralidharan, Y. Mostofi, Occupancy Estimation Using Only WiFi Power Measurements, IEEE J. Sel. Areas Commun. 33 (2015) 1381-1393. https://doi.org/10.1109/JSAC.2015.2430272.

[85] P. Dickinson, G. Cielniak, O. Szymanezyk, M. Mannion, Indoor positioning of shoppers using a network of Bluetooth Low Energy beacons, in: 2016 Int. Conf. Indoor Position. Indoor Navig. IPIN 2016, Institute of Electrical and Electronics Engineers Inc., 2016. https://doi.org/10.1109/IPIN.2016.7743684.

[86] G. Jekabsons, V. Kairish, V. Zuravlyov, An Analysis of Wi-Fi Based Indoor Positioning Accuracy, Sci. J. Riga Tech. Univ. Comput. Sci. 44 (2011) 131-137.

[87] R. Jia, M. Jin, H. Zou, Y. Yesilata, L. Xie, C. Spanos, Poster abstract: Mapsentinel: Map-aided non-intrusive indoor tracking in sensor-rich environments, in: BuildSys 2015 - Proc. 2nd ACM Int. Conf. Embed. Syst. Energy-Efficient Built, Association for Computing Machinery, Inc, 2015: pp. 109-110. https://doi.org/10.1145/2821650.2830302.

[88] S. Gansemer, S. Hakobyan, S. Püschel, U. Großmann, 3D WLAN indoor positioning in multi-storey buildings, in: Proc. 5th IEEE Int. Work. Intell. Data Acquis. Adv. Comput. Syst. Technol. Appl. IDAACS'2009, 2009: pp. 669-672. https://doi.org/10.1109/IDAACS.2009.5342893.

[89] R. Mautz, The challenges of indoor environments and specification on some alternative positioning systems, in: Proc. - 6th Work. Positioning, Navig. Commun. WPNC 2009, 2009: pp. 29-36. https://doi.org/10.1109/WPNC.2009.4907800.

[90] X. Tang, S. Mandal, Indoor Occupancy Awareness and Localization Using Passive Electric Field Sensing, IEEE Trans. Instrum. Meas. 68 (2019) 4535-4549. https://doi.org/10.1109/TIM.2018.2890319.

[91] K. Al Nuaimi, H. Kamel, A survey of indoor positioning systems and algorithms, in: 2011 Int. Conf. Innov. Inf. Technol. IIT 2011, 2011: pp. 185-190. https://doi.org/10.1109/INNOVATIONS.2011.5893813.

[92] C. Liao, Y. Lin, P. Barooah, Agent-based and graphical modelling of building occupancy, J. Build. Perform. Simul. 5 (2012) 5-25. https://doi.org/10.1080/19401493.2010.531143.

[93] J.F. Nicol, Characterising occupant behaviour in buildings : towards a stochastic model of occupant use of windows, lights, blinds, heaters and fans, Proc. 7th Int. IBPSA Conf. Rio de. Janeiro, Brazil, 2001. (2001).

[94] F. Haldi, D. Robinson, A comparison of alternative approaches for the modeling of window opening and closing behaviour, in: Proc. Conf. Air Cond. Low Carbon Cool. Chall., 2008: pp. 27-9.

[95] S. Pan, Y. Han, S. Wei, Y. Wei, L. Xia, L. Xie, X. Kong, W. Yu, A model based on Gauss Distribution for predicting window behavior in building, Build. Environ. 149 (2019) 210-219. https://doi.org/10.1016/j.buildenv.2018.12.008.

[96] F. Stazi, F. Naspi, M. D’Orazio, Modelling window status in school classrooms. Results from a case study in Italy, Build. Environ. 111 (2017) 24-32. https://doi.org/10.1016/j.buildenv.2016.10.013.

[97] S. Pan, Y. Xiong, Y. Han, X. Zhang, L. Xia, S. Wei, J. Wu, M. Han, A study on influential factors of occupant window-opening behavior in an office building in China, Build. Environ. 133 (2018) 41-50. https://doi.org/10.1016/j.buildenv.2018.02.008.

[98] Z. Shi, H. Qian, X. Zheng, Z. Lv, Y. Li, L. Liu, P. V. Nielsen, Seasonal variation of window opening behaviors in two naturally ventilated hospital wards, Build. Environ. 130 (2018) 85-93. https://doi.org/10.1016/j.buildenv.2017.12.019.

[99] N. Li, J. Li, R. Fan, H. Jia, Probability of occupant operation of windows during transition seasons in office buildings, Renew. Energy. 73 (2015) 84-91. https://doi.org/10.1016/j.renene.2014.05.065.

[100] S. Dutton, L. Shao, WINDOW OPENING BEHAVIOUR IN A NATURALLY VENTILATED SCHOOL, 
in: Proc. SimBuild, 2010: pp. 260-268.

[101] S. Shi, B. Zhao, Occupants' interactions with windows in 8 residential apartments in Beijing and Nanjing, China, Build. Simul. 9 (2016) 221-231. https://doi.org/10.1007/s12273-015-0266-z.

[102] F. Stazi, F. Naspi, G. Bernardini, M. D’Orazio, Comparing real and predicted window use in offices. A POE-based assessment, in: Energy Procedia, Elsevier Ltd, 2017: pp. 141-150. https://doi.org/10.1016/j.egypro.2017.09.552.

[103] Y. Wei, H. Yu, S. Pan, L. Xia, J. Xie, X. Wang, J. Wu, W. Zhang, Q. Li, Comparison of different window behavior modeling approaches during transition season in Beijing, China, Build. Environ. 157 (2019) 1-15. https://doi.org/10.1016/j.buildenv.2019.04.040.

[104] M. Yao, B. Zhao, Factors affecting occupants' interactions with windows in residential buildings in Beijing, China, in: Procedia Eng., Elsevier Ltd, 2017: pp. 3428-3434. https://doi.org/10.1016/j.proeng.2017.09.857.

[105] R. Andersen, V. Fabi, J. Toftum, S.P. Corgnati, B.W. Olesen, Window opening behaviour modelled from measurements in Danish dwellings, Build. Environ. 69 (2013) 101-113. https://doi.org/10.1016/j.buildenv.2013.07.005.

[106] D. Calì, R.K. Andersen, D. Müller, B.W. Olesen, Analysis of occupants' behavior related to the use of windows in German households, Build. Environ. 103 (2016) 54-69. https://doi.org/10.1016/j.buildenv.2016.03.024.

[107] R. V. Jones, A. Fuertes, E. Gregori, A. Giretti, Stochastic behavioural models of occupants' main bedroom window operation for UK residential buildings, Build. Environ. 118 (2017) 144-158. https://doi.org/10.1016/j.buildenv.2017.03.033.

[108] F. Naspi, M. Arnesano, L. Zampetti, F. Stazi, G.M. Revel, M. D’Orazio, Experimental study on occupants' interaction with windows and lights in Mediterranean offices during the non-heating season, Build. Environ. 127 (2018) 221-238. https://doi.org/10.1016/j.buildenv.2017.11.009.

[109] R. Fritsch, A. Kohler, M. Nygård-Ferguson, J.L. Scartezzini, A stochastic model of user behaviour regarding ventilation, Build. Environ. 25 (1990) 173-181. https://doi.org/10.1016/0360-1323(90)90030-U.

[110] D. Calì, M.T. Wesseling, D. Müller, WinProGen: A Markov-Chain-based stochastic window status profile generator for the simulation of realistic energy performance in buildings, Build. Environ. 136 (2018) 240 258. https://doi.org/10.1016/j.buildenv.2018.03.048.

[111] V. Fabi, R.K. Andersen, S. Corgnati, Verification of stochastic behavioural models of occupants' interactions with windows in residential buildings, Build. Environ. 94 (2015) 371-383. https://doi.org/10.1016/j.buildenv.2015.08.016.

[112] F. Haldi, D. Robinson, Interactions with window openings by office occupants, Build. Environ. 44 (2009) 2378-2395. https://doi.org/10.1016/j.buildenv.2009.03.025.

[113] R. Markovic, E. Grintal, D. Wölki, J. Frisch, C. van Treeck, Window opening model using deep learning methods, Build. Environ. 145 (2018) 319-329. https://doi.org/10.1016/j.buildenv.2018.09.024.

[114] O.I. Abiodun, A. Jantan, A.E. Omolara, K.V. Dada, N.A.E. Mohamed, H. Arshad, State-of-the-art in artificial neural network applications: A survey, Heliyon. 4 (2018). https://doi.org/10.1016/j.heliyon.2018.e00938.

[115] M. Jamil, S.K. Sharma, R. Singh, Fault detection and classification in electrical power transmission system using artificial neural network, Springerplus. 4 (2015) 334. https://doi.org/10.1186/s40064-015-1080-x.

[116] S.A. Kalogirou, M. Bojic, Artificial neural networks for the prediction of the energy consumption of a passive solar building, Energy. 25 (2000) 479-491. https://doi.org/10.1016/S0360-5442(99)00086-9.

[117] V.M. Barthelmes, Y. Heo, V. Fabi, S.P. Corgnati, Exploration of the Bayesian Network framework for modelling window control behaviour, Build. Environ. 126 (2017) 318-330. https://doi.org/10.1016/j.buildenv.2017.10.011.

[118] S. D'Oca, T. Hong, A data-mining approach to discover patterns of window opening and closing behavior in offices, Build. Environ. 82 (2014) 726-739. https://doi.org/10.1016/j.buildenv.2014.10.021.

[119] Z. Deme Belafi, F. Naspi, M. Arnesano, A. Reith, G.M. Revel, Investigation on window opening and closing behavior in schools through measurements and surveys: A case study in Budapest, Build. Environ. 143 (2018) 523-531. https://doi.org/10.1016/j.buildenv.2018.07.022.

[120] N. Nord, T. Tereshchenko, L.H. Qvistgaard, I.S. Tryggestad, Influence of occupant behavior and operation on performance of a residential Zero Emission Building in Norway, Energy Build. 159 (2018) 75-88. https://doi.org/10.1016/j.enbuild.2017.10.083.

[121] F. Naspi, M. Arnesano, F. Stazi, M. D'Orazio, G.M. Revel, Measuring occupants' behaviour for buildings' dynamic cosimulation, J. Sensors. 2018 (2018). https://doi.org/10.1155/2018/2756542.

[122] F. Haldi, D. Calì, R.K. Andersen, M. Wesseling, D. Müller, Modelling diversity in building occupant behaviour: a novel statistical approach, J. Build. Perform. Simul. 10 (2017) 527-544. https://doi.org/10.1080/19401493.2016.1269245.

[123] M. Schweiker, A. Wagner, The effect of occupancy on perceived control, neutral temperature, and 
behavioral patterns, Energy Build. 117 (2016) 246-259. https://doi.org/10.1016/j.enbuild.2015.10.051.

[124] Y. Rafiq, S. Wei, R. Guest, R. Stone, P. de Wilde, Applying Artificial Neural Networks to Promote Behaviour Change for Saving Residential Energy, (2014) 3-10. https://doi.org/10.5220/0005049600030010.

[125] S. D'Oca, V. Fabi, S.P. Corgnati, R.K. Andersen, Effect of thermostat and window opening occupant behavior models on energy use in homes, Build. Simul. 7 (2014) 683-694. https://doi.org/10.1007/s12273014-0191-6.

[126] G.M. Stavrakakis, P.L. Zervas, H. Sarimveis, N.C. Markatos, Optimization of window-openings design for thermal comfort in naturally ventilated buildings, Appl. Math. Model. 36 (2012) 193-211. https://doi.org/10.1016/j.apm.2011.05.052.

[127] G.Y. Yun, K. Steemers, Night-time naturally ventilated offices: Statistical simulations of window-use patterns from field monitoring, Sol. Energy. $84 \quad$ (2010) 1216-1231. https://doi.org/10.1016/j.solener.2010.03.029.

[128] G.Y. Yun, P. Tuohy, K. Steemers, Thermal performance of a naturally ventilated building using a combined algorithm of probabilistic occupant behaviour and deterministic heat and mass balance models, Energy Build. 41 (2009) 489-499. https://doi.org/10.1016/j.enbuild.2008.11.013.

[129] R. Markovic, S. Wolf, J. Cao, E. Spinnräker, D. Wölki, J. Frisch, C. Van Treeck, Comparison of Different Classification Algorithms for the Detection of User's Interaction with Windows in Office Buildings, in: Energy Procedia, Elsevier Ltd, 2017: pp. 337-342. https://doi.org/10.1016/j.egypro.2017.07.333.

[130] G.Y. Yun, K. Steemers, Time-dependent occupant behaviour models of window control in summer, Build. Environ. 43 (2008) 1471-1482. https://doi.org/10.1016/j.buildenv.2007.08.001.

[131] R. Markovic, J. Frisch, C. van Treeck, Learning short-term past as predictor of window opening-related human behavior in commercial buildings, Energy Build. 185 (2019) 1-11. https://doi.org/10.1016/j.enbuild.2018.12.012.

[132] F. Haldi, D. Robinson, On the behaviour and adaptation of office occupants, Build. Environ. 43 (2008) 2163-2177. https://doi.org/10.1016/j.buildenv.2008.01.003.

[133] S. Herkel, U. Knapp, J. Pfafferott, Towards a model of user behaviour regarding the manual control of windows in office buildings, Build. Environ. 43 (2008) 588-600. https://doi.org/10.1016/j.buildenv.2006.06.031.

[134] F. Stazi, F. Naspi, M. D’Orazio, A literature review on driving factors and contextual events influencing occupants' behaviours in buildings, Build. Environ. 118 (2017) 40-66. https://doi.org/10.1016/j.buildenv.2017.03.021.

[135] V.M. Barthelmes, Y. Heo, R.K. Andersen, V. Fabi, S.P. Corgnati, Towards A Comprehensive Model Of Window Control Behaviour: A Survey-based Investigation On Interdisciplinary Drivers In Danish Dwellings, in: Build. Simul. Optim., 2018: pp. 649-656.

[136] Y.S. Lee, A.M. Malkawi, Simulating multiple occupant behaviors in buildings: An agent-based modeling approach, Energy Build. 69 (2014) 407-416. https://doi.org/10.1016/j.enbuild.2013.11.020.

[137] D.R.G. Hunt, The use of artificial lighting in relation to daylight levels and occupancy, Build. Environ. 14 (1979) 21-33. https://doi.org/10.1016/0360-1323(79)90025-8.

[138] F. Haldi, D. Robinson, Adaptive actions on shading devices in response to local visual stimuli, J. Build. Perform. Simul. 3 (2010) 135-153. https://doi.org/10.1080/19401490903580759.

[139] C.F. Reinhart, Lightswitch-2002: A model for manual and automated control of electric lighting and blinds, Sol. Energy. 77 (2004) 15-28. https://doi.org/10.1016/j.solener.2004.04.003.

[140] R.V. Andersen, J. Toftum, K.K. Andersen, B.W. Olesen, Survey of occupant behaviour and control of indoor environment in Danish dwellings, Energy Build. 41 (2009) 11-16. https://doi.org/10.1016/j.enbuild.2008.07.004.

[141] A. Mahdavi, A. Mohammadi, E. Kabir, L. Lambeva, Occupants' operation of lighting and shading systems in office buildings, J. Build. Perform. Simul. 1 (2008) 57-65. https://doi.org/10.1080/19401490801906502.

[142] G.R. Newsham, Manual Control of Window Blinds and Electric Lighting: Implications for Comfort and Energy Consumption, Indoor Environ. 3 (1994) 135-144. https://doi.org/10.1177/1420326X9400300307.

[143] S. Yeon, B. Yu, B. Seo, Y. Yoon, K.H. Lee, ANN based automatic slat angle control of venetian blind for minimized total load in an office building, Sol. Energy. (2019) 133-145. https://doi.org/10.1016/j.solener.2019.01.027.

[144] D. Makkar, P. Syal, Simulation of Intelligent Room Lighting Illuminance Control, in: 2017 IEEE Int. Conf. Comput. Intell. Comput. Res. ICCIC 2017, Institute of Electrical and Electronics Engineers Inc., 2018. https://doi.org/10.1109/ICCIC.2017.8524356.

[145] C. Kurian, R. Aithal, J. Bhat, V. George, Robust control and optimisation of energy consumption in daylight-artificial light integrated schemes, Light. Res. Technol. 40 (2008) 7-24. https://doi.org/10.1177/1477153507079511. 
[146] M. Trobec Lah, B. Zupančič, J. Peternelj, A. Krainer, Daylight illuminance control with fuzzy logic, Sol. Energy. 80 (2006) 307-321. https://doi.org/10.1016/j.solener.2005.02.002.

[147] A. Guillemin, N. Morel, Innovative lighting controller integrated in a self-adaptive building control system, Energy Build. 33 (2001) 477-487. https://doi.org/10.1016/S0378-7788(00)00100-6.

[148] Y. Chen, H. Li, X. Chen, Venetian blind control system based on fuzzy neural network for indoor daylighting, in: 2009 Int. Conf. Comput. Electr. Eng. ICCEE 2009, 2009: pp. 269-273. https://doi.org/10.1109/ICCEE.2009.18.

[149] Y.F. Chen, H. Li, H. Li, Indoor dynamic lighting control system for a full-scale private office, in: Proc. 2012 24th Chinese Control Decis. Conf. CCDC 2012, 2012: pp. 1691-1695. https://doi.org/10.1109/CCDC.2012.6244270.

[150] Z. Cheng, Q. Zhao, F. Wang, Y. Jiang, L. Xia, J. Ding, Satisfaction based Q-learning for integrated lighting and blind control, Energy Build. 127 (2016) 43-55. https://doi.org/10.1016/j.enbuild.2016.05.067.

[151] D. Daum, N. Morel, Assessing the total energy impact of manual and optimized blind control in combination with different lighting schedules in a building simulation environment, J. Build. Perform. Simul. 3 (2010) 1-16. https://doi.org/10.1080/19401490903362810.

[152] N.K. Kandasamy, G. Karunagaran, C. Spanos, K.J. Tseng, B.H. Soong, Smart lighting system using ANNIMC for personalized lighting control and daylight harvesting, Build. Environ. 139 (2018) 170-180. https://doi.org/10.1016/j.buildenv.2018.05.005.

[153] X. Ding, J. Yu, Y. Si, Office light control moving toward automation and humanization: a literature review, Intell. Build. Int. (2018). https://doi.org/10.1080/17508975.2018.1555087.

[154] V. Singhvi, A. Krause, C. Guestrin, J.H. Garrett, H. Scott Matthews, Intelligent light control using sensor networks, in: SenSys 2005 - Proc. 3rd Int. Conf. Embed. Networked Sens. Syst., Association for Computing Machinery, 2005: pp. 218-229. https://doi.org/10.1145/1098918.1098942.

[155] I. Hidayat, Faridah, S. Sesotya Utami, Activity Based Smart Lighting Control For Energy Efficient Building By Neural Network Model, E3S Web Conf. $43 \quad$ (2018) 01017. https://doi.org/10.1051/e3sconf/20184301017.

[156] A.H. Khalili, C. Wu, H. Aghajan, Hierarchical preference learning for light control from user feedback, in: 2010 IEEE Comput. Soc. Conf. Comput. Vis. Pattern Recognit. - Work. CVPRW 2010, 2010: pp. 56-62. https://doi.org/10.1109/CVPRW.2010.5543265.

[157] C.A. Hernandez S, R. Romero, D. Giral, Optimization of the use of residential lighting with neural network, in: 2010 Int. Conf. Comput. Intell. Softw. Eng. CiSE 2010, 2010. https://doi.org/10.1109/CISE.2010.5677018.

[158] S.A.M. Offermans, van H.A. Essen, J.H. Eggen, Exploring a hybrid control approach for enhanced user experience of interactive lighting, in: Proc. 27th Int. BCS Hum. Comput. Interact. Conf. (HCI 2013), British Computer Society (BCS), 2013: pp. 1-9.

[159] J.Y. Park, T. Dougherty, H. Fritz, Z. Nagy, LightLearn: An adaptive and occupant centered controller for lighting based on reinforcement learning, Build. Environ. 147 (2019) 397-414. https://doi.org/10.1016/j.buildenv.2018.10.028.

[160] D.A. Giral, R.R. Romero, C. Hernández, Analysis and review of the contribution of neural networks to saving electricity in residential lighting by a design in MATLAB, in: Proc. - 2012 9th Electron. Robot. Automot. Mech. Conf. CERMA 2012, 2012: pp. 182-190. https://doi.org/10.1109/CERMA.2012.37.

[161] V. Lobato-Rios, V. Del Rocio Hernandez-Castanon, J.A. Carrasco-Ochoa, J.F. Martinez-Trinidad, Linear model optimizer vs Neural Networks: A comparison for improving the quality and saving of LED-Lighting control systems, in: Proc. - Int. Conf. Pattern Recognit., Institute of Electrical and Electronics Engineers Inc., 2016: pp. 2664-2669. https://doi.org/10.1109/ICPR.2016.7900037.

[162] S. Atis, N. Ekren, Development of an outdoor lighting control system using expert system, Energy Build. 130 (2016) 773-786. https://doi.org/10.1016/j.enbuild.2016.08.066.

[163] A. Mohagheghi, M. Moallem, A. Khayatian, Neural network-based LED lighting control with modeling uncertainty and daylight disturbance, in: Proc. IECON 2017 - 43rd Annu. Conf. IEEE Ind. Electron. Soc., Institute of Electrical and Electronics Engineers Inc., 2017: pp. 3627-3632. https://doi.org/10.1109/IECON.2017.8216615.

[164] W. Si, X. Pan, H. Ogai, K. Hirai, A novel lambertian-RBFNN for office light modeling, IEICE Trans. Inf. Syst. E99D (2016) 1742-1752. https://doi.org/10.1587/transinf.2015EDP7411.

[165] J. Hu, E. Shen, Y. Gu, Evaluation of Lighting Performance Risk Using Surrogate Model and EnergyPlus, in: Procedia Eng., Elsevier Ltd, 2015: pp. 522-529. https://doi.org/10.1016/j.proeng.2015.08.471.

[166] W. SI, X. PAN, H. OGAI, K. HIRAI, N. YAMAUCHI, T. LI, Illumination Modeling Method for Office Lighting Control by Using RBFNN, IEICE Trans. Inf. Syst. E97.D (2014) 3192-3200. https://doi.org/10.1587/transinf.2013EDP7384.

[167] Y. Gao, Y. Lin, Y. Sun, A wireless sensor network based on the novel concept of an I-matrix to achieve 
high-precision lighting control, Build. Environ. $70 \quad$ (2013) 223-231. https://doi.org/10.1016/j.buildenv.2013.08.011.

[168] W. Si, H. Ogai, T. Li, K. Hirai, A novel energy saving system for office lighting control by using RBFNN and PSO, in: IEEE 2013 Tencon - Spring, TENCONSpring 2013 - Conf. Proc., 2013: pp. 347-351. https://doi.org/10.1109/TENCONSpring.2013.6584469.

[169] Z. Wang, Y.K. Tan, Illumination control of LED systems based on neural network model and energy optimization algorithm, Energy Build. 62 (2013) 514-521. https://doi.org/10.1016/j.enbuild.2013.03.029.

[170] R.R. Cardoso, A.F. Brandao, Artificial neural network application to a building hybrid illumination system, in: IEEE Int. Symp. Ind. Electron., 2008: pp. 866-871. https://doi.org/10.1109/ISIE.2008.4677011.

[171] C. Kurian, S. Kuriachan, J. Bhat, R. Aithal, An adaptive neuro-fuzzy model for the prediction and control of light in integrated lighting schemes, Light. Res. Technol. 37 (2005) 343-351. https://doi.org/10.1191/1365782805li150oa.

[172] M.M. Ouf, H.B. Gunay, W. O’Brien, A method to generate design-sensitive occupant-related schedules for building performance simulations, Sci. Technol. Built Environ. 25 (2019) 221-232. https://doi.org/10.1080/23744731.2018.1514855.

[173] F.H. Sakaci, E. Cetiner, H. Chaouch, S.C. Yener, Smart office for managing energy of lighting control system, in: Proc. - 2018 6th Int. Istanbul Smart Grids Cities Congr. Fair, ICSG 2018, Institute of Electrical and Electronics Engineers Inc., 2018: pp. 101-104. https://doi.org/10.1109/SGCF.2018.8408951.

[174] K. Rijal Wagiman, M. Noor Abdullah, Intelligent lighting control system for energy savings in office building, Indones. J. Electr. Eng. Comput. Sci. $11 \quad$ (2018) 195-202. https://doi.org/10.11591/ijeecs.v11.i1.pp195-202.

[175] S.A. Raziei, H. Mohscnian-Had, Optimal demand response capacity of automatic lighting control, in: 2013 IEEE PES Innov. Smart Grid Technol. Conf. ISGT 2013, 2013. https://doi.org/10.1109/ISGT.2013.6497854.

[176] D. Lindelöf, N. Morel, Bayesian estimation of visual discomfort, Build. Res. Inf. 36 (2008) 83-96. https://doi.org/10.1080/09613210701544061.

[177] D. Lindelöf, N. Morel, A field investigation of the intermediate light switching by users, Energy Build. 38 (2006) 790-801. https://doi.org/10.1016/j.enbuild.2006.03.003.

[178] Z.N. Zhen, Q.S. Jia, C. Song, X. Guan, An indoor localization algorithm for lighting control using RFID, in: 2008 IEEE Energy 2030 Conf. ENERGY 2008, 2008. https://doi.org/10.1109/ENERGY.2008.4781041.

[179] S.N. Patel, T. Robertson, J.A. Kientz, M.S. Reynolds, G.D. Abowd, At the Flick of a Switch: Detecting and Classifying Unique Electrical Events on the Residential Power Line, in: UbiComp 2007 Ubiquitous Comput., Springer Berlin Heidelberg, 2007: pp. 271-288. https://doi.org/10.1007/978-3-540-74853-3_16.

[180] P. Kar, A. Shareef, A. Kumar, K.T. Harn, B. Kalluri, S.K. Panda, ReViCEE: A recommendation based approach for personalized control, visual comfort \& energy efficiency in buildings, Build. Environ. 152 (2019) 135-144. https://doi.org/10.1016/j.buildenv.2019.01.035.

[181] L. Bandić, J. Kevrić, Near Zero-Energy Home Prediction of Appliances Energy Consumption Using the Reduced Set of Features and Random Decision Tree Algorithms, in: Lect. Notes Networks Syst., Springer, 2019: pp. 164-171. https://doi.org/10.1007/978-3-030-02574-8_13.

[182] A.P. Chandrasiri, D. Geekiyanage, Real-time object detection system for building energy conservation: An IP camera based system, in: 34th Annu. Assoc. Res. Constr. Manag., 2018.

[183] S. Borile, A. Pandharipande, D. Caicedo, L. Schenato, A. Cenedese, A Data-Driven Daylight Estimation Approach to Lighting Control, IEEE Access. 5 (2017) 21461-21471. https://doi.org/10.1109/ACCESS.2017.2679807.

[184] R. Paulson, R. Paulson, R. Basu, A.M. Agogino, S. Poll, Inverse Modeling Using a Wireless Sensor Network (WSN) for Personalized Daylight Harvesting, SENSORNETS. (n.d.) 213-221.

[185] J.F. Nicol, M.H.-A. Transactions, U. 2004, A Stochastic Approach to Thermal Comfort-Occupant Behavior and Energy Use in Buildings/DISCUSSION, ASHRAE Trans. 110 (2004) 554.

[186] C. Wang, D. Yan, X. Ren, Modeling Individual's Light Switching Behavior to Understand Lighting Energy Use of Office Building, Energy Procedia. 88 (2016) 781-787. https://doi.org/10.1016/j.egypro.2016.06.128.

[187] A. Galatioto, M. Beccali, Assessment of the entropy of spatial and time distributions of rooms daylighting: A possible tool for a sustainable design, J. Sustain. Dev. Energy, Water Environ. Syst. 3 (2015) 425-435. https://doi.org/10.13044/j.sdewes.2015.03.0032.

[188] H.-O. Kim, J. Cha, A Study on LED Lights Dimming Control for BEMS based on Detection People Staying, 2013.

[189] M. Fischer, K. Wu, P. Agathoklis, Intelligent illumination model-based lighting control, in: Proc. - 32nd IEEE Int. Conf. Distrib. Comput. Syst. Work. ICDCSW 2012, 2012: pp. 245-249. https://doi.org/10.1109/ICDCSW.2012.75.

[190] K. Onobayashi, M. Miki, Y. Sakakibara, H. Ikegami, H. Aida, Comparison of Power Consumption Reduce 
Effect of Intelligent Lighting System and Lighting Control System by Using Motion Sensor, 2014.

[191] P. Lee, P.T.I. Lam, W.L. Lee, Performance risks of lighting retrofit in Energy Performance Contracting projects, Energy Sustain. Dev. 45 (2018) 219-229. https://doi.org/10.1016/j.esd.2018.07.004.

[192] J.R. Villar, E. De La Cal, J. Sedano, M. García-Tamargo, Analysing the low quality of the data in lighting control systems, in: Int. Conf. Hybrid Artif. Intell. Syst., 2010: pp. 421-428. https://doi.org/10.1007/978-3642-13769-3_51.

[193] Y. Chen, Q. Sun, Artificial intelligent control for indoor lighting basing on person number in classroom, in: 2013 9th Asian Control Conf. ASCC 2013, 2013. https://doi.org/10.1109/ASCC.2013.6606030.

[194] J. Feng, Y. Yang, Design and implementation of lighting control system for smart rooms, in: 2017 2nd IEEE Int. Conf. Comput. Intell. Appl. ICCIA 2017, Institute of Electrical and Electronics Engineers Inc., 2017: pp. 476-481. https://doi.org/10.1109/CIAPP.2017.8167263.

[195] A. Ahuja, K. Mosalam, T.I. Zohdi, K.M. Mosalam, T.I. Zohdi, An illumination model for translucent concrete using radiance, in: Proc., 14th Conf., Int. Build. Perform. Simul. Assoc., 2015.

[196] J. Widén, E. Wäckelgård, A high-resolution stochastic model of domestic activity patterns and electricity demand, Appl. Energy. 87 (2010) 1880-1892. https://doi.org/10.1016/j.apenergy.2009.11.006.

[197] P. Faria, Â. Pinto, Z. Vale, M. Khorram, F.B. De Lima Neto, T. Pinto, Lighting consumption optimization using fish school search algorithm, in: 2017 IEEE Symp. Ser. Comput. Intell. SSCI 2017 - Proc., Institute of Electrical and Electronics Engineers Inc., 2018: pp. 1-5. https://doi.org/10.1109/SSCI.2017.8285441.

[198] C. De Bakker, T. Van de Voort, A. Rosemann, The Energy Saving Potential of Occupancy-Based Lighting Control Strategies in Open-Plan Offices: The Influence of Occupancy Patterns, Energies. 11 (2017) 2. https://doi.org/10.3390/en11010002.

[199] C. De Bakker, T. Van De Voort, J. Van Duijhoven, A. Rosemann, Assessing the energy use of occupancybased lighting control strategies in open-plan offices, in: Proc. 2017 IEEE 14th Int. Conf. Networking, Sens. Control. ICNSC 2017, Institute of Electrical and Electronics Engineers Inc., 2017: pp. 476-481. https://doi.org/10.1109/ICNSC.2017.8000139.

[200] M.H.T. Imam, S. Afshari, S. Mishra, An experimental survey of feedback control methodologies for $\begin{array}{llllll}\text { advanced lighting } & \text { (2016) 600-612. }\end{array}$ https://doi.org/10.1016/j.enbuild.2016.08.088.

[201] M. Stokes, M. Rylatt, K. Lomas, A simple model of domestic lighting demand, Energy Build. 36 (2004) 103-116. https://doi.org/10.1016/j.enbuild.2003.10.007.

[202] I. Richardson, M. Thomson, D. Infield, A high-resolution domestic building occupancy model for energy demand simulations, Energy Build. 40 (2008) 1560-1566. https://doi.org/10.1016/j.enbuild.2008.02.006.

[203] J. Widén, A.M. Nilsson, E. Wäckelgård, A combined Markov-chain and bottom-up approach to modelling of domestic lighting demand, Energy Build. 41 (2009) 1001-1012. https://doi.org/10.1016/j.enbuild.2009.05.002.

[204] X. Zhou, D. Yan, T. Hong, X. Ren, Data analysis and stochastic modeling of lighting energy use in large office buildings in China, Energy Build. 86 (2015) 275-287. https://doi.org/10.1016/j.enbuild.2014.09.071.

[205] I. Richardson, M. Thomson, D. Infield, A. Delahunty, Domestic lighting: A high-resolution energy demand model, Energy Build. 41 (2009) 781-789. https://doi.org/10.1016/j.enbuild.2009.02.010.

[206] O.K. Larsen, R.L. Jensen, T. Antonsen, I. Strømberg, Estimation methodology for the electricity consumption with daylight- and occupancy-controlled artificial lighting, in: Energy Procedia, Elsevier Ltd, 2017: pp. 733-738. https://doi.org/10.1016/j.egypro.2017.07.388.

[207] D. Caicedo, A. Pandharipande, Energy performance prediction of lighting systems, in: IEEE Int. Work. Mach. Learn. Signal Process. MLSP, IEEE Computer Society, 2016. https://doi.org/10.1109/MLSP.2016.7738858.

[208] D. Caicedo, A. Pandharipande, Sensor Data-Driven Lighting Energy Performance Prediction, IEEE Sens. J. 16 (2016) 6397-6405. https://doi.org/10.1109/JSEN.2016.2579663.

[209] T.M. Sanjeev Kumar, C.P. Kurian, K. Shreeya, A. Amulya, Data Analytic Models for Lighting Energy Sensitivity Analysis of Building, in: 2018 Int. Conf. Control. Power, Commun. Comput. Technol. ICCPCCT 2018, Institute of Electrical and Electronics Engineers Inc., 2018: pp. 118-122. https://doi.org/10.1109/ICCPCCT.2018.8574270.

[210] L.M. Candanedo, V. Feldheim, D. Deramaix, Data driven prediction models of energy use of appliances in a low-energy house, Energy Build. 140 (2017) 81-97. https://doi.org/10.1016/j.enbuild.2017.01.083.

[211] S. Gilani, W. O'Brien, A preliminary study of occupants' use of manual lighting controls in private offices: A case study, Energy Build. 159 (2018) 572-586. https://doi.org/10.1016/j.enbuild.2017.11.055.

[212] V.R.M. Lo Verso, A. Pellegrino, F. Pellerey, A multivariate non-linear regression model to predict the energy demand for lighting in rooms with different architectural features and lighting control systems, Energy Build. 76 (2014) 151-163. https://doi.org/10.1016/j.enbuild.2014.02.063.

[213] Wu Yong-ling, Yang Jie, Pan Xiao-hui, Yu Chang-qing, Design and simulation of the auto-control system 
of classroom lights, in: Int. Conf. Autom. Control Artif. Intell. (ACAI 2012), Institution of Engineering and Technology, 2012: pp. 794-798. https://doi.org/10.1049/cp.2012.1097.

[214] P. Rajaram, R. Rawal, Potential savings in lighting energy due to advancement in Indian standard time: An enquiry in context of commercial office spaces in India., in: Proc. Build. Simul. 2011 12th Conf. Int. Build. Perform. Simul. Assoc., 2011: p. 14/16.

[215] L. Brackney, R. Shoureshi, Fuzzy-based self-organizing control for building systems, in: Proc. Am. Control Conf., American Automatic Control Council, 1994: pp. 3060-3064. https://doi.org/10.1109/acc.1994.735133.

[216] N. Khera, A. Khan, P. Biswal, C. Likhith, Development of an Intelligent Light Intensity Control System for LED Lighting, in: 2018 Int. Conf. Power Energy, Environ. Intell. Control. PEEIC 2018, Institute of Electrical and Electronics Engineers Inc., 2019: pp. 141-144. https://doi.org/10.1109/PEEIC.2018.8665595.

[217] L. Gomes, C. Ramos, A. Jozi, B. Serra, L. Paiva, Z. Vale, IoH: A Platform for the Intelligence of Home with a Context Awareness and Ambient Intelligence Approach, Futur. Internet. 11 (2019) 58. https://doi.org/10.3390/fi11030058.

[218] S. Gilani, W. O’Brien, H.B. Gunay, Simulating occupants' impact on building energy performance at $\begin{array}{lllllll}\text { different } & \text { spatial } & \text { scales, } & \text { Build. } & \text { Environ. } & 132 & \text { (2018) }\end{array}$ https://doi.org/10.1016/j.buildenv.2018.01.040.

[219] J. Coutaz, A. Carlesso, N. Bonnefond, R. Balzarini, Y. Laurillau, N. Mandran, J.L. Crowley, "Will the Last one out, please turn off the lights": Promoting energy awareness in public areas of office buildings, in: Lect. Notes Comput. Sci. (Including Subser. Lect. Notes Artif. Intell. Lect. Notes Bioinformatics), Springer Verlag, 2018: pp. 20-36. https://doi.org/10.1007/978-3-030-03062-9_2.

[220] S. Niu, W. Pan, Y. Zhao, A Virtual Reality Supported Approach to Occupancy Engagement in Building Energy Design for Closing the Energy Performance Gap, in: Procedia Eng., Elsevier Ltd, 2015: pp. 573580. https://doi.org/10.1016/j.proeng.2015.08.487.

[221] A.A. Kim, S. Wang, L.J. McCunn, Building value proposition for interactive lighting systems in the workplace: Combining energy and occupant perspectives, J. Build. Eng. 24 (2019). https://doi.org/10.1016/j.jobe.2019.100752.

[222] Y. Huo, H. Wang, X. Zuo, Z. Cui, A college teaching building lighting control system based on power line carrier, in: Proc. - 2013 Int. Conf. Inf. Sci. Cloud Comput. Companion, ISCC-C 2013, Institute of Electrical and Electronics Engineers Inc., 2014: pp. 441-445. https://doi.org/10.1109/ISCC-C.2013.11.

[223] N. Verma, A. Jain, Optimized Automatic Lighting Control in a Hotel Building for Energy Efficiency, in: 2018 Int. Conf. Power Energy, Environ. Intell. Control. PEEIC 2018, Institute of Electrical and Electronics Engineers Inc., 2019: pp. 168-172. https://doi.org/10.1109/PEEIC.2018.8665417.

[224] X. Pan, B. Lee, An Approach of Reinforcement Learning Based Lighting Control for Demand Response, in: PCIM Eur. 2016; Int. Exhib. Conf. Power Electron. Intell. Motion, Renew. Energy Energy Manag., VDE, 2016: pp. 1-8.

[225] D. Finney, Probit analysis, Cambridge University Press, Cambridge Univ. Press. (1971).

[226] P. de Wilde, The gap between predicted and measured energy performance of buildings: A framework for investigation, Autom. Constr. 41 (2014) 40-49.

[227] X. Ren, D. Yan, C. Wang, Air-conditioning usage conditional probability model for residential buildings, Build. Environ. 81 (2014) 172-182. https://doi.org/10.1016/j.buildenv.2014.06.022.

[228] C. Fan, F. Xiao, C. Yan, C. Liu, Z. Li, J. Wang, A novel methodology to explain and evaluate data-driven building energy performance models based on interpretable machine learning, Appl. Energy. (2019) 15511560. https://doi.org/10.1016/j.apenergy.2018.11.081.

[229] R. Baetens, D. Saelens, Modelling uncertainty in district energy simulations by stochastic residential occupant behaviour, J. Build. Perform. Simul. 9 (2016) 431-447. https://doi.org/10.1080/19401493.2015.1070203.

[230] D. Urieli, P. Stone, A Learning Agent for Heat-Pump Thermostat Control, Proc. 12th Int'l Conf Auton. Agents Multiagent Syst. (AAMAS 2013). (2013) 1093-1100.

[231] M.M. Gouda, S. Danaher, C.P. Underwood, Application of an Artificial Neural Network for Modelling the Thermal Dynamics of a Building?s Space and its Heating System, Math. Comput. Model. Dyn. Syst. 8 (2003) 333-344. https://doi.org/10.1076/mcmd.8.3.333.14097.

[232] G.S. Virk, D. Azzi, A.E. Gegov, B.P. Haynes, K.I. Alkadhimi, Intelligent soft-computing based modelling of naturally ventilated buildings, Int. J. Sol. Energy. 22 (2002) 131-140. https://doi.org/10.1080/0142591031000091112.

[233] V. Fabi, R.V. Andersen, S.P. Corgnati, Influence of occupant's heating set-point preferences on indoor environmental quality and heating demand in residential buildings, in: HVAC R Res., 2013: pp. 635-645. https://doi.org/10.1080/10789669.2013.789372. 
[234] S. Chen, Y. Zhuang, J. Zhang, Y. Fu, H. Zhang, Statistical Characteristics of Usage Behavior of Air Conditioners in the University Students' Dormitories, in: Procedia Eng., Elsevier Ltd, 2017: pp. 3593-3598. https://doi.org/10.1016/j.proeng.2017.10.209.

[235] M. Schweiker, M. Shukuya, Comparison of theoretical and statistical models of air-conditioning-unit usage behaviour in a residential setting under Japanese climatic conditions, Build. Environ. 44 (2009) 2137-2149. https://doi.org/10.1016/j.buildenv.2009.03.004.

[236] J. Langevin, J. Wen, P.L. Gurian, Simulating the human-building interaction: Development and validation of an agent-based model of office occupant behaviors, Build. Environ. 88 (2015) 27-45. https://doi.org/10.1016/j.buildenv.2014.11.037.

[237] Y. Peng, Z. Nagy, A. Schlüter, Temperature-preference learning with neural networks for occupant-centric building indoor climate controls, Build. Environ. $154 \quad$ (2019) 296-308. https://doi.org/10.1016/j.buildenv.2019.01.036.

[238] International Energy Agency, World Energy Outlook 2016, 2016. https://doi.org/https://doi.org/10.1787/weo-2016-en.

[239] N. Pathak, M.A.A.H. Khan, N. Roy, Acoustic based appliance state identifications for fine-grained energy analytics, in: 2015 IEEE Int. Conf. Pervasive Comput. Commun. PerCom 2015, Institute of Electrical and Electronics Engineers Inc., 2015: pp. 63-70. https://doi.org/10.1109/PERCOM.2015.7146510.

[240] Z. (Jerry) Yu, B. Hu, Y. Sun, A. Li, J. Li, G. Zhang, Standby energy use and saving potentials associated with occupant behavior of chinese rural homes, Energy Build. 154 (2017) 295-304. https://doi.org/10.1016/j.enbuild.2017.08.070.

[241] R. McCann, A.T. Le, D. Traore, Stochastic sliding mode arbitration for energy management in smart building systems, in: Conf. Rec. - IAS Annu. Meet. (IEEE Ind. Appl. Soc., 2008. https://doi.org/10.1109/08IAS.2008.8.

[242] C. Ganesh Kumar, S. Januja Josephine, P. V. Chandramani, Mining-based device control for home automation, in: Adv. Intell. Syst. Comput., Springer Verlag, 2016: pp. 1049-1058. https://doi.org/10.1007/978-81-322-2656-7_97.

[243] S. Chen, F. Gao, X. Guan, T. Liu, Y. Che, Y. Liu, A residential load scheduling approach based on load behavior analysis, in: IEEE Int. Conf. Autom. Sci. Eng., IEEE Computer Society, 2014: pp. 954-959. https://doi.org/10.1109/CoASE.2014.6899441.

[244] S. Spiegel, Optimization of in-house energy demand, Adv. Comput. Vis. Pattern Recognit. 66 (2015) $217-$ 289. https://doi.org/10.1007/978-3-319-14178-7_10.

[245] G.Y. Lin, S.C. Lee, J.Y.J. Hsu, W.R. Jih, Applying power meters for appliance recognition on the electric panel, in: Proc. 2010 5th IEEE Conf. Ind. Electron. Appl. ICIEA 2010, 2010: pp. 2254-2259. https://doi.org/10.1109/ICIEA.2010.5515385.

[246] F. Jazizadeh, Building Energy Monitoring Realization: Context-Aware Event Detection Algorithms for Non-Intrusive Electricity Disaggregation, in: Constr. Res. Congr. 2016 Old New Constr. Technol. Converg. Hist. San Juan - Proc. 2016 Constr. Res. Congr. CRC 2016, 2016. https://doi.org/10.1061/9780784479827.085.

[247] O. Van Cutsem, G. Lilis, M. Kayal, Automatic multi-state load profile identification with application to energy disaggregation, in: IEEE Int. Conf. Emerg. Technol. Fact. Autom. ETFA, Institute of Electrical and Electronics Engineers Inc., 2018: pp. 1-8. https://doi.org/10.1109/ETFA.2017.8247684.

[248] D. Egarter, V.P. Bhuvana, W. Elmenreich, PALDi: Online load disaggregation via particle filtering, IEEE Trans. Instrum. Meas. 64 (2015) 467-477. https://doi.org/10.1109/TIM.2014.2344373.

[249] A. Ridi, C. Gisler, J. Hennebert, Appliance and state recognition using Hidden Markov Models, in: DSAA 2014 - Proc. 2014 IEEE Int. Conf. Data Sci. Adv. Anal., Institute of Electrical and Electronics Engineers Inc., 2014: pp. 270-276. https://doi.org/10.1109/DSAA.2014.7058084.

[250] X. Zhang, Y. Wang, L. Chao, C. Li, L. Wu, X. Peng, Z. Xu, IEHouse: A non-intrusive household appliance state recognition system, in: 2017 IEEE SmartWorld Ubiquitous Intell. Comput. Adv. Trust. Comput. Scalable Comput. Commun. Cloud Big Data Comput. Internet People Smart City Innov. SmartWorld/SCALCOM/UIC/ATC/CBDCom/IOP/SCI 2017 - ，2018. https://doi.org/10.1109/UICATC.2017.8397510.

[251] A.R. Rababaah, E. Tebekaemi, Electric load monitoring of residential buildings using goodness of fit and multi-layer perceptron neural networks, in: CSAE 2012 - Proceedings, 2012 IEEE Int. Conf. Comput. Sci. Autom. Eng., 2012: pp. 733-737. https://doi.org/10.1109/CSAE.2012.6272871.

[252] A.F. Ebrahim, O.A. Mohammed, Energy disaggregation based deep learning techniques: A pre-processing stage to enhance the household load forecasting, in: 2018 IEEE Ind. Appl. Soc. Annu. Meet. IAS 2018, Institute of Electrical and Electronics Engineers Inc., 2018. https://doi.org/10.1109/IAS.2018.8544664.

[253] Q. Liu, X. Yang, L. Deng, An IBeacon-Based Location System for Smart Home Control., Sensors (Basel). 18 (2018). https://doi.org/10.3390/s18061897. 
[254] D. Frazzetto, B. Neupane, T.B. Pedersen, T.D. Nielsen, Adaptive user-Oriented direct load-Control of residential flexible devices, in: E-Energy 2018 - Proc. 9th ACM Int. Conf. Futur. Energy Syst., Association for Computing Machinery, Inc, 2018: pp. 1-11. https://doi.org/10.1145/3208903.3208924.

[255] Y. Kashimoto, K. Hata, H. Suwa, M. Fujimoto, Y. Arakawa, T. Shigezumi, K. Komiya, K. Konishi, K. Yasumoto, Low-cost and device-free activity recognition system with energy harvesting PIR and door sensors, in: ACM Int. Conf. Proceeding Ser., Association for Computing Machinery, 2016: pp. 6-11. https://doi.org/10.1145/3004010.3006378.

[256] K. Ueda, M. Tamai, K. Yasumoto, A method for recognizing living activities in homes using positioning sensor and power meters, in: 2015 IEEE Int. Conf. Pervasive Comput. Commun. Work. PerCom Work. 2015, Institute of Electrical and Electronics Engineers Inc., 2015: pp. 354-359. https://doi.org/10.1109/PERCOMW.2015.7134062.

[257] H.A. Cao, T.K. Wijaya, K. Aberer, N. Nunes, Temporal association rules for electrical activity detection in residential homes, in: Proc. - 2016 IEEE Int. Conf. Big Data, Big Data 2016, Institute of Electrical and Electronics Engineers Inc., 2016: pp. 3097-3106. https://doi.org/10.1109/BigData.2016.7840964.

[258] A. Albert, R. Rajagopal, Cost-of-service segmentation of energy consumers, IEEE Trans. Power Syst. (2014). https://doi.org/10.1109/TPWRS.2014.2312721.

[259] S. D’Oca, T. Hong, Occupancy schedules learning process through a data mining framework, Energy Build. 88 (2015) 395-408. https://doi.org/10.1016/j.enbuild.2014.11.065.

[260] M. Wang, X. Wang, G. Zhang, C. Li, Occupancy detection based on Spiking Neural Networks for green building automation systems, in: Proc. World Congr. Intell. Control Autom., Institute of Electrical and Electronics Engineers Inc., 2015: pp. 2681-2686. https://doi.org/10.1109/WCICA.2014.7053149.

[261] R.M. Tetlow, C. van Dronkelaar, C.P. Beaman, A.A. Elmualim, K. Couling, Identifying behavioural predictors of small power electricity consumption in office buildings, Build. Environ. 92 (2015) 75-85. https://doi.org/10.1016/j.buildenv.2015.04.009.

[262] H.B. Gunay, W. O’Brien, I. Beausoleil-Morrison, S. Gilani, Modeling plug-in equipment load patterns in private office spaces, Energy Build. 121 (2016) 234-249. https://doi.org/10.1016/j.enbuild.2016.03.001.

[263] Y.L. Hsu, P.H. Chou, H.C. Chang, S.L. Lin, S.C. Yang, H.Y. Su, C.C. Chang, Y.S. Cheng, Y.C. Kuo, Design and implementation of a smart home system using multisensor data fusion technology, Sensors (Switzerland). (2017). https://doi.org/10.3390/s17071631.

[264] Z. Deng, Q. Chen, Artificial neural network models using thermal sensations and occupants' behavior for predicting thermal comfort, Energy Build. $174 \quad$ (2018) 587-602. https://doi.org/10.1016/j.enbuild.2018.06.060.

[265] ISO, ISO - ISO 7730:1994 - Moderate thermal environments - Determination of the PMV and PPD indices and specification of the conditions for thermal comfort, (1994).

[266] T. Chaudhuri, D. Zhai, Y.C. Soh, H. Li, L. Xie, Thermal comfort prediction using normalized skin temperature in a uniform built environment, Energy Build. 159 (2018) 426-440. https://doi.org/10.1016/j.enbuild.2017.10.098.

[267] S. Lu, E. Cochran Hameen, INTEGRATED IR VISION SENSOR FOR ONLINE CLOTHING INSULATION MEASUREMENT, 2018.

[268] S. Schiavon, K.H. Lee, Dynamic predictive clothing insulation models based on outdoor air and indoor operative temperatures, Build. Environ. 59 (2013) 250-260.

[269] R. Rana, B. Kusy, R. Jurdak, J. Wall, W. Hu, Feasibility analysis of using humidex as an indoor thermal comfort predictor, Energy Build. 64 (2013) 17-25. https://doi.org/10.1016/j.enbuild.2013.04.019.

[270] K. Ahmed, J. Kurnitski, B. Olesen, Data for occupancy internal heat gain calculation in main building categories, Data Br. 15 (2017) 1030-1034. https://doi.org/10.1016/j.dib.2017.10.036.

[271] S. Atthajariyakul, T. Leephakpreeda, Neural computing thermal comfort index for HVAC systems, Energy Convers. Manag. 46 (2005) 2553-2565. https://doi.org/10.1016/j.enconman.2004.12.007.

[272] F. Gugliermetti, G. Passerini, F. Bisegna, Climate models for the assessment of office buildings energy performance, Build. Environ. 39 (2004) 39-50. https://doi.org/10.1016/S0360-1323(03)00138-0.

[273] J. Redmon, A. Farhadi, YOLO9000: Better, Faster, Stronger, in: Proc. - 30th IEEE Conf. Comput. Vis. Pattern Recognition, CVPR 2017, 2017.

[274] H.J. Jeong, K.S. Park, Y.G. Ha, Image Preprocessing for Efficient Training of YOLO Deep Learning Networks, in: Proc. - 2018 IEEE Int. Conf. Big Data Smart Comput. BigComp 2018, Institute of Electrical and Electronics Engineers Inc., 2018: pp. 635-637. https://doi.org/10.1109/BigComp.2018.00113.

[275] Z. Wang, T. Hong, M.A. Piette, Predicting plug loads with occupant count data through a deep learning approach, Energy. 181 (2019) 29-42. https://doi.org/10.1016/j.energy.2019.05.138.

[276] J. Redmon, S. Divvala, R. Girshick, A. Farhadi, You Only Look Once: Unified, Real-Time Object Detection, in: IEEE Conf. Comput. Vis. Pattern Recognit., 2016: pp. 779-788.

[277] M. Jia, R.S. Srinivasan, R. Ries, N. Weyer, G. Bharathy, A systematic development and validation approach 
to a novel agent-based modeling of occupant behaviors in commercial buildings, Energy Build. 199 (2019) 352-367. https://doi.org/10.1016/j.enbuild.2019.07.009.

[278] T. Csoknyai, J. Legardeur, A.A. Akle, M. Horváth, Analysis of energy consumption profiles in residential buildings and impact assessment of a serious game on occupants' behavior, Energy Build. 196 (2019) 120. https://doi.org/10.1016/j.enbuild.2019.05.009.

[279] M. Arslan, C. Cruz, D. Ginhac, Understanding Occupant Behaviors in Dynamic Environments using OBiDE framework, Build. Environ. 166 (2019) 106412. https://doi.org/10.1016/j.buildenv.2019.106412. 


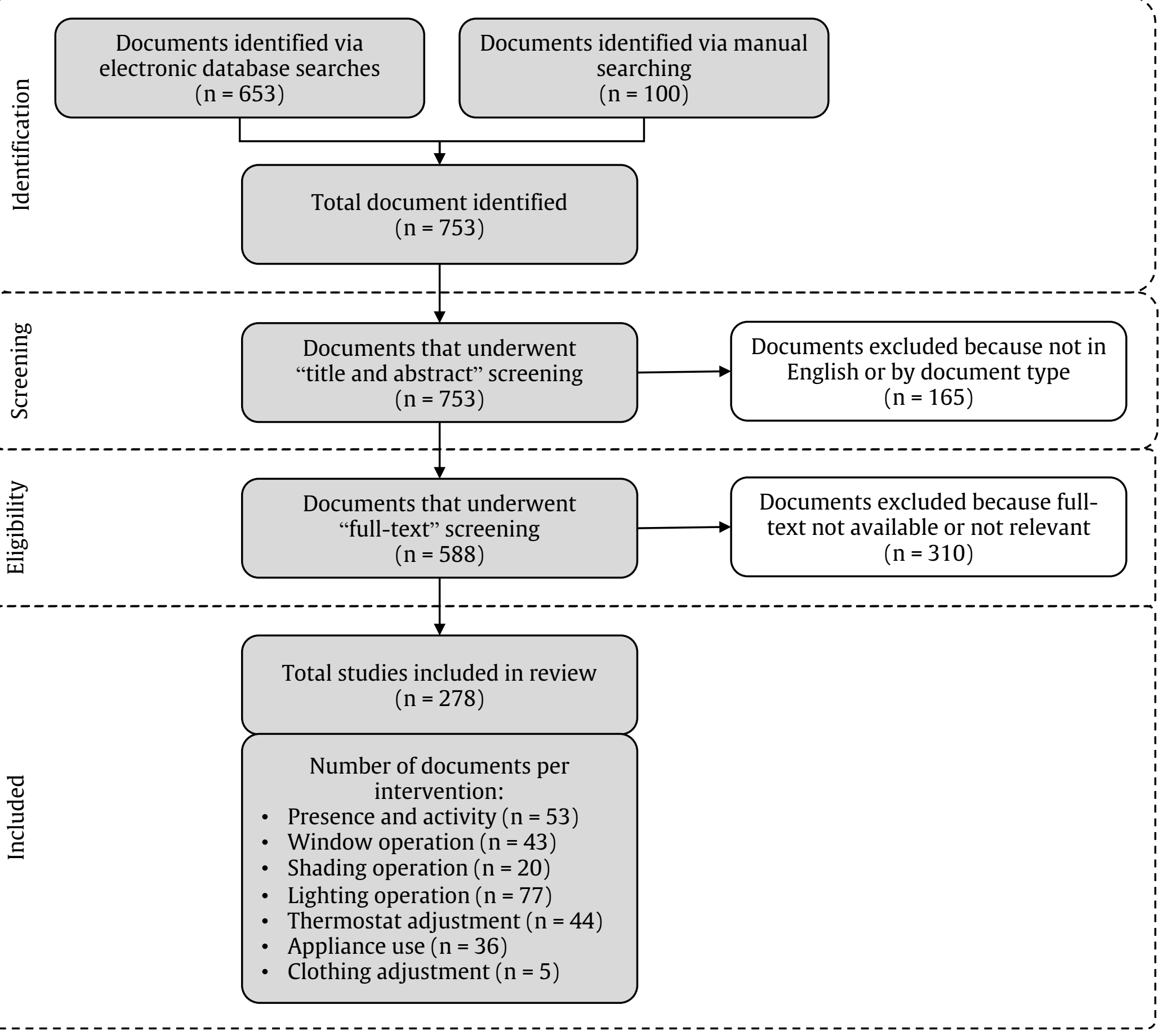




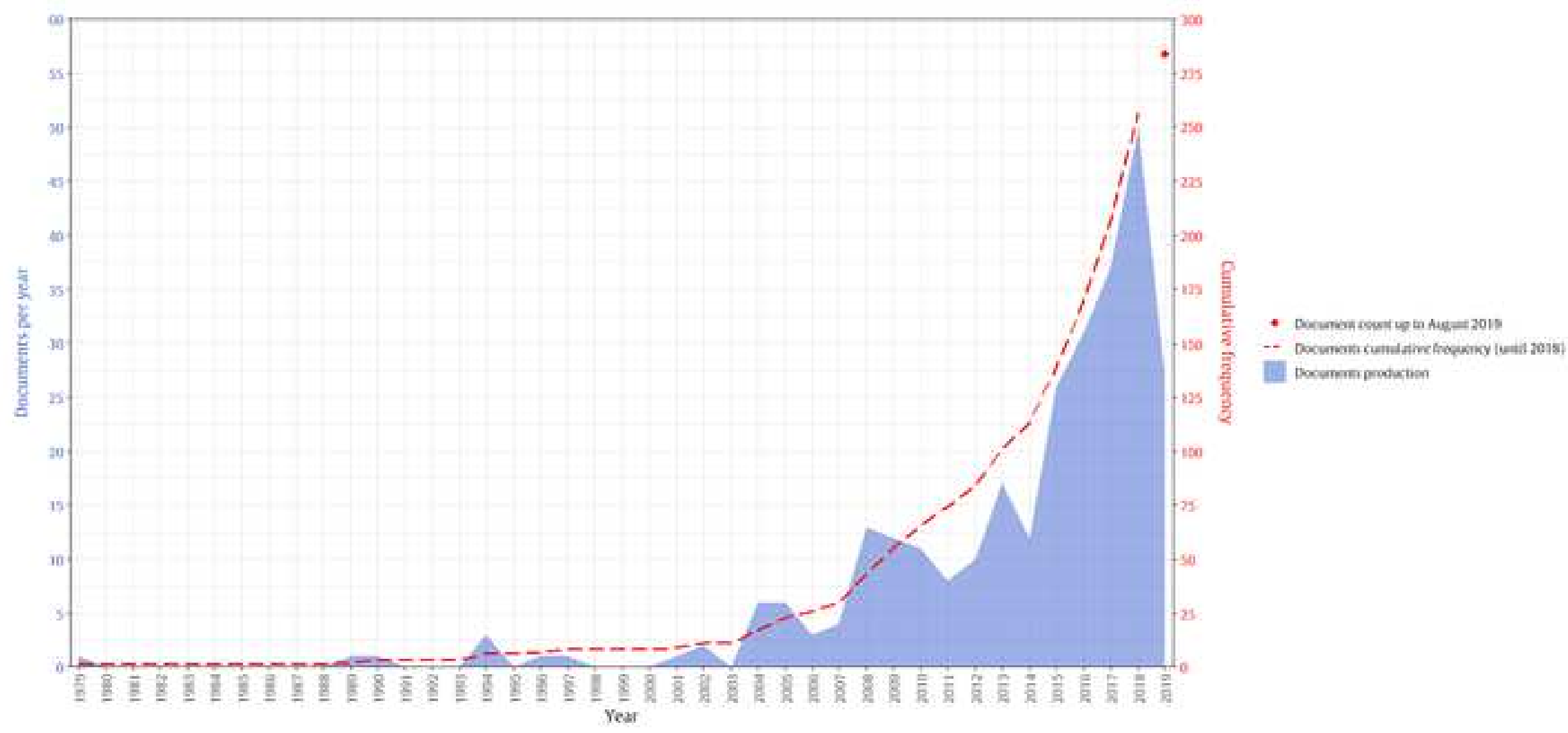




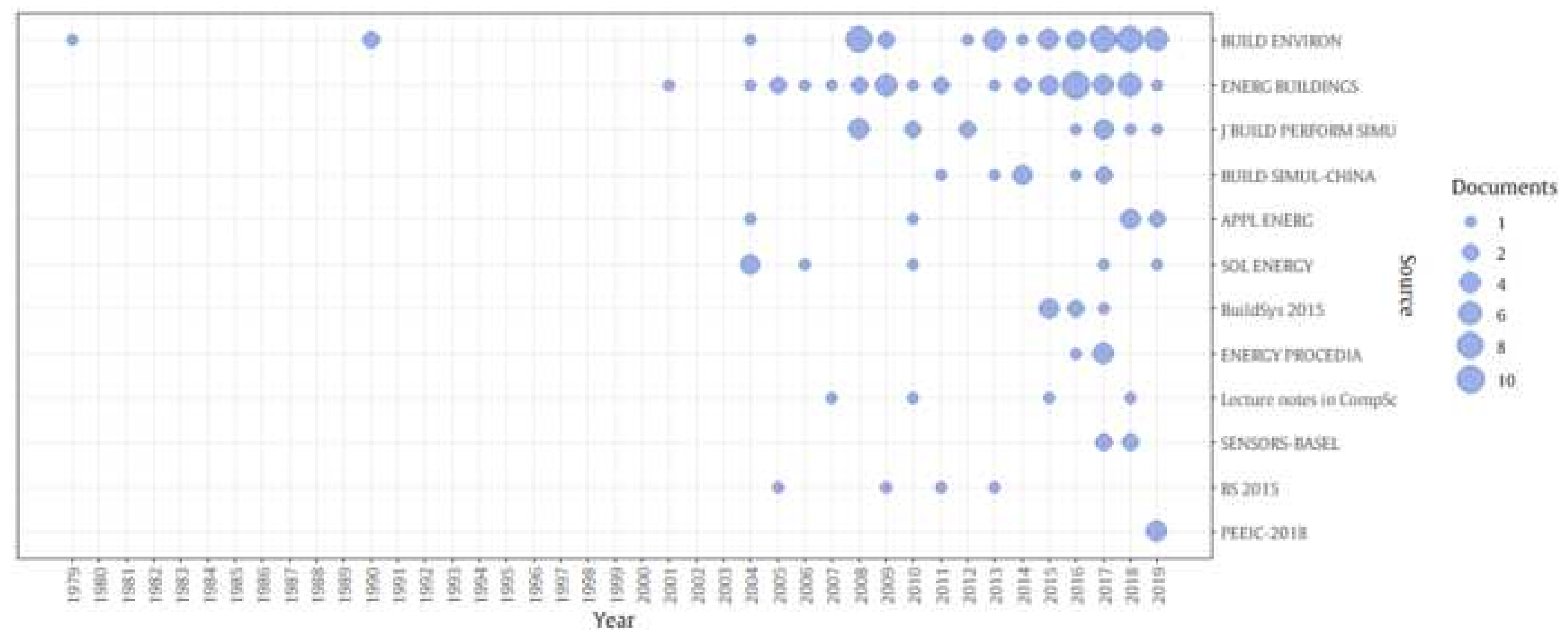

Tomenomes

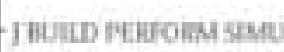

miD SIMULCHANA

toritive

OLENEACY

着

ENCYPWOCEDIA

PEEC 201:
Documents

- 1

Q. 4

C. $\mathrm{s}$

(.) 10

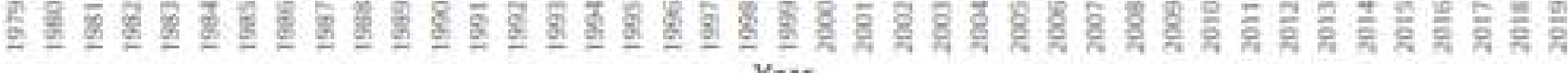




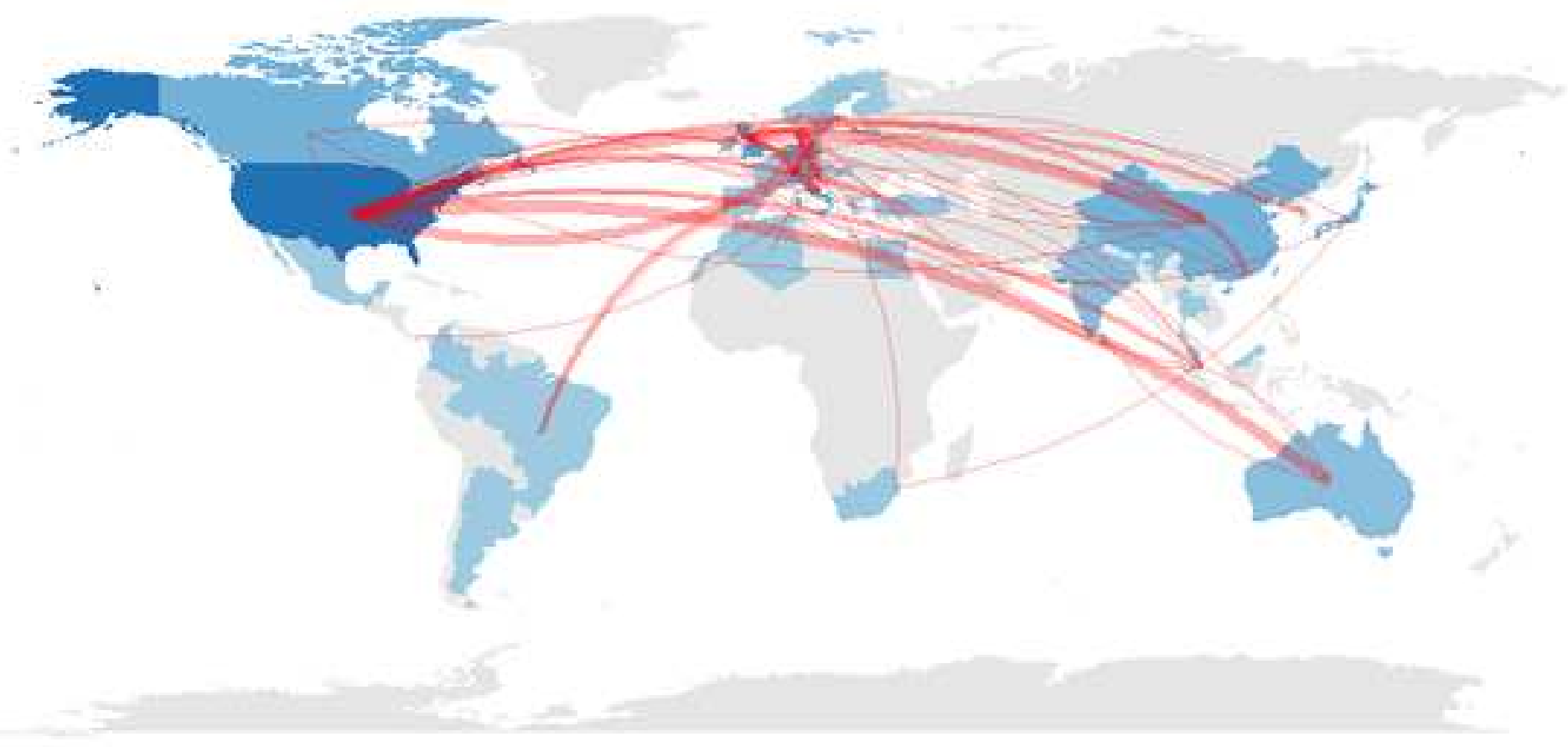

\section{Scientific production}

T 36

30

24
18

12

6
1

\section{Frequency of collaboration}

$-1$

$-2$

$-3$

$=4$

$=5$ 
a) Type for OPA model developanent

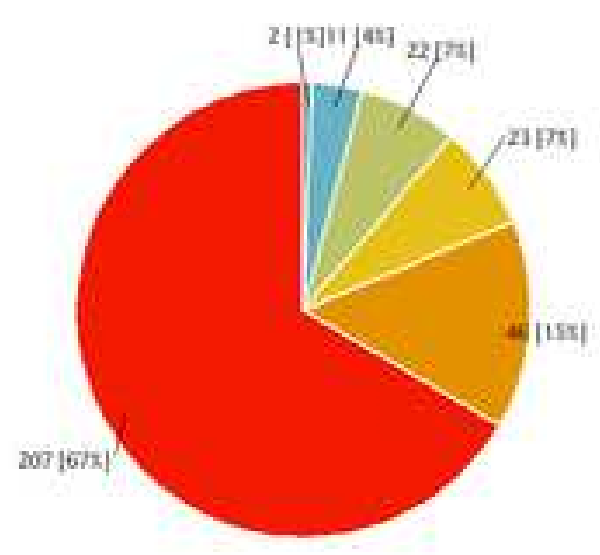

国 Merumanmas

Eiritesies

Dines

Ii Mesuremeas and narver

id semen

- Nor wallabir information b) CrA models by building type

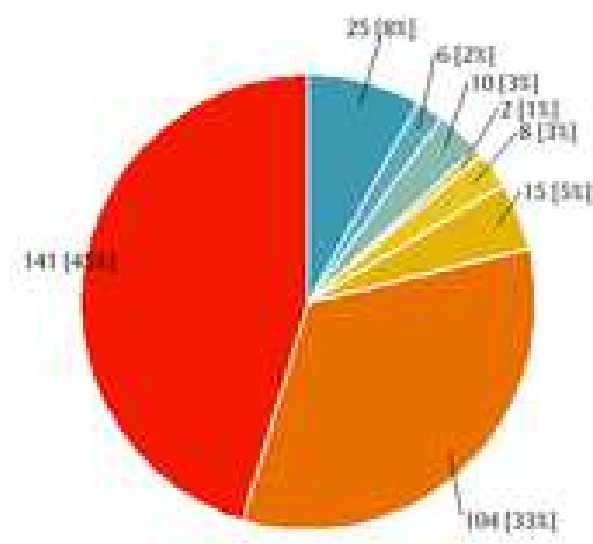
20tice balding
acidertid twill-

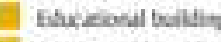

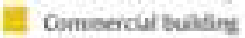
IIIt) Hat
E Trubst
aters
Eot analube inforinatiot

c) OPA models by operation mode

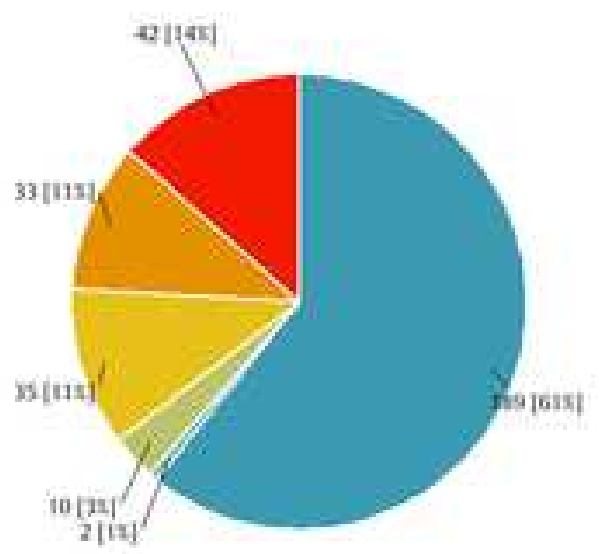

Nunutaly verciluted bualings

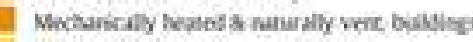

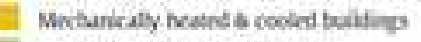

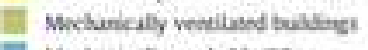

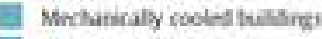

国 Nor avalutie bofomation d) Type of methods ased foc Obs model development

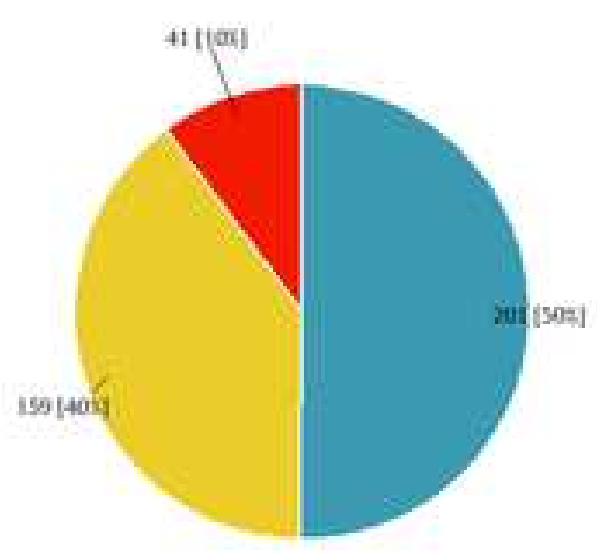

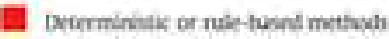

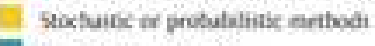
1. bucs driven anthots 


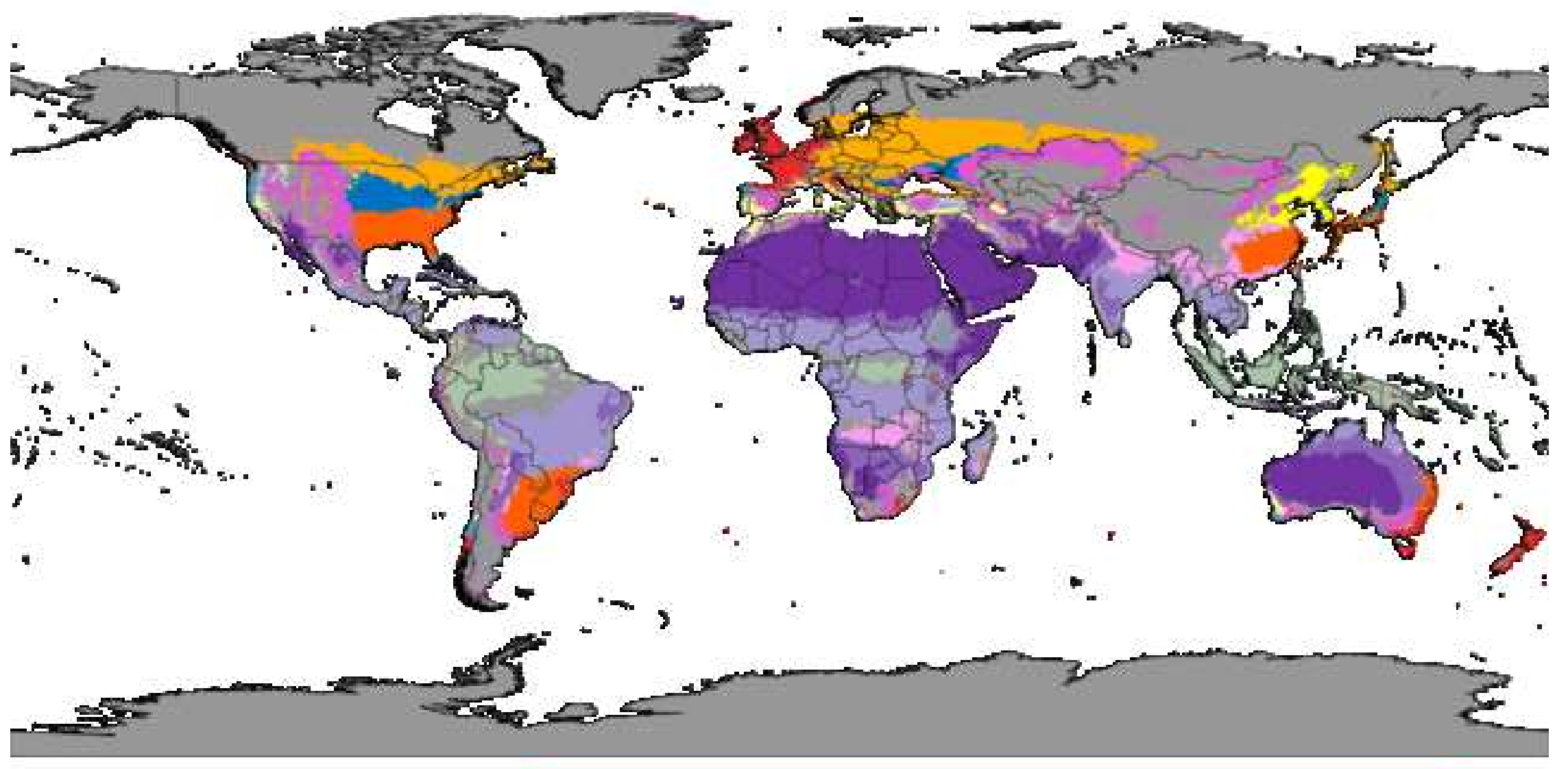

\section{C. oevite}

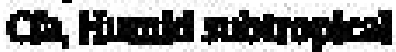

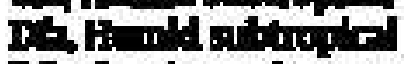

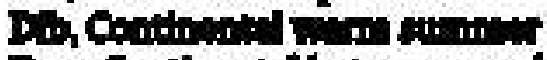

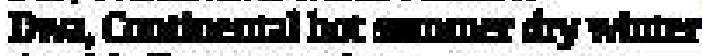

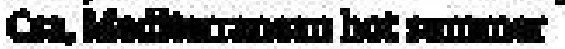

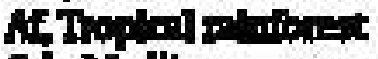

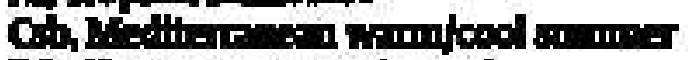

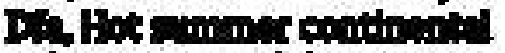

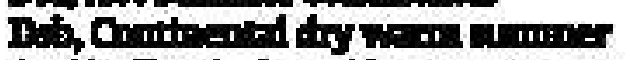

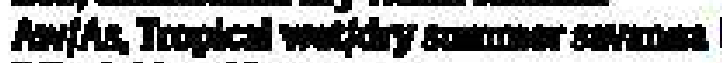

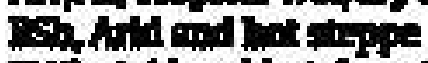

Fifl thid ard boteset

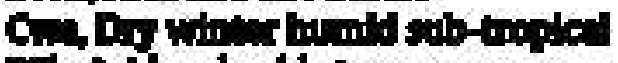

Es, And ari orid tere

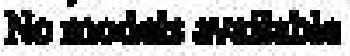

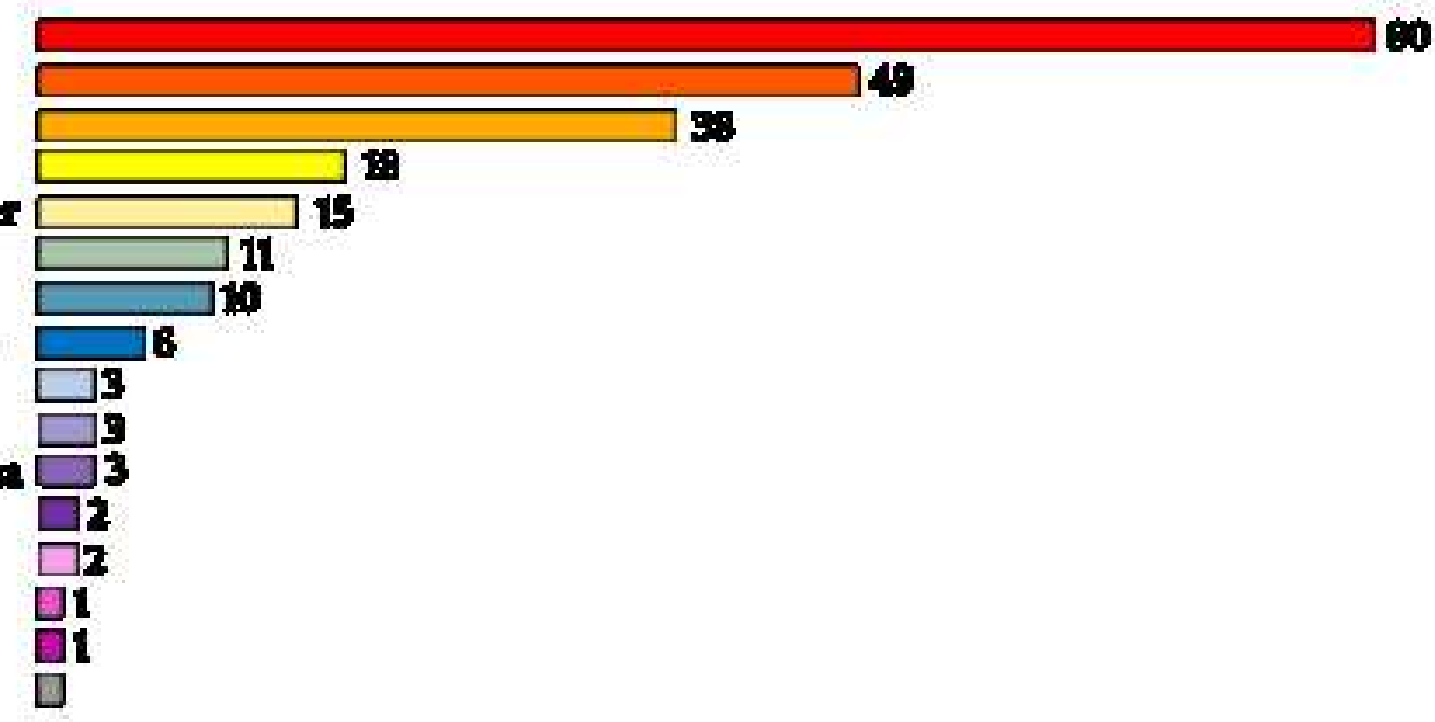

\section{o}




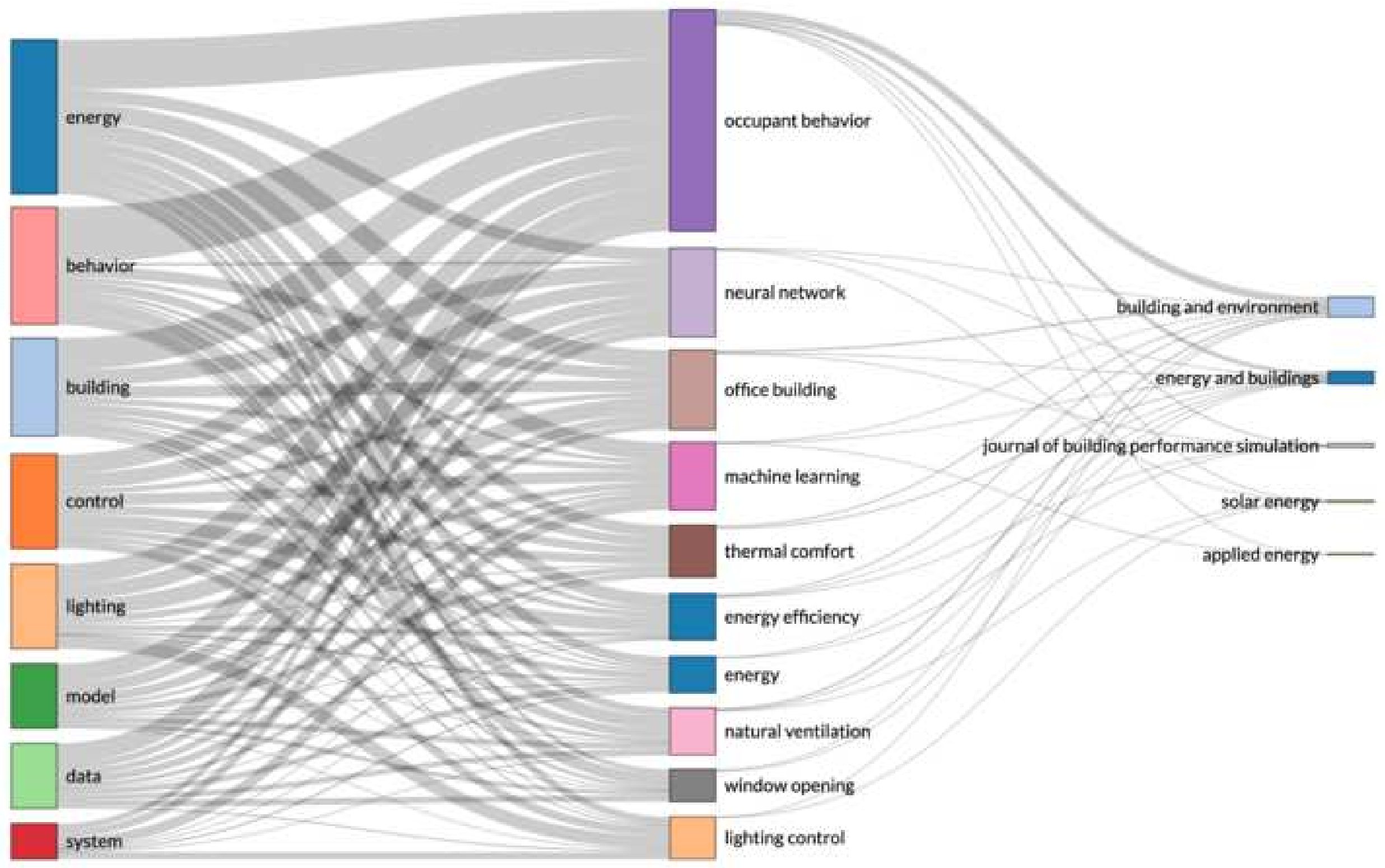




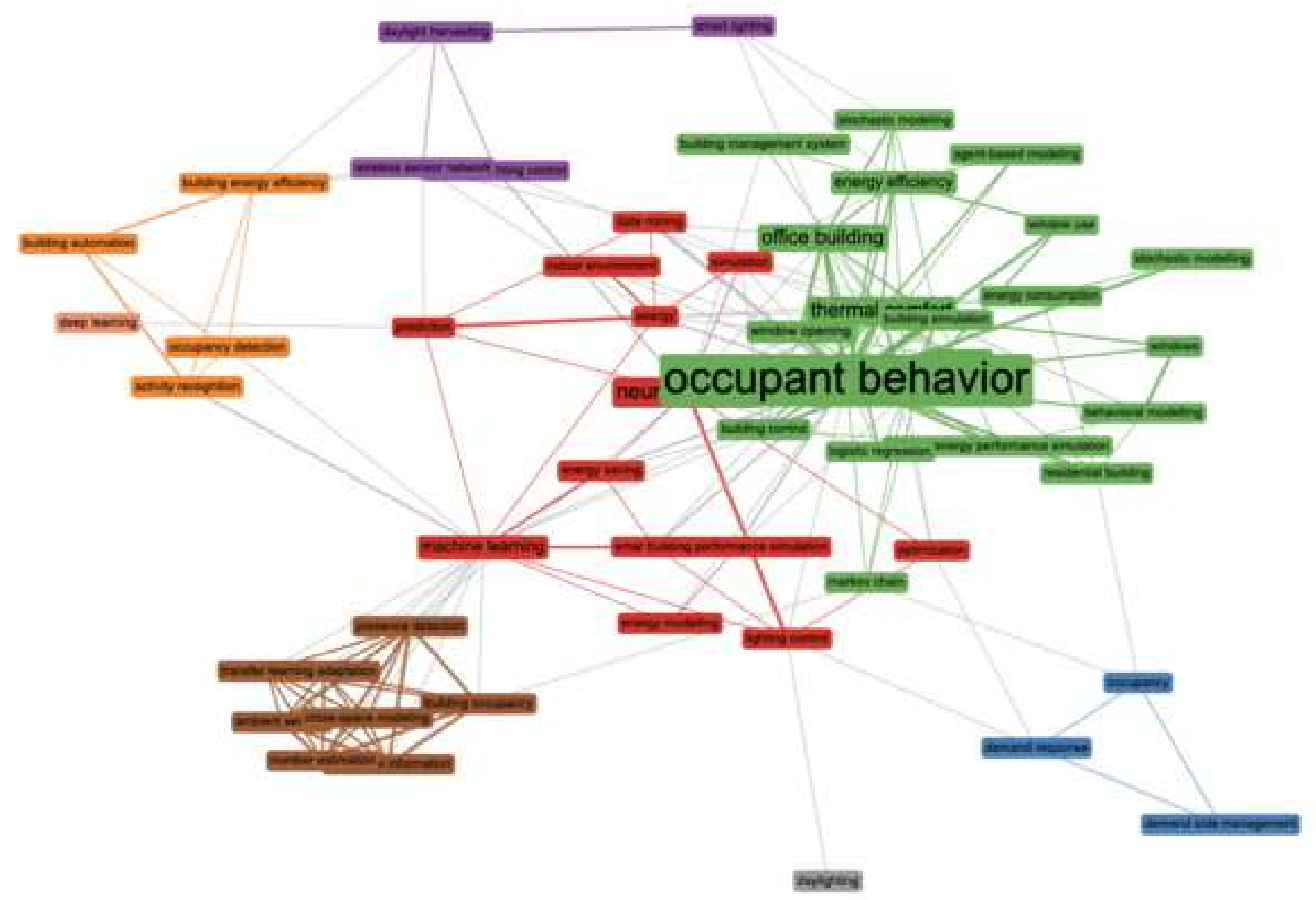

Fowimater 

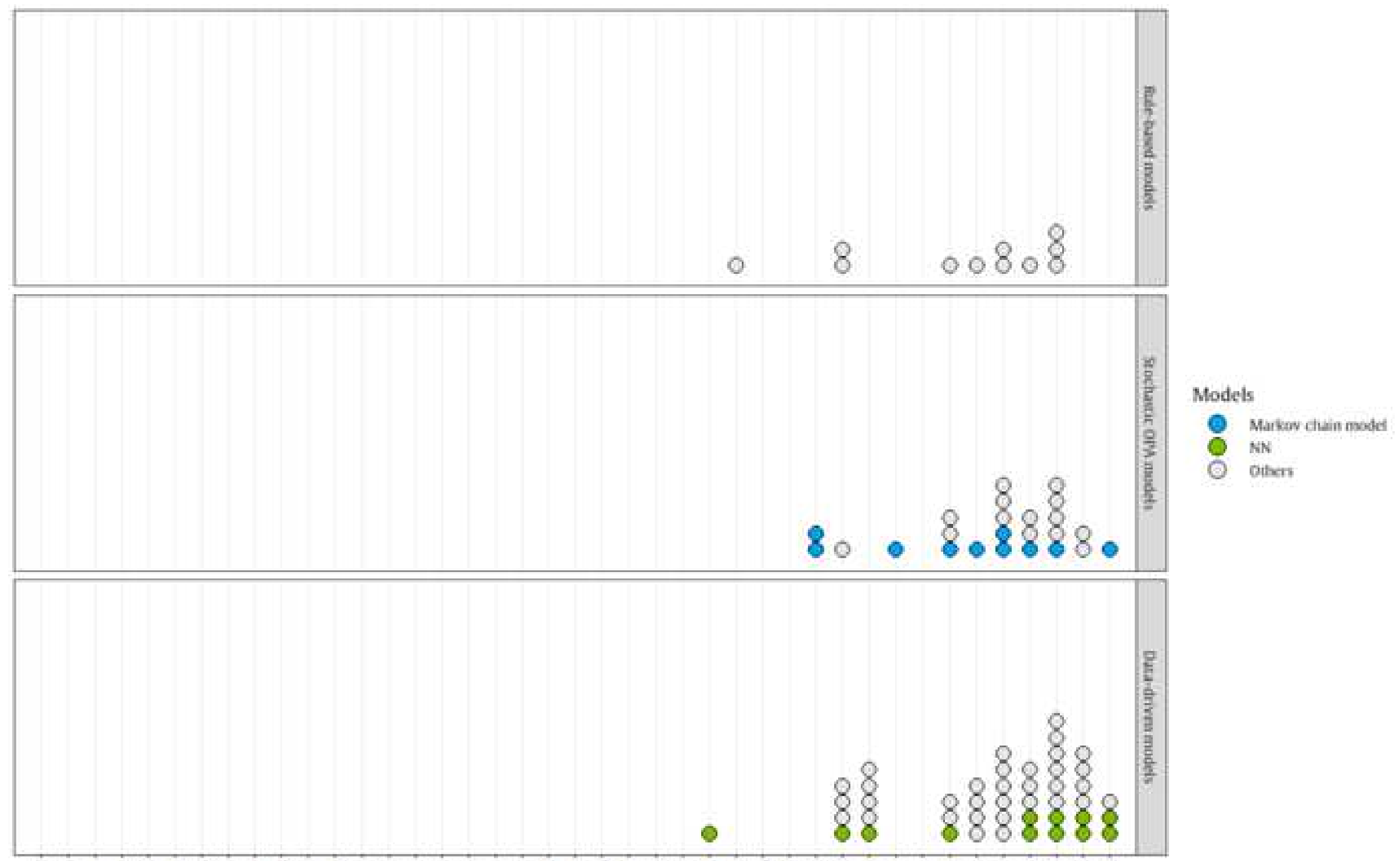

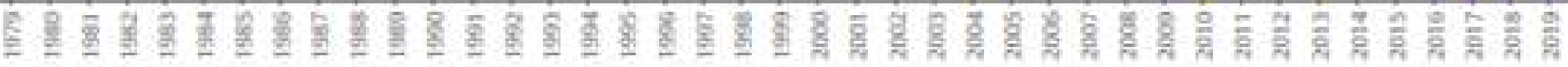

Year 

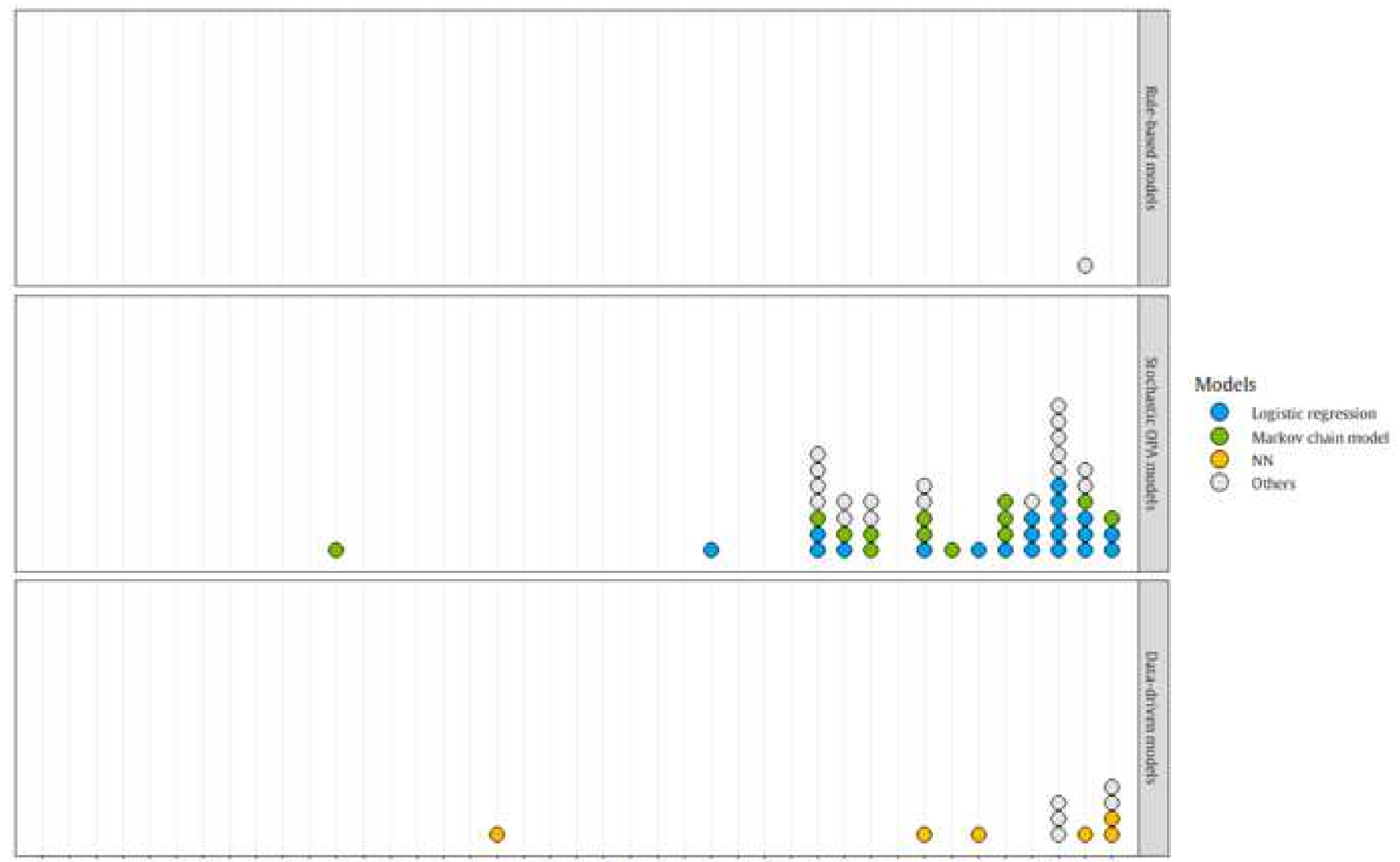

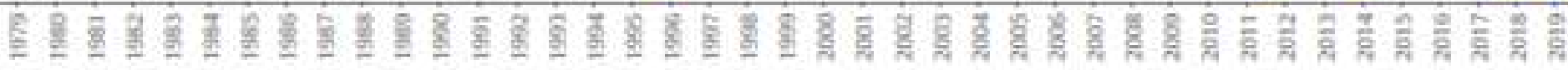

Year 


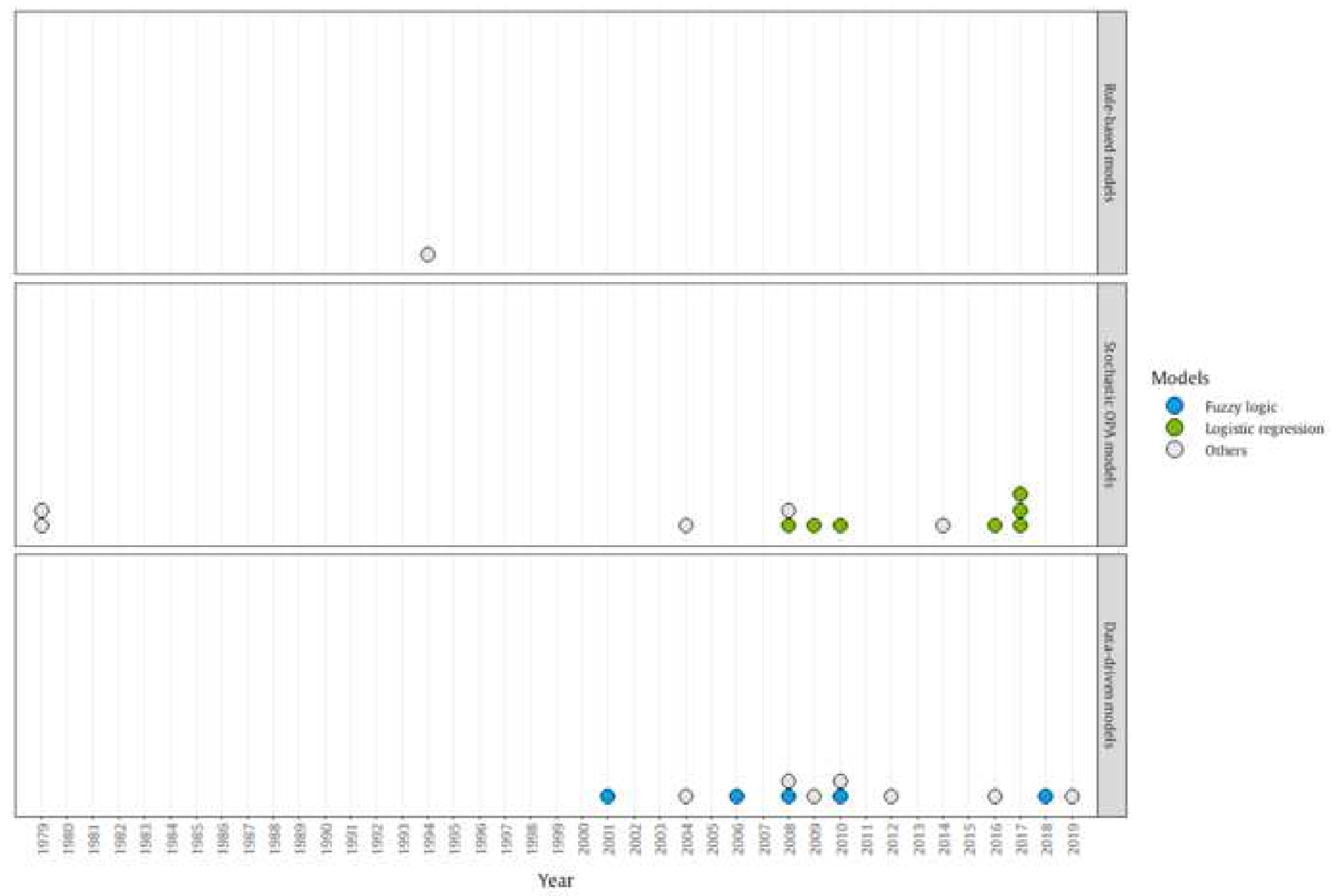



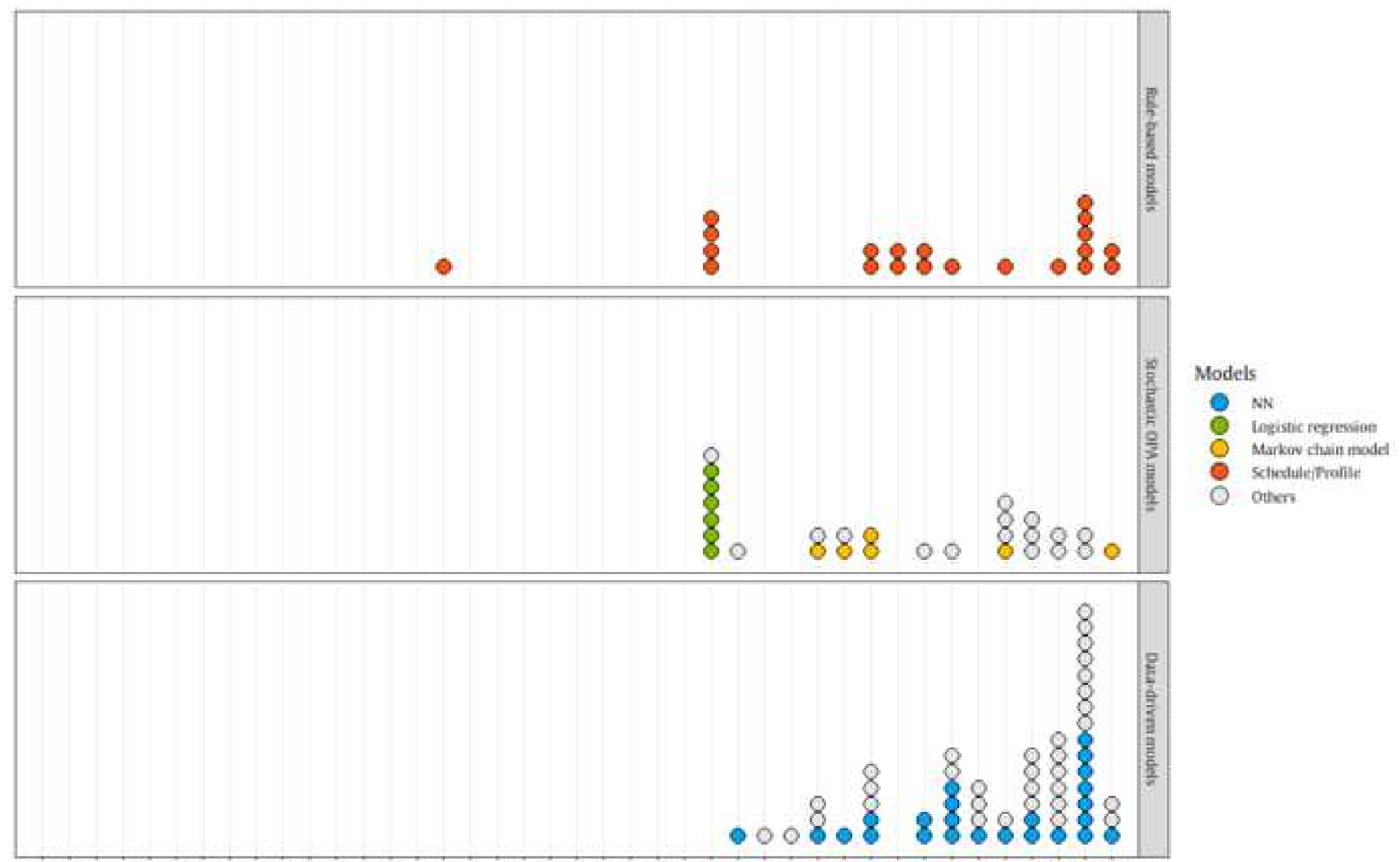

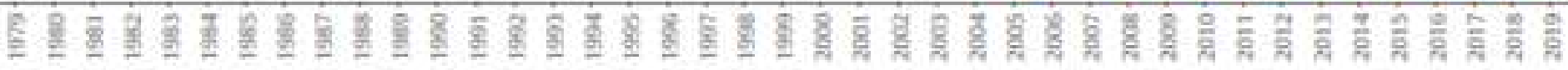

Year 


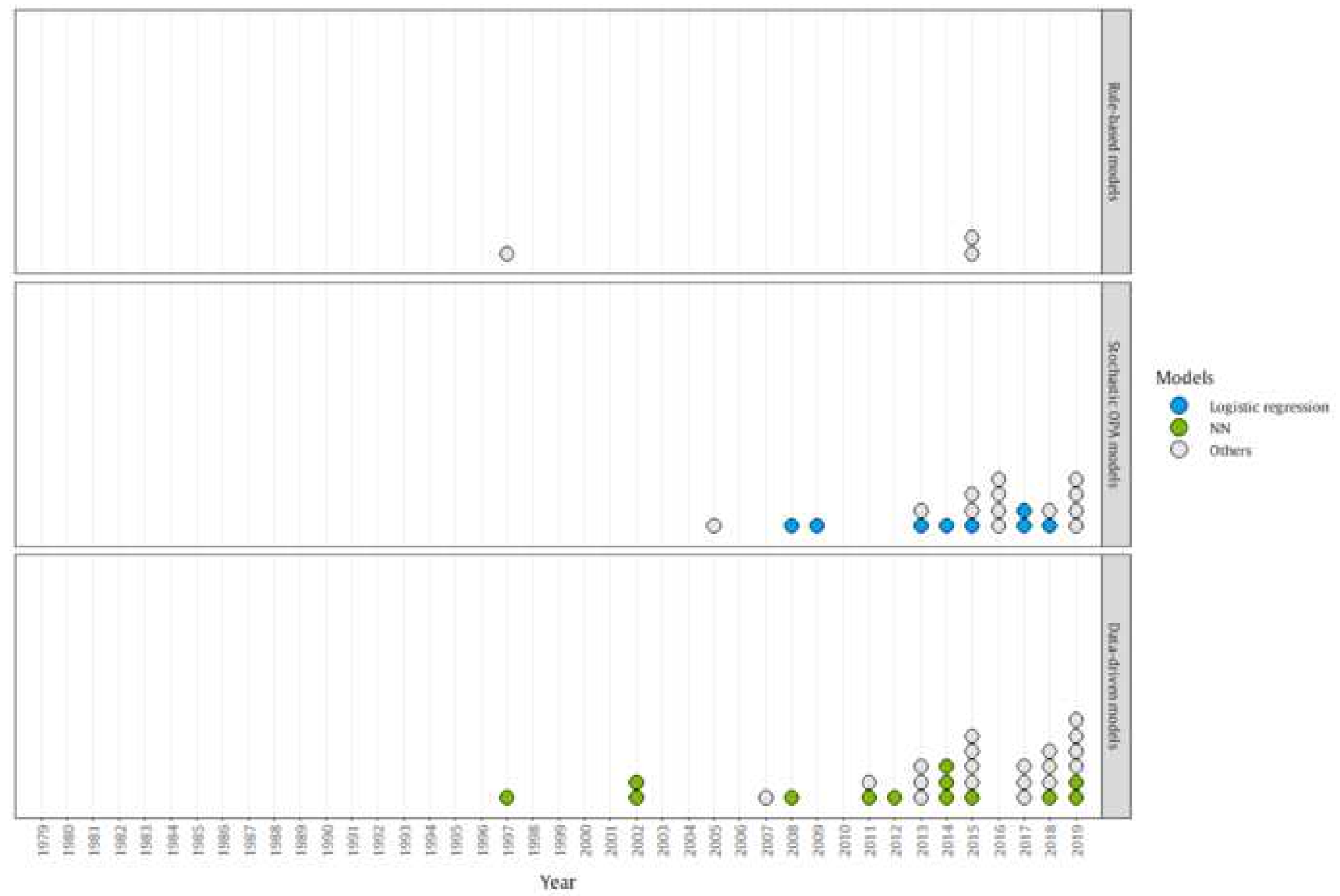



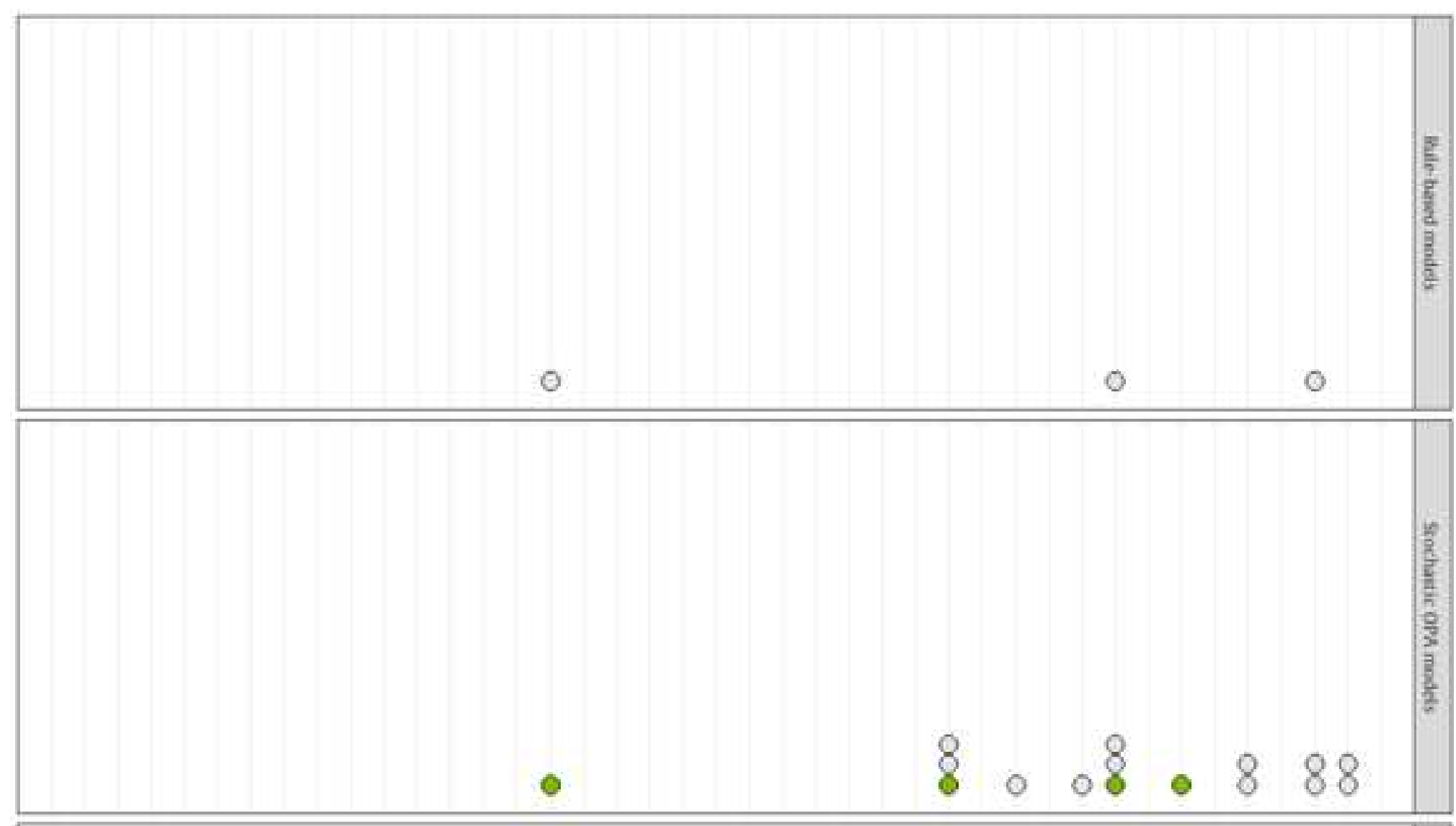

\section{Models}

(1) Cascan mixzure

- Mone Carlo micthod ( $\mathrm{NN}$

(1) Down

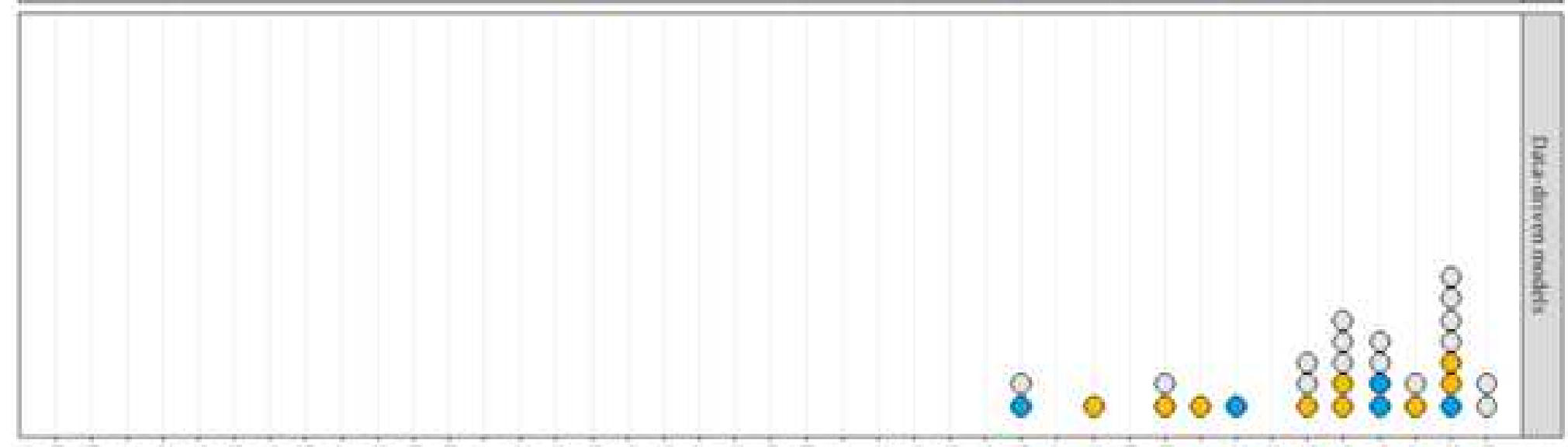

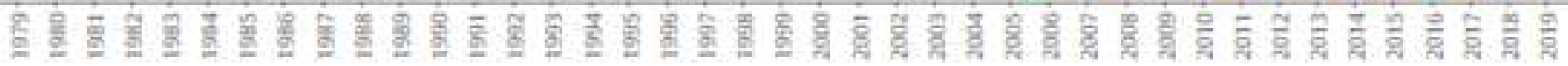

